\title{
Report on the Economic Optimization of a Demonstration Case for a Static N-R HES Configuration using RAVEN
}

Aaron Epiney (INL)

Cristian Rabiti (INL)

Andrea Alfonsi (INL)

Paul Talbot (INL)

Francesco Ganda (ANL)

April 2017
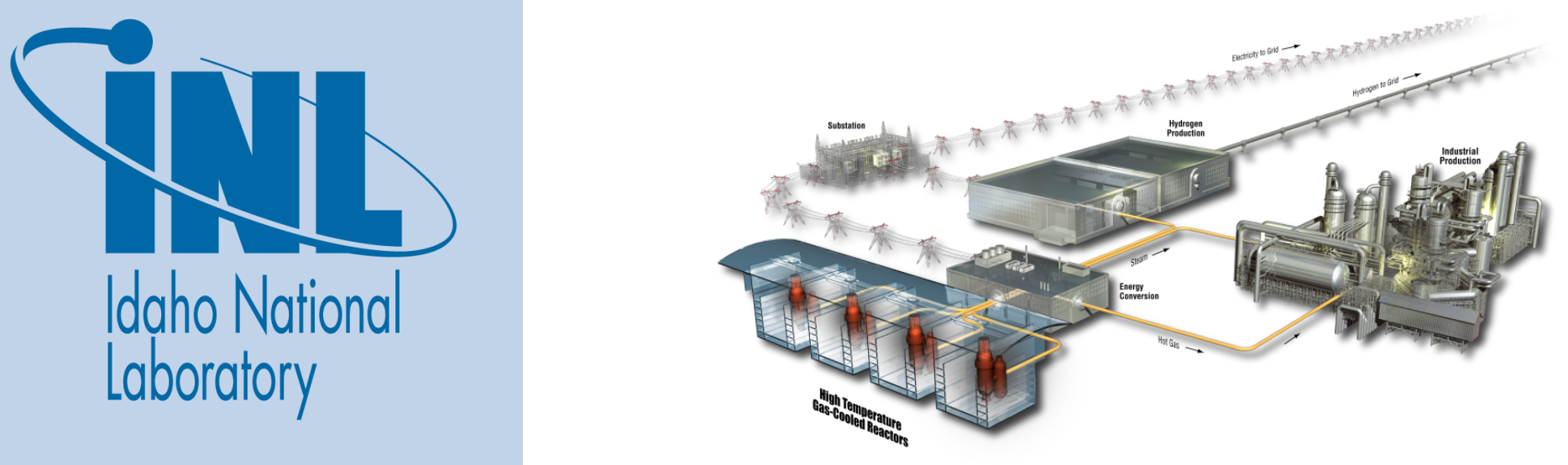


\section{DISCLAIMER}

This information was prepared as an account of work sponsored by an agency of the U.S. Government. Neither the U.S. Government nor any agency thereof, nor any of their employees, makes any warranty, expressed or implied, or assumes any legal liability or responsibility for the accuracy, completeness, or usefulness, of any information, apparatus, product, or process disclosed, or represents that its use would not infringe privately owned rights. References herein to any specific commercial product, process, or service by trade name, trade mark, manufacturer, or otherwise, does not necessarily constitute or imply its endorsement, recommendation, or favoring by the U.S. Government or any agency thereof. The views and opinions of authors expressed herein do not necessarily state or reflect those of the U.S. Government or any agency thereof. 
INL/EXT-17-41915

Revision 0

\title{
Report on the Economic Optimization of a Demonstration Case for a Static N-R HES Configuration using RAVEN
}

\author{
Aaron Epiney (INL) \\ Cristian Rabiti (INL) \\ Andrea Alfonsi (INL) \\ Paul Talbot (INL) \\ Francesco Ganda (ANL)
}

April 2017

Idaho National Laboratory
Idaho Falls, Idaho 83415

http://www.inl.gov

Prepared for the

U.S. Department of Energy

Office of Nuclear Energy

Under DOE Idaho Operations Office

Contract DE-AC07-05ID14517 



\section{ABSTRACT}

The synthetic time history generation algorithm in RAVEN has been extensively tested and used to perform qualitative assessments of the statistical characteristics of the net demand vs. demand for different values of the penetration of wind generation. Reported results highlight the need to consider the impact of variable renewable generation on the electricity net demand profile, due to the increase in its volatility with increased wind penetration. This analysis provides a strong foundation for the modeling and simulation needs expressed under the "Nuclear-Renewable Hybrid Energy Systems" (NRHES) project.

Following this confirmative analysis the entire stochastic optimization framework was tested in a demonstration case. The case chosen is an optimization driven by profitability for a system comprised of a nuclear plant and a hydrogen production industrial process. This type of economic analysis is aimed at assessing the capability of a hybrid system to penetrate the current energy market. In this sense it differs from the approach suggested under NRHES, where a cost minimization approach is suggested. This analysis is instead intended to show the flexibility of the developed framework, e.g. for the evaluation of retrofitting projects of already existing plants.

The system considered is subject to variable prices of electricity, which are simulated using the algorithm for the production of synthetic time histories. The physical system is considered without inertia so that it can be replaced by dispatching rules based on the highest marginal profit. Two optimization problems have been considered. For the first problem the size of the nuclear plant is fixed and the optimization variable is the capacity of the hydrogen production plant. For the second problem, both the nuclear and hydrogen plant sizes are optimization parameters while the overall capital expenditure is capped. The economic figures of merit considered are the Internal Rate of Return (IRR) and/or Profitability Index (PI) for the first case (since no cap is placed on the investment size) and Net Present Value (NPV) and/or IRR for the second case in which the capital expenditure is constrained.

Economic input data concerning capital costs, size-scaling factors, and operational costs for both plants have been collected from literature in order to achieve a simulation as realistic as possible. More work will be needed to obtain even more realistic numbers, possibly from industrial partners, and considering market elasticity for the hydrogen market.

In order to perform the optimization of the cases described above, the economic external RAVEN module (CashFlow) for financial analysis has been improved in flexibility and generality. Some improvements have also been made to the optimization algorithm for a more efficient treatment of the boundary constraints.

In conclusion, three major results have been obtained: a) collection of the economic parameters characterizing the nuclear plants and hydrogen production plants, b) extension of the financial analysis module (CashFlow) to drive the calculation of all needed cash flow streams and c) the testing of the full framework in a nearly final configuration. 


\section{CONTENTS}

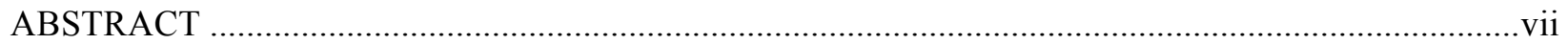

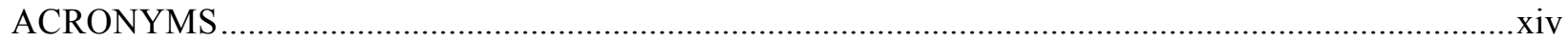

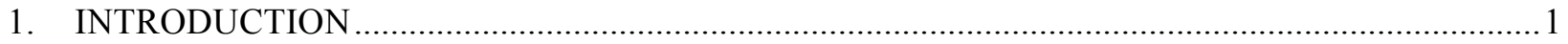

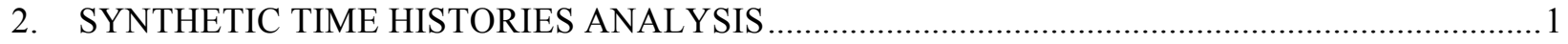

2.1 Time History Generation Algorithm and Electricity Conversion ......................................... 1

2.2 Database Characterization and Surrogate Construction ........................................................ 3

2.3 Assessment of the Impact of Wind Penetration on the Statistical Properties of the

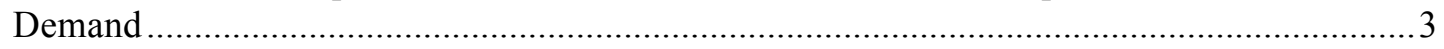

2.4 Future Work on the Synthetic Time History Generation .....................................................

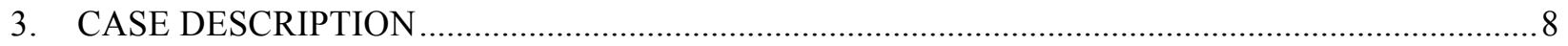

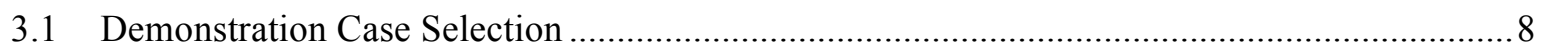

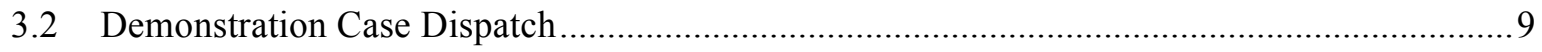

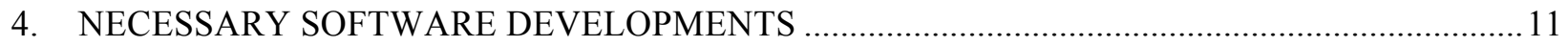

4.1 Generalized Economics Module as an External Model in RAVEN ........................................ 11

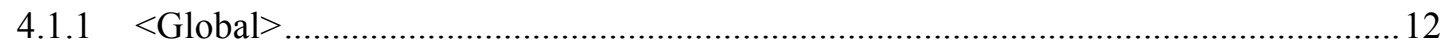

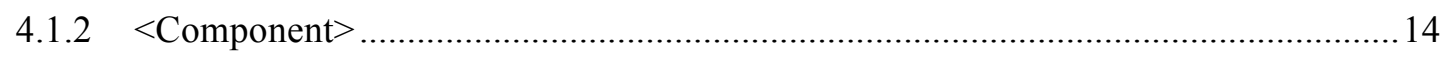

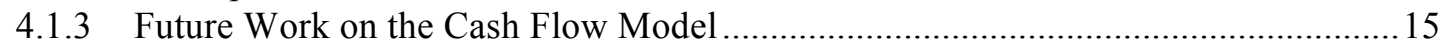

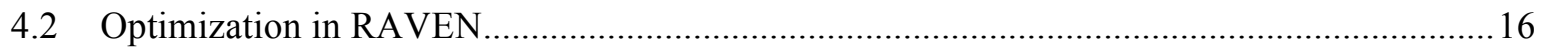

4.2.1 Improved Treatment of Boundary Constrain .................................................... 16

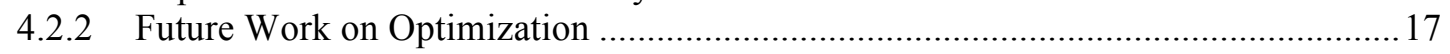

5. ECONOMIC DATA FOR NUCLEAR AND HYDROGEN PLANTS …..................................... 18

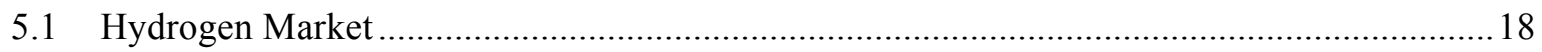

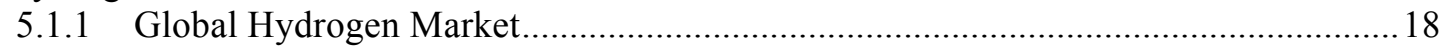

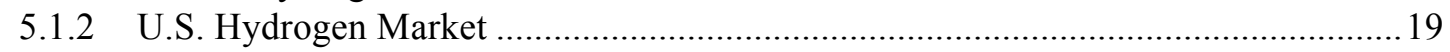

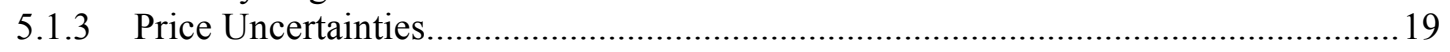

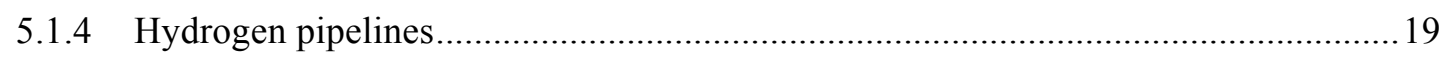

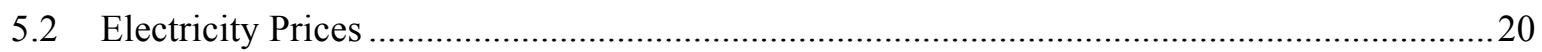

5.3 Additional data found for MISO (useful for future reference) ...........................................25

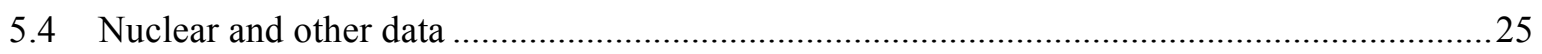

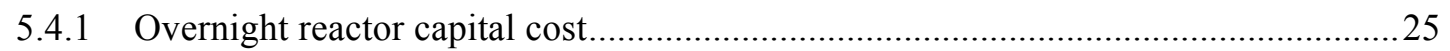

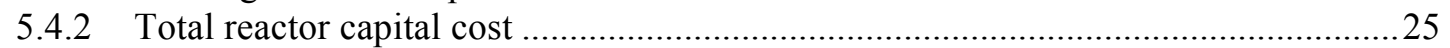

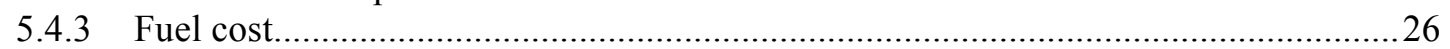

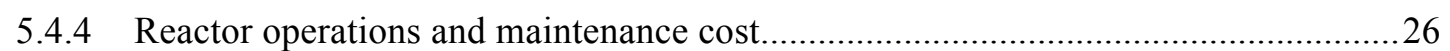

5.4.5 More discussion on fixed variable O\&M reactor costs ..........................................27

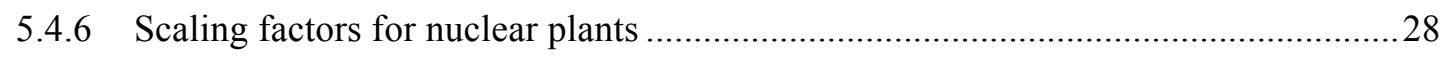

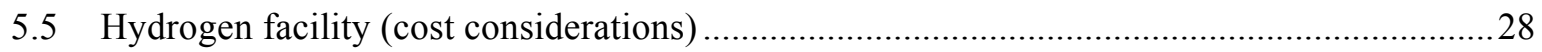

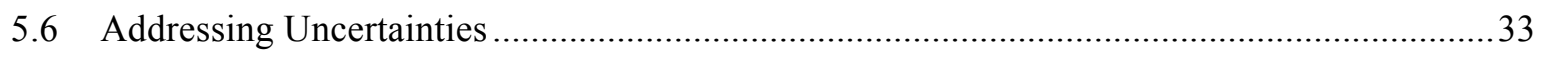

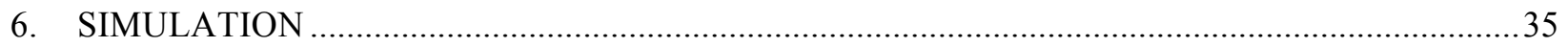




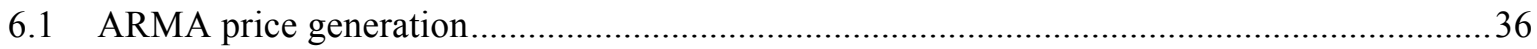

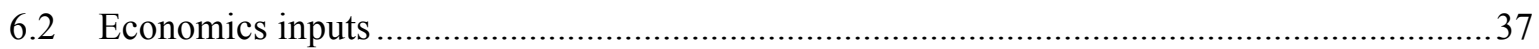

6.2.1 FCFF $_{\mathrm{R}, \mathrm{y}}$ (Free Cash Flow to Firm, Real discounting, year y) ..................................37

6.3 Results Problem 1: Find the Optimum IP Capacity for a Fixed Reactor Capacity..................42

6.4 Results Problem 2: Find the Optimum IP and Nuclear Reactor Capacity for a Capped

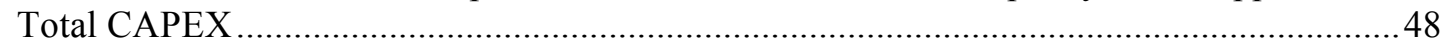

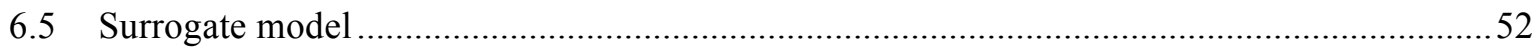

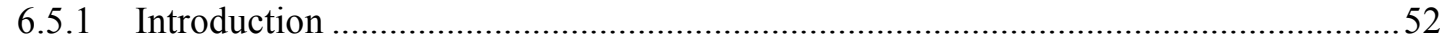

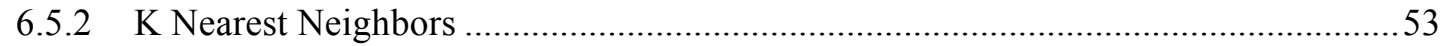

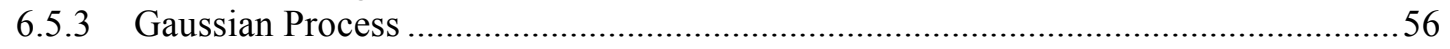

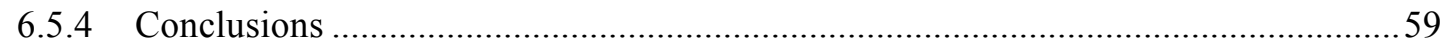

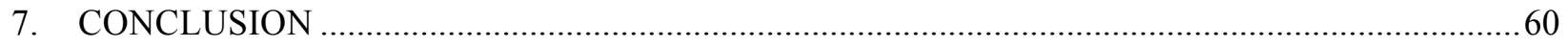

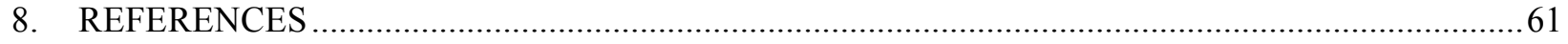




\section{FIGURES}

Figure 1. Wind speed to electricity conversion.

Figure 2. Demand and net demand (with respect to their means) for the month of February for different wind penetrations.

Figure 3. Demand and net demand first percentile (with respect to their means) for the month of February for different wind penetrations.

Figure 4. Demand and net demand first percentile (with respect to their means) for the whole year for different wind penetrations.

Figure 5. Demand and net demand $99.999 \%$ percentile (with respect their means) for the whole year for different wind penetrations.

Figure 6. Demand and net demand sigma (with respect their means) for the whole year for different wind penetrations.

Figure 7. Dispatch rules.

Figure 8. Economics input example.

Figure 9. CashFlow input example.

Figure 10. RAVEN optimization workflow.

Figure 11. Map of Air Product's hydrogen network, including $\mathrm{H}_{2}$ production plants and major pipelines. Source: [13]....

Figure 12. Screen capture of the MISO area that is overlapping with the Air Product $\mathrm{H}_{2}$ network of Figure 11.

Figure 13. Negative and scarcity prices could co-exist in LA: screenshot from [15], February 16, 2017 at 7:35 AM central.

Figure 14. Highlights of some of the node names and name of areas in the region of interest for this study (source MISO web site with superposition of names and circles for areas).

Figure 15. Plot of the 5 minutes interval LMP for the EES node for the entire year 2012.

Figure 16. Plot of the 5 minute interval LMP for the EES node for the entire year 2013. Since the EES node was fully integrated into MISO and split into multiple nodes beginning December 19, 2013, the ESS.DOWCHEM was chosen as the representative node after this date.

Figure 17. Description of the methodology to compute the Interest During Construction in NECOST, from [24].

Figure 18. Calculated cost of SOEC replacement at 5\% and at 10\% discount rates for different capacity factors. A unit cost for SOEC cell replacement of 8 cents $/ \mathrm{kgH}_{2}$ would be consistent with a $10 \%$ capacity factor and a discount rate of $5 \%$ or with a $20 \%$ capacity factor and a discount rate of $10 \%$.

Figure 19. Calculated capital cost for the plant (minus the SOEC) at $5 \%$ and at $10 \%$ discount rates for different capacity factors.

Figure 20. Data flow for optimization calculation.

Figure 21. Problem $1, \mathrm{X}(\mathrm{IP})=0.64, \mathrm{CO}_{2}$ tax $=0 \$ /$ tonCO $\mathrm{C}_{2}$, IRR as a function of IP capacity and hydrogen price, $3 \mathrm{D}$ plot. 
Figure 22. Problem $1, \mathrm{X}(\mathrm{IP})=0.64, \mathrm{CO}_{2}$ tax $=0 \$ /$ tonCO $\mathrm{C}_{2}$, IRR as a function of IP capacity and hydrogen price, $2 \mathrm{D}$ projection.

Figure 23. Problem $1, \mathrm{X}(\mathrm{IP})=0.64, \mathrm{CO}_{2}$ tax $=15 \$ /$ tonCO $\mathrm{C}_{2}$, IRR as a function of IP capacity and hydrogen price, $2 \mathrm{D}$ projection.

Figure 24. Problem 1, X(IP) $=0.64, \mathrm{CO}_{2}$ tax $=75 \$ /$ tonCO $\mathrm{C}_{2}$, IRR as a function of IP capacity and hydrogen price, $2 \mathrm{D}$ projection.

Figure 25. Problem 1, X(IP) $=1.0, \mathrm{CO}_{2}$ tax $=0 \$ /$ tonCO $\mathrm{C}_{2}, \mathrm{IRR}$ as a function of IP capacity and hydrogen price, $2 \mathrm{D}$ projection.

Figure 26. Problem $1, \mathrm{X}(\mathrm{IP})=1.0, \mathrm{CO}_{2}$ tax $=75 \$ / \mathrm{tonCO}_{2}$, IRR as a function of IP capacity and hydrogen price, $2 \mathrm{D}$ projection.

Figure 27. Problem $1, \mathrm{X}(\mathrm{IP})=0.64, \mathrm{CO}_{2}$ tax $=0 \$ /$ tonCO $\mathrm{C}_{2}$, Industrial process capacity factor as a function of IP capacity and hydrogen price, $3 \mathrm{D}$ plot.

Figure 28. Problem 1, $\mathrm{X}(\mathrm{IP})=0.64, \mathrm{CO}_{2}$ tax $=75 \$ /$ tonCO $\mathrm{CO}_{2}$, IRR optimizer convergence path.

Figure 29. Problem 2, $\mathrm{X}(\mathrm{IP})=0.64, \mathrm{CO}_{2}$ tax $=0 \$ /$ tonCO $\mathrm{CO}_{2}, \mathrm{NPV}$ as a function of IP and nuclear capacity for a hydrogen price of $\$ 1.5 \mathrm{~kg} / \mathrm{H}_{2}$; left: full picture, right: zoom on origin.

Figure 30. Problem 2, X(IP) $=0.64, \mathrm{CO}_{2}$ tax $=20 \$ /$ tonCO $\mathrm{C}_{2}, \mathrm{NPV}$ as a function of IP and nuclear capacity for a hydrogen price of $\$ 1.25 \mathrm{~kg} / \mathrm{H}_{2}$.

Figure 31. Problem 2, X(IP) $=0.64, \mathrm{CO}_{2}$ tax $=20 \$ /$ tonCO $\mathrm{C}_{2}, \mathrm{NPV}$ as a function of IP and nuclear capacity for a hydrogen price of $\$ 1.5 \mathrm{~kg} / \mathrm{H}_{2}$.

Figure 32. Problem 2, X(IP) $=0.64, \mathrm{CO}_{2}$ tax $=20 \$ /$ tonCO $\mathrm{C}_{2}, \mathrm{NPV}$ as a function of IP and nuclear capacity for a hydrogen price of $\$ 2 \mathrm{~kg} / \mathrm{H}_{2}$

Figure 33. Problem 2, $\mathrm{X}(\mathrm{IP})=1.0, \mathrm{CO}_{2}$ tax $=15 \$ /$ tonCO 2 , NPV as a function of IP and nuclear capacity for a hydrogen price of $\$ 1.5 \mathrm{~kg} / \mathrm{H}_{2}$.

Figure 34. Problem 2, $\mathrm{X}(\mathrm{IP})=1.0, \mathrm{CO}_{2}$ tax $=15 \$ /$ tonCO $\mathrm{CO}_{2}, \mathrm{NPV}$ as a function of IP and nuclear capacity for a hydrogen price of $\$ 1.75 \mathrm{~kg} / \mathrm{H}_{2}$.

Figure 35. Problem 2, $\mathrm{X}(\mathrm{IP})=1.0, \mathrm{CO}_{2}$ tax $=15 \$ /$ tonCO 2 , NPV as a function of IP and nuclear capacity for a hydrogen price of $\$ 3 \mathrm{~kg} / \mathrm{H}_{2}$

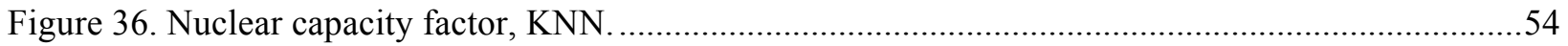

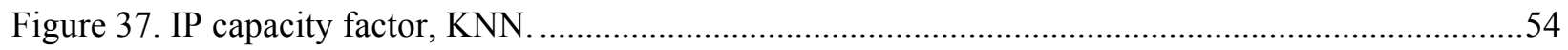

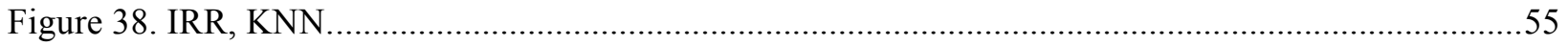

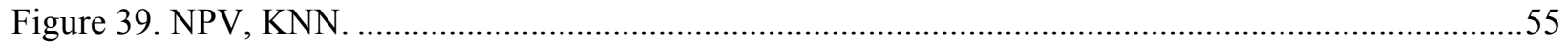

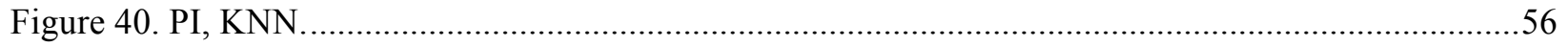

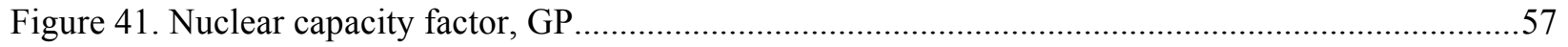

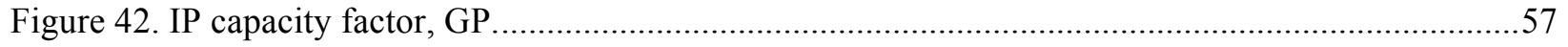

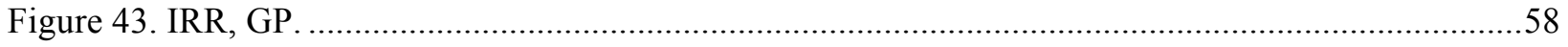

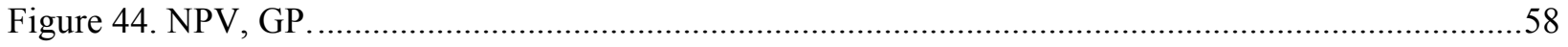

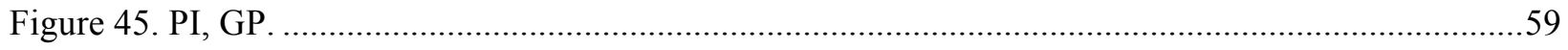




\section{TABLES}

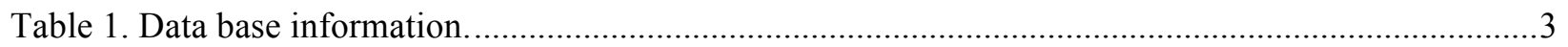

Table 2. Comparison of synthetic demand and actual demand. .................................................................

Table 3. Net demand sigma as a function of wind penetration...............................................................

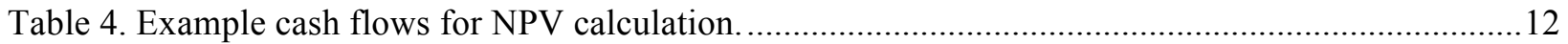

Table 5. Reference data for fixed and variable costs from Ref [8] and consequent deduction of variable costs based on current fixed cost data from Cost Basis Report....................................27

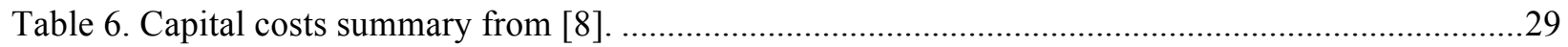

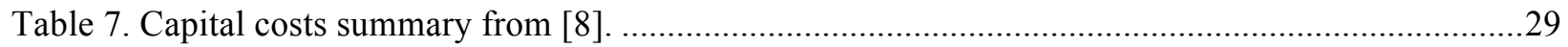

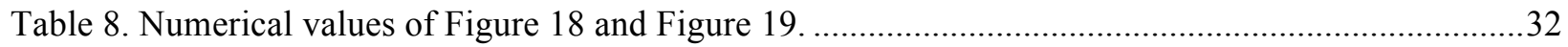

Table 9. Summary of the Fixed and Variable O\&M costs as a function of the unit capacity factor...........32

Table 10. Summary table of the $\mathrm{H}_{2}$ production cost as a function of the plant capacity factor.

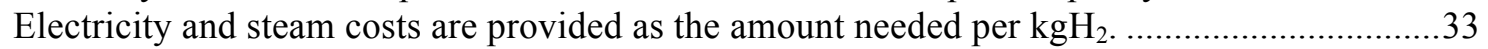

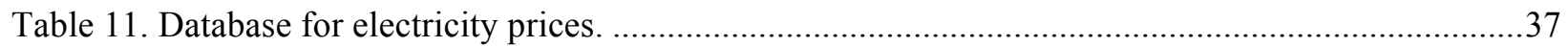

Table 12. MACRS applicable percentage for 15 year property class.....................................................39

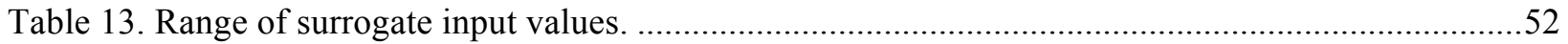

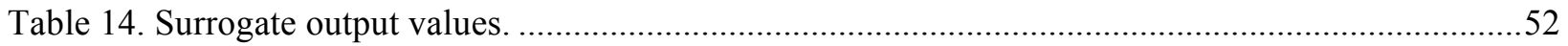

Table 15. Relative percent difference between the original model responses and KNN surrogate. ...........53

Table 16. Relative percent difference between the original model responses and GP surrogate...............56 


\section{ACRONYMS}

ARMA

ANL

CAGR

CAPEX

CCGT

CT

EOL

ERCOT

HDSAM

HTSE

IDC

INL

IP

IRR

LCM

LMP

LWR

MISO

NPP

NPV

NREL

O\&M

PI

PWR

RAVEN

SOEC

SPSA

WACC

XML
Autoregressive Moving Average

Argonne National Laboratory

Compound Annual Growth Rate

Capital expenditure

Combined Cycles Gas Turbines

Combustion Turbine

End of Life

Electric Reliability Council of Texas

Hydrogen Delivery Scenario Analysis Model

high temperature steam electrolysis

Interest During Construction

Idaho National Laboratory

Industrial Process

Internal Rate of Return

Least Common Multiple

Locational Marginal Prices

Light Water Reactor

Midcontinent Independent System Operator

Nuclear Power Plant

Net Present Value

National Renewable Energy Laboratory

Operation and Maintenance

Profitability index

Pressurized Water Reactor

Risk Analysis Virtue Environment

Solid Oxide Electrolyzer Cell

Simultaneous Perturbation Stochastic Approximation

Weighted Average Cost of Capital

eXtensible Markup Language 


\section{Report on the Economic Optimization of a Demonstration Case for a Static N-R HES Configuration using RAVEN}

\section{INTRODUCTION}

The overall goal of the report is to test several of the capabilities so far developed under the N-R HES project in the context of a demonstration test. In particular the wind generation model has been extensively tested, the financial analysis module has been expanded to accommodate the new set of data recovered on the cost of nuclear energy and hydrogen production. The data collected and the new financial capabilities implemented have been used to create a scenario which has ben optimized using the stochastic optimization algorithm.

After this introduction, the second section of this report is focused on extensively testing the synthetic time histories algorithm. Five million synthetic time histories were generated for a prototypical year of electricity demand and wind speed with an hourly resolution. This data was then used to create the corresponding net demand for different levels of wind generation penetration. Statistical analysis was then completed to characterize the difference between demand and net demand.

The third section of the report describes the code improvements that have been implemented to improve the flexibility, scalability and performance of the simulation framework.

The fourth section derives the layout of the demonstration case starting from economic considerations for the market and initial existence of the nuclear power plant. This section is followed by the collection of all needed economic parameters derived from a literature review.

Analysis of the optimization results and assessment of the gaps, before the full system analysis could be performed (real time simulation of the physical system using Modelica [1]), conclude the report.

\section{SYNTHETIC TIME HISTORIES ANALYSIS}

As already discussed, the synthetic time history generation algorithm is tested in this section. The algorithm is used to perform a statistical comparative analysis of the net demand versus demand for different levels of penetration of wind generation.

\subsection{Time History Generation Algorithm and Electricity Conversion}

The synthetic time histories generation algorithm [2,3] is briefly summarized here. This process includes the following steps (time periods are arbitrary; for convenience, years, months and hours are chosen here):

1. For each hour $\mathrm{i}$ in month $\mathrm{j}$, the average across all the years contained in a regional database (electricity demand and wind speed are dependent on the geographical location) is computed.

2. For each month $\mathrm{j}$, the one having the hourly value closest to the average values is chosen as being the prototypical month.

3. The prototypical months are assembled to construct the prototypical year.

4. The values for the prototypical year are decomposed using the discrete Fourier transform. An arbitrary number of frequencies can be used, e.g. frequencies from 1 year down to a few hours. 
5. The signal produced by the Fourier transform is subtracted from the original time history; the residual is normalized and used to train an Auto Regressive Moving Average (ARMA) model.

Two Fourier plus ARMA models have been trained: one for the electricity demand and one for the wind speed. In order to construct the net demand, a transfer function from wind speed to electricity generated by wind is needed. The corresponding function reported in Eq. 1 can be found in [4].

$$
E[M W e]=\left\{\begin{array}{lc}
0 & U \leq 3\left[\frac{m}{s}\right] \text { or }, U \geq 25\left[\frac{m}{s}\right] \\
0.5 \eta \rho U^{3} \frac{\pi d^{2}}{4} & 3\left[\frac{m}{s}\right]<U \leq 14\left[\frac{m}{s}\right] \\
3.6 & 14\left[\frac{m}{s}\right]<U \leq 25\left[\frac{m}{s}\right]
\end{array}\right.
$$

where $\quad \eta \quad$ conversion efficiency of the wind turbine

$\rho \quad$ density of the air at the site

U wind speed

d diameter of the turbine blades.

In this study the values used for each parameter are: $\eta=35 \%, \rho=1.17682 \mathrm{~g} / \mathrm{m} 3, \mathrm{~d}=90.00 \mathrm{~m}$.

Figure 1 shows the power conversion profile. The value of 3.6 MWe is chosen as nominal value for computing the installed wind capacity.

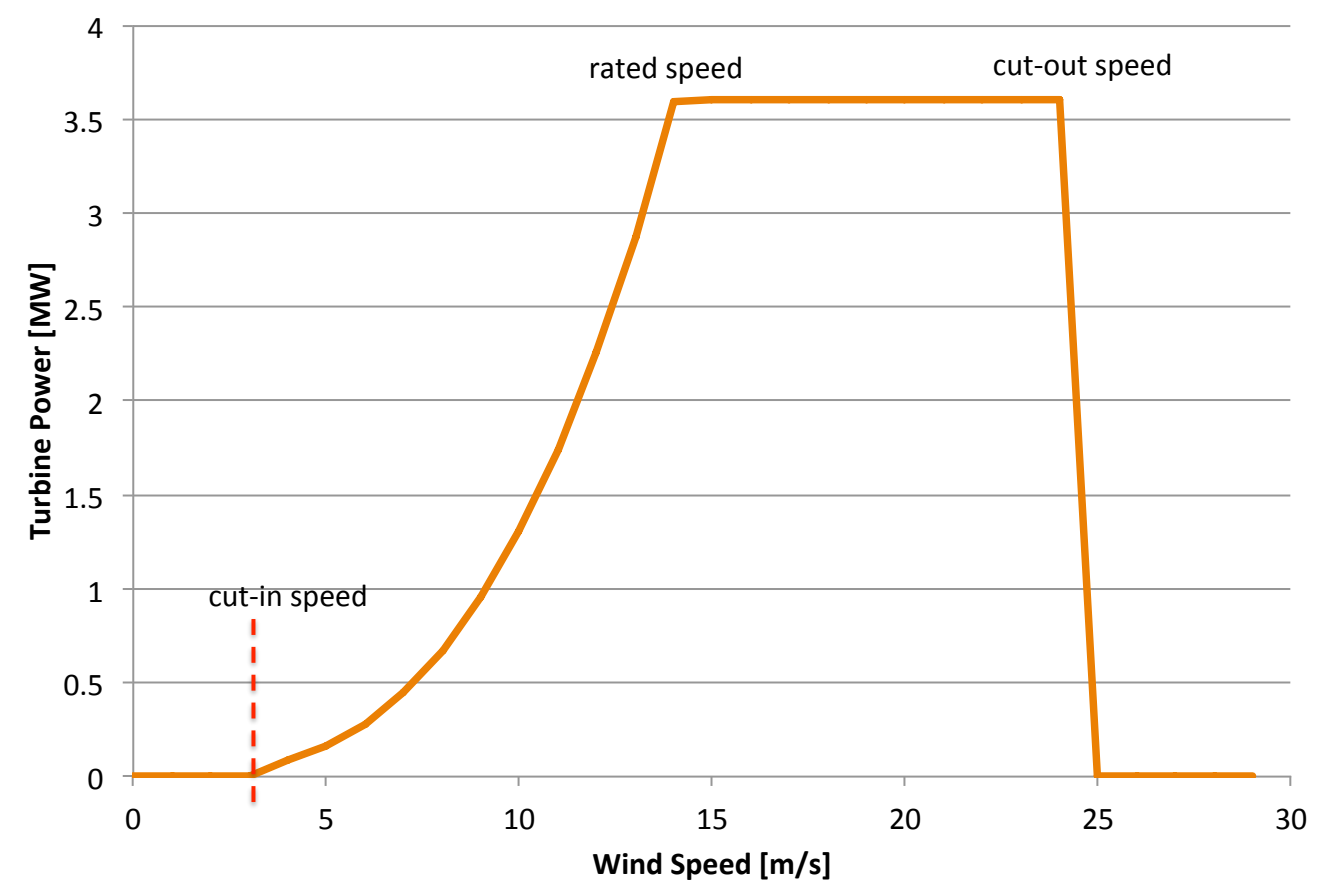

Figure 1. Wind speed to electricity conversion. 


\subsection{Database Characterization and Surrogate Construction}

The data source and the frequency of the data are reported in Table 1. Preprocessing was performed by averaging the values to obtain an hourly resolution, where the original frequency was less than an hour.

Table 1. Data base information.

\begin{tabular}{|c|c|c|c|c|}
\hline Data Type & Time Span & Resolution & Region & Source \\
\hline Wind Speed & $2004-2006$ & 10 min (collapsed to 1 hour) & Site 3247 & NREL [5] \\
\hline Load & $2011-2015$ & Hourly & West & ERCOT [6] \\
\hline
\end{tabular}

The minimal frequency captured using the discrete Fourier transform was 3 hours and the months were chosen as representative periods over the years. For the statistical comparison one million synthetic time histories were realized for each wind penetration scenario, both for the wind and electricity demand. Table 2 shows the comparison of the $0^{\text {rd }}$ and $1^{\text {st }}$ statistical order moments of the synthetic and actual data for the demand (for one ARMA realization). As expected, the differences are minimal.

Table 2. Comparison of synthetic demand and actual demand.

\begin{tabular}{|c|c|c|}
\hline Value & Synthetic & Actual \\
\hline Mean & $1.101 \mathrm{GW}$ & $1.095 \mathrm{GW}$ \\
\hline Sigma & $20.626 \%$ & $21.331 \%$ \\
\hline
\end{tabular}

For the wind time histories the reference value used for the comparison is the load capacity factor obtained by dividing the generated electricity (using the conversion function between wind end electricity shown in the previous section) by the value obtained by using the nominal value. The actual value for the database is $27.93 \%$, while the one obtained using the synthetic data is $27.44 \%$.

\subsection{Assessment of the Impact of Wind Penetration on the Statistical Properties of the Demand}

Five different cases are considered, where the nominal capacity of the installed windmills equals $10 \%, 20 \%, 30 \%, 40 \%$ and $50 \%$ of the mean electricity demand. The net demand is computed as the difference between the wind supplied electricity and electricity demand. Table 3 shows some global statistical quantities as a function of the wind penetration. First, it shows how the mean net demand decreases with increasing wind penetration. As one can see, the decrease in mean net demand is well in line with the expected decrease computed from "wind penetration" multiplied by "wind load capacity factor (27.44\%)". The last line of the table shows the sigma of the time dependent mean net demands. Differently from the sigma reported in Table 2 this is the sigma with respect to the hourly mean. To be more clear, for each hour of the year the mean is computed, which should converge, with growing number of runs, to the value obtained using only the Fourier component of the synthetic data algorithm generation, and this hourly mean is used to determine the hourly sigma. These hourly sigma are then averaged over the year to obtain the number in Table $3^{\mathrm{a}}$. These results are important since they highlight the sigma of the net demand residuum (i.e. the component remaining after de trending). In case the Fourier fitting would be used as a predictive model, the sigma reported in Table 3 would represent the not predictable part of the demand. It is also clear how this value grows for growing wind penetration.

\footnotetext{
a The "pooled standard deviation" method indicates that the average of standard deviations for different populations can be used as estimator of the variance of the combined populations.
} 
Table 3. Net demand sigma as a function of wind penetration.

\begin{tabular}{|l|c|c|c|c|c|c|}
\hline Wind penetration & $\mathbf{0 \%}$ & $\mathbf{1 0 \%}$ & $\mathbf{2 0 \%}$ & $\mathbf{3 0 \%}$ & $\mathbf{4 0 \%}$ & $\mathbf{5 0 \%}$ \\
\hline Mean & $1.104 \mathrm{GW}$ & $1.076 \mathrm{GW}$ & $1.048 \mathrm{GW}$ & $1.021 \mathrm{GW}$ & $0.993 \mathrm{GW}$ & $0.965 \mathrm{GW}$ \\
\hline $\begin{array}{l}\text { Decrease in mean } \\
\text { demand (expected) }\end{array}$ & 0 & $-2.744 \%$ & $-5.488 \%$ & $-8.232 \%$ & $-10.976 \%$ & $-13.720 \%$ \\
\hline $\begin{array}{l}\text { Decrease in mean } \\
\text { demand (computed) }\end{array}$ & 0 & $-2.536 \%$ & $-5.072 \%$ & $-7.518 \%$ & $-10.054 \%$ & -12.591 \\
\hline Relative Sigma & $14.339 \%$ & $14.876 \%$ & $15.815 \%$ & $17.102 \%$ & $18.847 \%$ & $20.904 \%$ \\
\hline
\end{tabular}

To appreciate the impact of wind penetration on fluctuation of the net demand, one can refer to Figure 2 where the monthly fluctuation (for the month of February) is shown in relative terms with respect to the mean (of demand and net demand, respectively). As seen in the Figure, a 50\% wind penetration, for example, corresponds to a reduction in the mean demand of $27.44 \% * 50 \%=13.7 \%$ and an $\sim 5 \%$ increase in the hourly mean sigma (Table 3 ).

This behavior is even more pronounced when considering Figure 3, where the first percentile is plotted as a function of time (normalized by the respective mean demand). The first percentile could be considered as the cut off at which demand should not be supplied anymore by base load generators such as nuclear power plants. The figure shows that with increasing renewable penetration, the base load allowed to participate to the market is dramatically reduced. Moreover, by looking to Figure 4 one can see that even wind supply alone would exceed demand for short periods over the year, reducing base load to practically zero (of course, wind curtailment and/or negative price of electricity are possible solutions).

The situation is even more drastic when the 99.999 percentile is considered. This is equivalent to the maximum load that is necessary to meet to satisfy one of the common Loss of Load Probability (LOLP) limit criteria (depending from the regulatory body different values are possible). Figure 5 shows clearly how, when considering the 99.999 percentile, the reduction in mean value of the demand is almost completely offset by the increase in volatility, so that the overall capacity needed (without the renewable) remains almost unaltered.

Overall, the analysis could benefit from several improvements, including a) consideration of the correlation between wind and electricity demand; b) wind data might need to be collected on larger regions to decrease the sigma, and c) 1 million points is still a low number to estimate the point wise 99.999 percentile since only 10 points are expected to construct such estimation leading to a $30 \%$ sigma on this estimation. Nevertheless, the effect is clear even considering such uncertainty.

The value of the sigma of the net demand (see Table 3) as a function of the wind penetration can instead be considered fully reliable given the large number of sampling. The sigma clearly shows an upward trend. For the case with $50 \%$ wind penetration that shows a decrease of $\sim 13.5 \%$ in the mean demand, the sigma increases from $14.339 \%$ to $20.904 \%$ meaning that the 1 sigma upper limit (mean+1 sigma) has decreased only by $\sim 4.06 \%$. The same can be seen from the time-dependent sigmas for the different wind penetrations shown in Figure 6.

\subsection{Future Work on the Synthetic Time History Generation}

It would be ideal to possess the capability to include the statistical fluctuation over the year without being forced to select representative periods from different years. Adding a statistical component to the moment of the Fourier expansion could eventually do this. Another issue that needs to be addressed soon 
is to connect the representation of energy production from solar. In this case the ARMA covariance matrix [3] will have to be expanded to correlated time histories to account for the correlation between solar energy supply and electricity demand. This aspect will be strongly dependent on the target geographical region for the analysis.

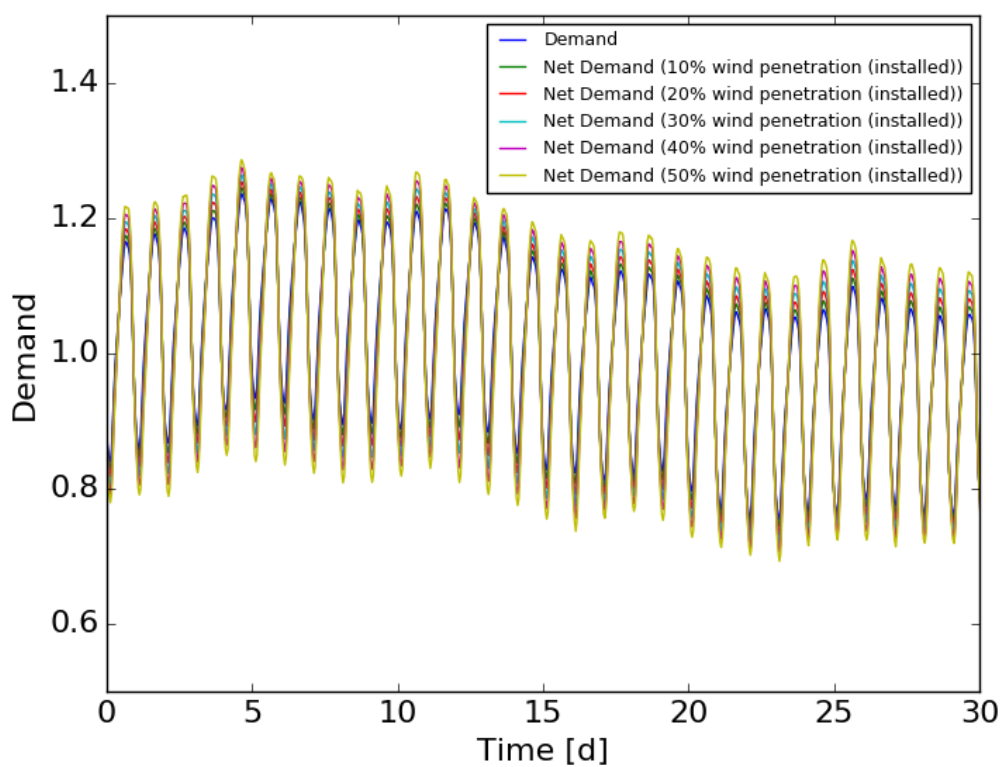

Figure 2. Demand and net demand (with respect to their means) for the month of February for different wind penetrations.

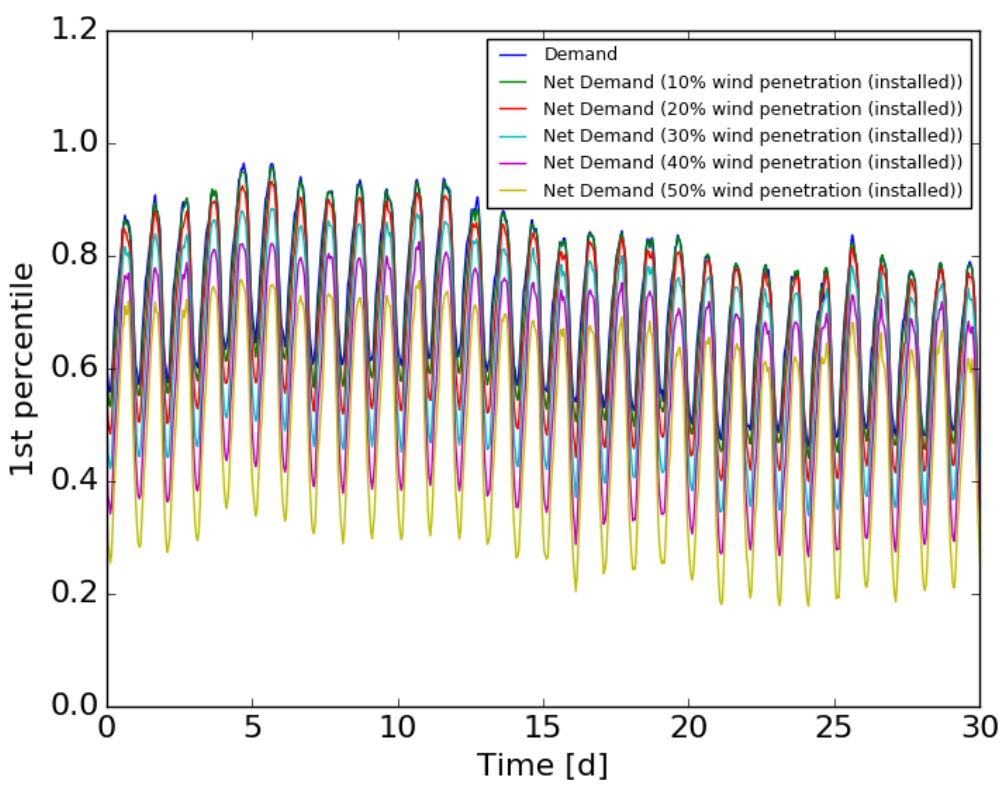

Figure 3. Demand and net demand first percentile (with respect to their means) for the month of February for different wind penetrations. 


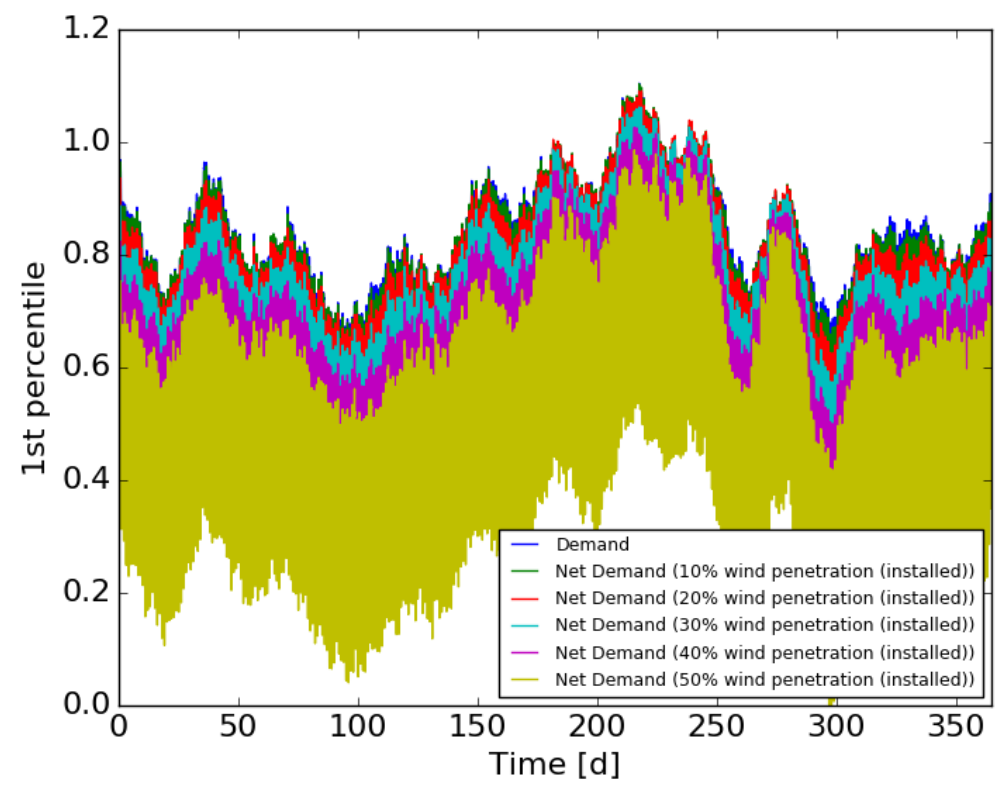

Figure 4. Demand and net demand first percentile (with respect to their means) for the whole year for different wind penetrations.

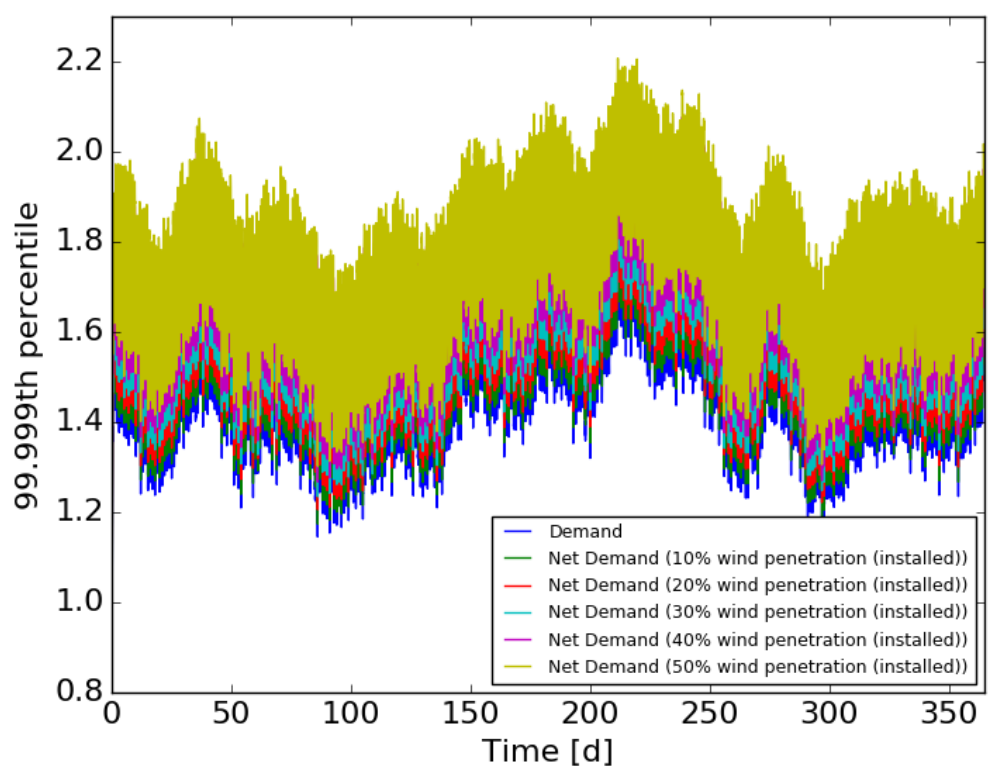

Figure 5. Demand and net demand 99.999\% percentile (with respect their means) for the whole year for different wind penetrations. 


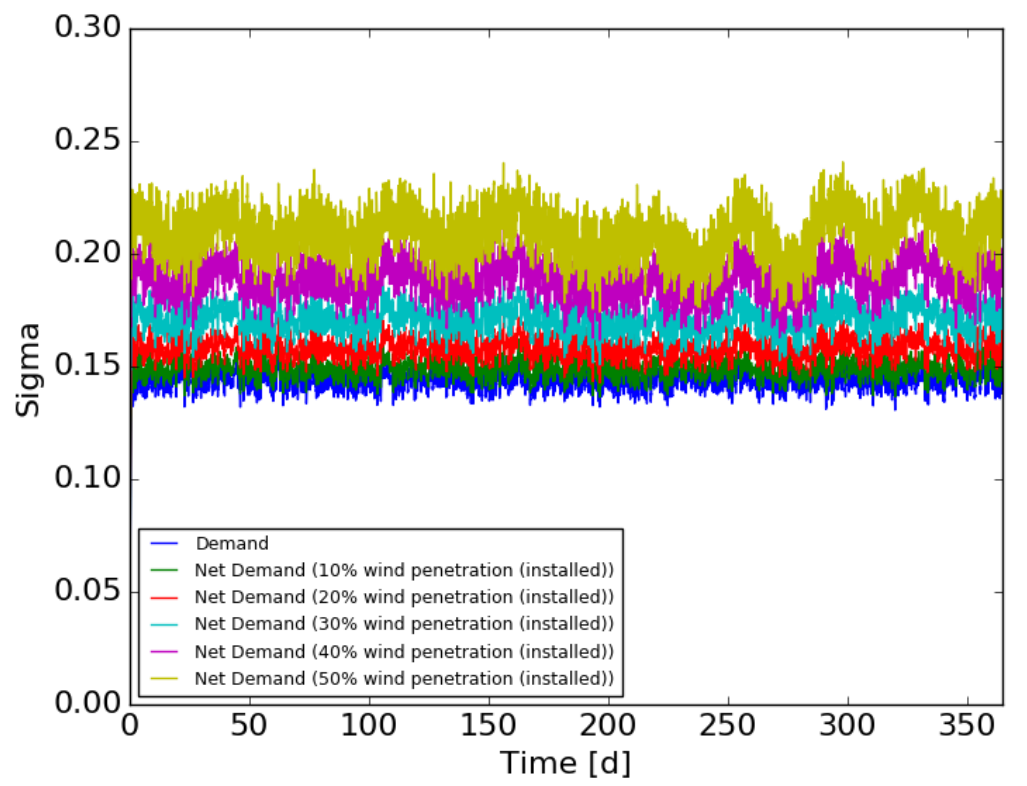

Figure 6. Demand and net demand sigma (with respect their means) for the whole year for different wind penetrations. 


\section{CASE DESCRIPTION}

\subsection{Demonstration Case Selection}

First, hourly time resolution was selected for the demonstration case. At this time scale, none of the components of the hybrid system (see [7] for reference), if considered in hot standby, have an issue reaching any prescribed level of power (within their capacity). The only exception may be the nuclear reactor; however, the current analysis assumes that the reactor operates at constant power and, therefore, its inertia is not relevant. Given these considerations, the system can be considered to be a "copper plate" type, meaning that it is possible to achieve immediately any prescribed level of production of either electricity or hydrogen within its capacity range.

Moreover, as already mentioned, it was decided to perform a penetration (i.e., profitability) analysis of a hybrid system for a given, existing market. The assumption made is that the hybrid system is considered to be a price taker without the capability to influence the market (neither electrical, nor hydrogen). This choice implies that the elasticity of the market does not have to be considered (either for hydrogen or electricity).

Under this assumption both markets, electricity and hydrogen, are infinite; therefore, a constraint must be defined to limit the components of the hybrid system, such that the system optimization does not diverge. The first choice is to consider the reactor to be fixed in capacity and operating at a steady thermal energy level (not electricity production). In this way it is expected that the direct heat coupling between the reactor and the Industrial Process (IP, in this case the High Temperature Steam Electrolysis system for hydrogen production) creates a maximum for the economic efficiency, without either driving the size of the IP to zero or infinity.

Another condition to avoid the system divergence (or near divergence) is to use the Internal Rate of Return (IRR) or the Profitability Index (PI) as the goal function versus the Net Present Value (NPV). In fact, the NPV would drive the optimization to increase the size of the IP as long as the IRR is positive, even if the IRR is decreasing.

It is not useful to add other components than the nuclear power plant and the IP to the simulation since the lack of inertia of the system would set their optimal size either to zero or infinity depending on a positive or negative economy of scale. For example (positive economy of scale), if the cost per MW installed for a gas turbine decreases for increasing size, the final capacity driven by the optimization will be infinite and vice versa (zero capacity) for a negative economy of scale. For a neutral economy of scale the capacity of such an additional component will be irrelevant for the optimization (IRR will not be sensitive to variation of this component capacity).

For a copper plate model, it can be proven that the most efficient, economical way to supply the electricity demand is based on the least marginal cost (as occurs in current deregulated markets). In the presence of system inertia, this is no longer true, since prediction of future demand has to be taken in account to justify, for example, selling at a loss (e.g., nuclear power plant coping with a negative price of electricity without reducing plant power, since the decision takes into account the profit that will be made a few hours later when the electricity price will spike again). In a hybrid system, the marginal cost should consider not only variable cost but also variable opportunity cost derived from selling/not selling the coproduct (hydrogen).

In conclusion, the first test was so composed:

- Goal function is the IRR

- Copper plate model (no inertia)

- Dispatching (reactor produces electricity or provides process heat) based on marginal cost

- Size of nuclear plant is fixed

- Variable size of hydrogen plant (optimization variable) 
In this report, a second test is also considered, where the nuclear plant capacity is no longer fixed but the total capital available to build the plants is fixed and the NPP and the IP is constrained. For the optimization, in this case both the IRR and the NPV will provide a bounded solution. The choice between NPV and IRR would be a strategically decision of the investors between optimizing the total money returned (NPV) or the interest rate (IRR). The optimization for the second problem is done for the NPV.

Both cases are treated as return to the company, so the total capital is shown as a negative cash outflow at year zero in spite of the company leverage ratio. Under the assumption that the IRR should be compared to the WACC (Weighted Average Cost of Money) and the NPV (or PI) should eventually be discounted using the WACC.

For completeness, the second case uses the following assumptions:

- Goal function is the NPV

- Copper plate model (no inertia)

- Dispatching (reactor produces electricity or provides process heat) based on marginal cost

- Variable size of hydrogen plant and nuclear plant (optimization variables)

Both cases are optimized using one year of hourly price of electricity, the synthetic time histories are generated with the algorithm described in the previous section and tested for the wind and the demand.

\subsection{Demonstration Case Dispatch}

For every hour of the simulation, the dispatch rules decide what the nuclear plant and the industrial process are going to do, i.e. first, is steam used to produce electricity or diverted to the hydrogen plant as process heat and second, is the industrial plant buying more electricity form the grid or not. The dispatch is based on marginal profit, as discussed in the previous section. The decision logic is depicted in Figure 7. Depending on the capacity of the industrial plant, 4 different scenarios are possible:

1. The marginal profit analysis dictates using all steam to produce electricity. In this case, it is never profitable for the industrial process to buy electricity from the grid. Therefore, no hydrogen is produced.

2. The marginal profit analysis dictates steam production. Three different cases can emerge:

a. The capacity of the hydrogen plant is small. In this case, the reactor provides all steam and electricity needed to the industrial process. Leftover electricity is sold to the grid. The industrial process works at $100 \%$ without the need to buy electricity from the grid.

b. The capacity of the industrial process is large. In this case, the reactor provides the maximum fraction of steam that the hydrogen plant can handle. The corresponding electrical energy needed is partly provided by the reactor and whatever part the reactor cannot provide (since it reached its capacity) is purchased from the grid. No electricity is sold from the reactor to the grid. The maximum case that can result is that the reactor provides all of its energy as steam to the hydrogen plant. All the corresponding electricity is then purchased from the grid.

c. The industrial process is even larger than in (b). In this case, if the reactor only provides steam and the corresponding electricity is purchased from the grid; the industrial process still does not reach its maximum capacity. In that case, the dispatch function evaluates whether it is profitable for the hydrogen plant to buy even more electricity from the grid to satisfy its maximum capacity. If the answer is no, the hydrogen plant will only buy the amount of electricity needed to utilize the steam coming from the reactor and the hydrogen plant will not run at full capacity. If the answer is yes, the hydrogen plant will buy (in addition to the amount of electricity needed to utilize the steam coming from the reactor) as much electricity is required to run at full capacity. 


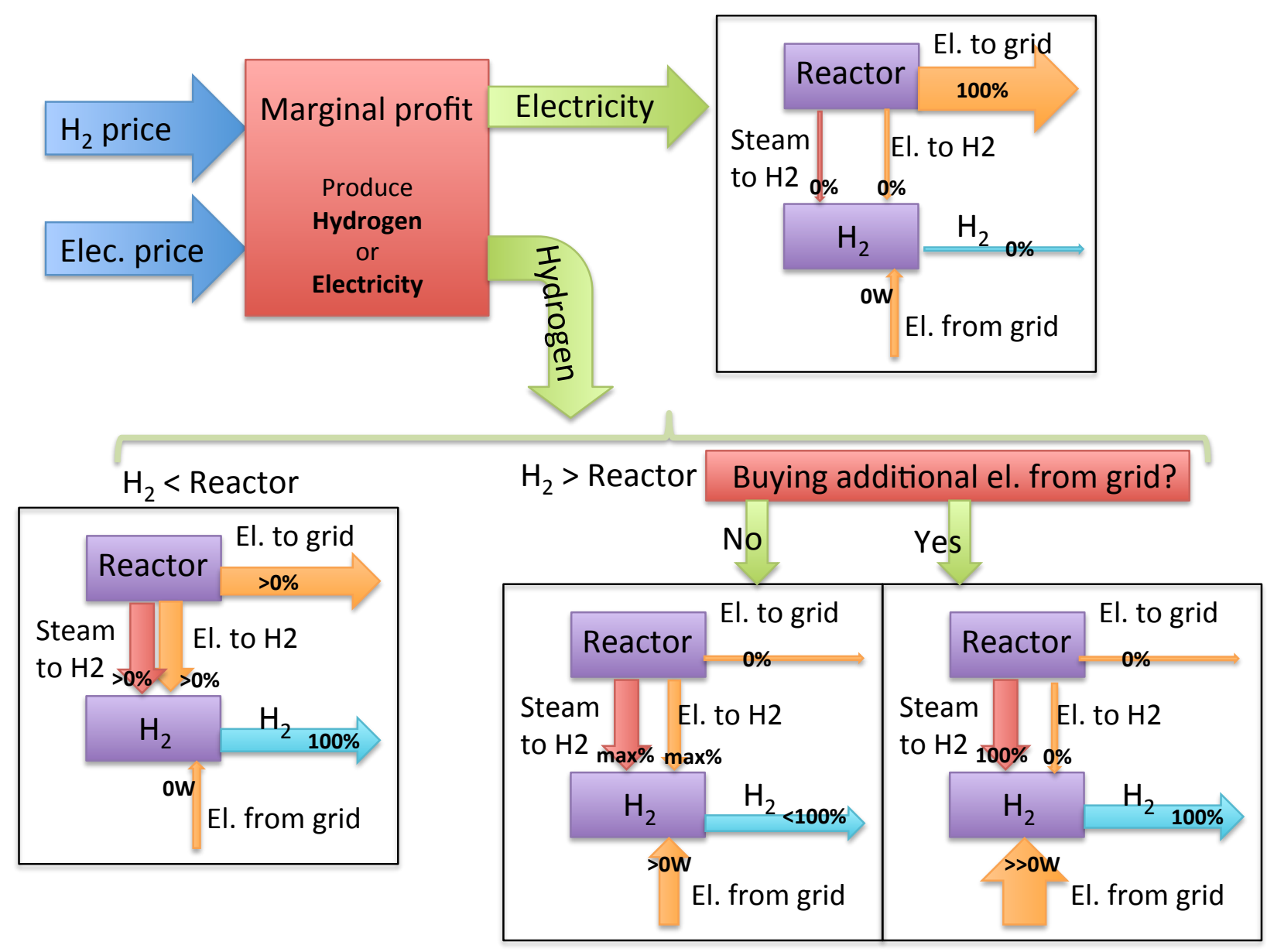

Figure 7. Dispatch rules. 


\section{NECESSARY SOFTWARE DEVELOPMENTS}

\subsection{Generalized Economics Module as an External Model in RAVEN}

A generalized module (called CashFlow) for economic analysis has been developed. The module is able to compute the NPV (Net Present Value), the IRR (Internal Rate of Return) and the PI (Profitability Index). Furthermore, it is possible to do an NPV, IRR or PI search, i.e. CashFlow will compute a multiplicative value (for example the production cost) so that the NPV, IRR or PI has a desired value (for details see below). This CashFlow module has been written using the script language Python. The Python code can be used as an "external model" in RAVEN.

The input of CashFlow is an XML file. An example of the input structure is given in Figure 8 . The following section will discuss the different keywords in the input and describe how they are used in the CashFlow module.

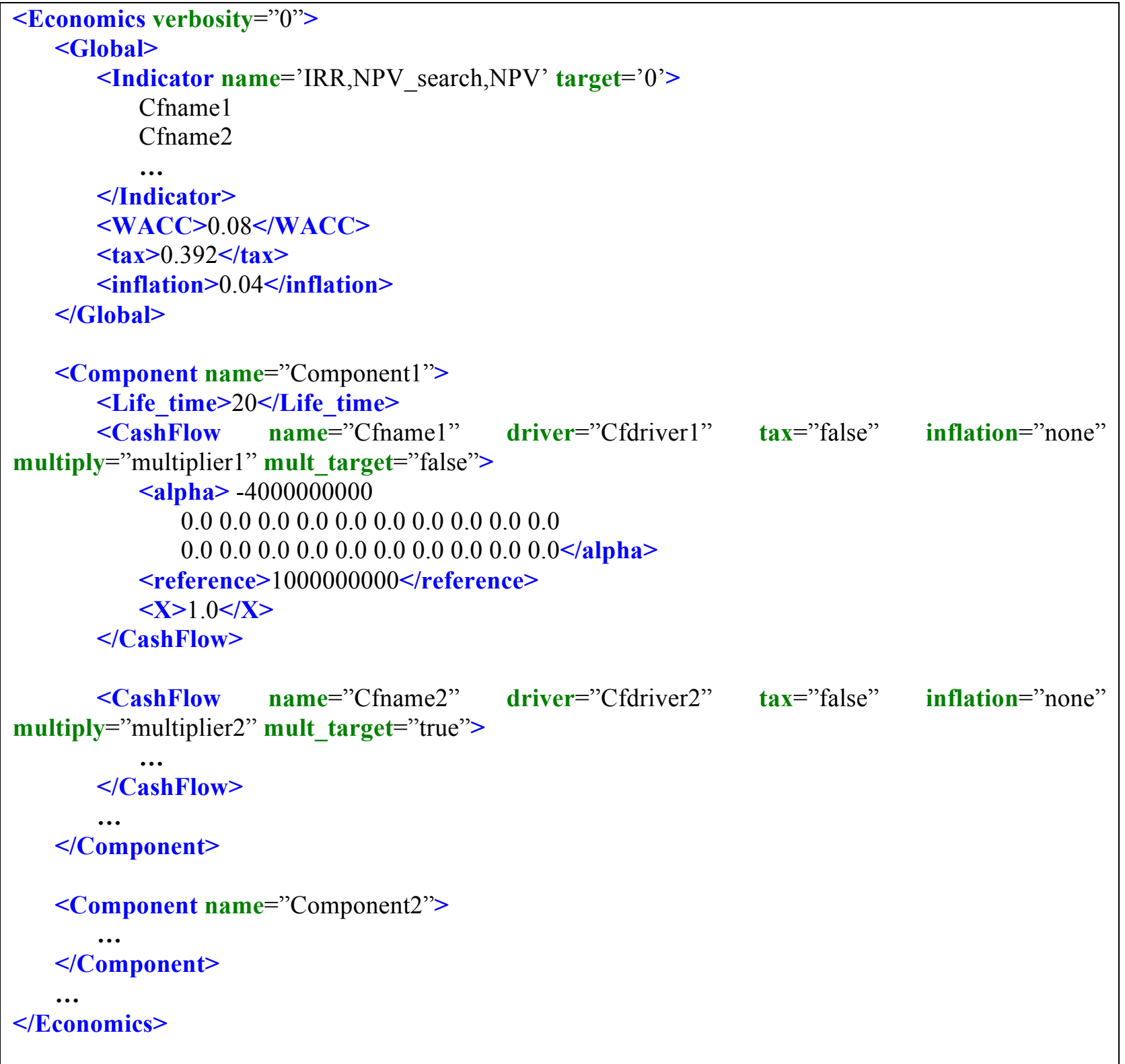

Figure 8. Economics input example. 
As one can see, all the specifications of the CashFlow module are given in the $<$ Economics $>$ block. The block accepts an attribute called verbosity, which can range from 0 to 100,0 meaning maximum debug verbosity and 100 meaning errors only. Inside the <Economics $>$ block, there are two types of blocks: <Global $>$ and $<$ Component $>$.

\subsection{1<Global>}

Exactly one $<$ Global $>$ block has to be provided. The $<$ Global $>$ block does not have any attributes. The following sub-blocks can be given in the <Global $>$ block:

<Indicator>: List of cash flows considered in the computation of the economic indicator. See later for the definition of the cash flows. Only cash flows listed here are considered, additional cash flows defined, but not listed are ignored. <Indicator $>$ can have two attributes:

name: The names of the economic indicators that should be computed. So far, 'NPV', 'NPV_search', 'IRR' and 'PI' are supported. More than one indicator can be asked for. The name attribute can contain a comma-separated list as shown in the example in Figure 8.

NPV: computes the NPV according to Eq. 2.

$$
N P V=\sum_{y=0}^{N} \frac{C F_{y}}{(1+W A C C)^{y}}
$$

The sum runs over the years $\mathrm{y}=0$ to $\mathrm{N}$. The net cash flows $\mathrm{CF}_{\mathrm{y}}$ are the sum of all cash flows defined in the indicator block (see later for how to define these cash flows). $\mathrm{N}$ is the least common multiple (LCM) of all component life times involved. This guarantees that the NPV is computed for a time span so that all components reach their end of life in the same year. The individual component cash flows are repeated until the LCM is reached. For example, lets assume the calculation involves two components Component 1 and Component 2 with life times of 60 years and 40 years respectively. $\mathrm{N}$ will be 120 years where 2 successive Component 1 and 3 successive Component 2 will be build. For every 'building year', the cash flow for the last year (of the old component) and the year zero (for the newly built component) will be summed. Table 4 shows an example for illustration.

Table 4. Example cash flows for NPV calculation.

\begin{tabular}{|c|c|c|c|c|c|}
\hline \multirow[b]{2}{*}{ Year } & Compo & 1 & Compo & 2 & \multirow[b]{2}{*}{$\begin{array}{l}\text { Total Net Cash flow } \\
\left(\mathrm{CF}_{\mathrm{y}}\right)\end{array}$} \\
\hline & $\begin{array}{l}\text { Comp. } \\
\text { lifetime }\end{array}$ & $\begin{array}{l}\text { Cash Flow } \\
\text { (year) }\end{array}$ & $\begin{array}{l}\text { Compo. } \\
\text { Lifetime }\end{array}$ & $\begin{array}{l}\text { Cash Flow } \\
\text { (year) }\end{array}$ & \\
\hline 0 & 0 & $\mathrm{CF}_{\text {compl }}(0)$ & 0 & $\mathrm{CF}_{\text {comp2 } 2}(0)$ & $\mathrm{CF}_{\text {compl }}(0)+\mathrm{CF}_{\text {comp2 }}(0)$ \\
\hline 1 & 1 & $\mathrm{CF}_{\text {compl }}(1)$ & 1 & $\mathrm{CF}_{\text {comp2 }}(1)$ & $\mathrm{CF}_{\text {compl }}(1)+\mathrm{CF}_{\text {comp2 }}(1)$ \\
\hline$\ldots$ & & & & & \\
\hline 39 & 39 & $\mathrm{CF}_{\text {compl } 1}(39)$ & 39 & $\mathrm{CF}_{\text {comp2 }}(39)$ & $\mathrm{CF}_{\text {comp1 }}(39)+\mathrm{CF}_{\text {comp2 }}$ (39) \\
\hline 40 & 40 & $\mathrm{CF}_{\text {compl } 1}(40)$ & 40 and 0 & $\begin{array}{l}\mathrm{CF}_{\text {comp2 }}(40) \\
+\mathrm{CF}_{\text {comp2 }}(0) \\
\end{array}$ & $\begin{array}{c}\mathrm{CF}_{\text {comp } 1}(40)+\mathrm{CF}_{\text {comp2 }}(40) \\
+\mathrm{CF}_{\text {comp } 2}(0) \\
\end{array}$ \\
\hline 41 & 41 & $\mathrm{CF}_{\text {compl }}(41)$ & 1 & $\mathrm{CF}_{\text {comp2 } 2}(1)$ & $\mathrm{CF}_{\text {comp1 }}(41)+\mathrm{CF}_{\text {comp2 }}(1)$ \\
\hline & & & & & \\
\hline
\end{tabular}




\begin{tabular}{|c|c|c|c|c|c|}
\hline 59 & 59 & $\mathrm{CF}_{\text {compl }}(59)$ & 19 & $\mathrm{CF}_{\text {comp2 }}(19)$ & $\mathrm{CF}_{\text {comp1 }}(59)+\mathrm{CF}_{\text {comp } 2}(19)$ \\
\hline 60 & 60 and 0 & $\begin{array}{l}\mathrm{CF}_{\text {comp } 1}(60) \\
+\mathrm{CF}_{\text {compl }}(0)\end{array}$ & 20 & $\mathrm{CF}_{\text {comp2 }}(20)$ & $\begin{array}{c}\mathrm{CF}_{\text {comp } 1}(60)+ \\
\mathrm{CF}_{\text {compl } 1}(0)+\mathrm{CF}_{\text {comp } 2}(20)\end{array}$ \\
\hline 61 & 1 & $\mathrm{CF}_{\text {compl }}(1)$ & 21 & $\mathrm{CF}_{\text {comp2 }}(21)$ & $\mathrm{CF}_{\text {comp1 }}(1)+\mathrm{CF}_{\text {comp2 }}(21)$ \\
\hline$\ldots$ & & & & & \\
\hline 79 & 19 & $\mathrm{CF}_{\text {compl }}(19)$ & 39 & $\mathrm{CF}_{\text {comp2 }}(39)$ & $\mathrm{CF}_{\text {compl }}(19)+\mathrm{CF}_{\text {comp } 2}(39)$ \\
\hline 80 & 20 & $\mathrm{CF}_{\text {compl } 1}(20)$ & 40 and 0 & $\begin{array}{l}\mathrm{CF}_{\text {comp2 }}(40) \\
+\mathrm{CF}_{\text {comp2 } 2}(0) \\
\end{array}$ & $\begin{array}{c}\mathrm{CF}_{\text {comp1 } 1}(20)+\mathrm{CF}_{\text {comp2 }}(40) \\
+\mathrm{CF}_{\text {comp } 2}(0)\end{array}$ \\
\hline 81 & 21 & $\mathrm{CF}_{\text {compl }}(21)$ & 1 & $\mathrm{CF}_{\text {comp2 }}(1)$ & $\mathrm{CF}_{\text {compl }}(21)+\mathrm{CF}_{\text {comp2 }}(1)$ \\
\hline$\ldots$ & & & & & \\
\hline 119 & 59 & $\mathrm{CF}_{\text {compl }}(59)$ & 39 & $\mathrm{CF}_{\text {comp2 }}(39)$ & $\mathrm{CF}_{\text {comp1 }}(59)+\mathrm{CF}_{\text {comp } 2}(39)$ \\
\hline 120 & 60 & $\mathrm{CF}_{\text {compl }}(60)$ & 40 & $\mathrm{CF}_{\text {comp2 }}(40)$ & $\mathrm{CF}_{\text {comp1 }}(60)+\mathrm{CF}_{\text {comp2 }}(40)$ \\
\hline
\end{tabular}

PI: computes the PI according to Eq 3.

$$
P I=\frac{N P V}{\text { Initial_investment }}
$$

where the NPV is calculated as explained above and the Initial_investment is the Total Net Cash flow at year zero, i.e. $\mathrm{CF}_{0}$ in the example above.

IRR: computes the IRR according to Eq 4.

$$
0=\sum_{y=0}^{N} \frac{C F_{y}}{(1+I R R)^{y}}
$$

Same as for the NPV, the sum runs over the years $y=0$ to N. The net cash flows $\mathrm{CF}_{\mathrm{y}}$ are the sum of all cash flows defined in the indicator block (see explanation of NPV above for details). $\mathrm{N}$ is the least common multiple (LCM) of all component life times involved.

NPV_search: The NPV search finds a multiplier ' $x$ ' that multiplies some of the cash flows, so that the NPV has a desired value (defined by the "target" attribute). The equation solved is shown in Eq. 5.

${ }^{\prime} t \arg e t^{\prime}=\sum_{y=0}^{N} \frac{C F_{y}^{\text {dependon } x}}{(1+W A C C)^{y}} x+\sum_{y=0}^{N} \frac{C F_{y}^{\text {notdependon } x}}{(1+W A C C)^{y}}$

The cash flows that multiply ' $x$ ' have to have the mult_target="true" attribute (see later in cash flow definition). This functionality can be used for example to find a commodity price so that the NPV is zero. In this case, the target will be set to " 0 " and all cash flows that depend (linearly) on the price will take mult_target="true", i.e. for example the revenue, while cash flows that do not depend on the price will have mult_target="false", i.e. for example the capital cost.

Note on IRR and PI search: It should be noted that although the only search keyword allowed in name is NPV_search, it is possible to perform IRR and PI searches as well. 
- To do an IRR search, the WACC is set to the desired IRR and a NPV search with the target of ' 0 ' is performed.

- To perform a PI search, an NPV search can be performed where the target PI is multiplied with the initial investment.

Target: Target value for the NPV search, i.e. " 0 " will look for ' $x$ ' so that NPV(x) $=0$.

$<$ WACC $>$ The WACC discount rate used to compute the NPV and PI. Not used for the computation of the IRR.

$<\operatorname{tax}>$ The tax rate used to compute the taxes. See later in the definition of the cash flows for more details how the tax rate is used.

<inflation> The inflation rate used to compute the inflation. See later in the definition of the cash flows for more details how the inflation rate is used.

\subsection{2 <Component>}

The user can define as many $<$ Component $>$ blocks as needed. A component is typically a part of the system that has the same lifetime and the same cash flows, i.e. for example a gas turbine, a battery or a nuclear plant. Each component needs to have a name attribute that is unique. Each $<$ Component $>$ has to have one $<$ Life_time $>$ block and as many $<$ CashFlow $>$ blocks as needed.

$<$ Life_time $>$ : The lifetime of the component in years. This is used to compute the least common multiple (LCM) of all components involved in the computation of the economics indicator. For more details see NPV, IRR and PI explanations above.

$<$ CashFlow >: The user can define any number of "cash flows" for a component. Each cash flow is of the form given in Eq. 6 where y is the year from 0 (capital investment) to the end of the $<$ Life_time $>$ of the component.

$$
C F_{y}=\text { mult } \cdot \alpha_{y}\left(\frac{\text { driver }_{y}}{\text { ref }}\right)^{X}
$$

name: The name of the Cash flow. Has to be unique across all components. This is the name that can be listed in the $<$ Indicator $>$ node of the $<$ Global $>$ block.

Driver: The driver of the cash flow. This can be any variable passed in from RAVEN or the name of another cash flow. If it is passed in from RAVEN, it has to be a scalar; so all driver ${ }_{y}$ are the same for all years of the project life (this limitation will be lifted in future versions of the CashFlow module). If the driver is another cash flow, the project $<$ Life_time $>$ of the component to which the driving cash flow belongs has to be the same than the project $<$ Life_time $>$ of the component to which this cash flow belongs. No loops of cash flows are allowed, i.e. the code will error out if there are loops of cash flows, i.e. A is the driver of B and B the driver of A.

tax: $\quad$ Can be true or false. If it is true, the cash flow is multiplied by (1-tax), where tax is the tax rate given in $\langle\operatorname{tax}>$ in the $<$ Global $>$ block. If a cash flow with tax="true" is the driver of another cash flow, the cash flow without the tax is used as driver for the new cash flow. The limitation of having a global tax rate will be lifted in future version of the CashFlow 
module. It is planned to have the possibility to input different tax rates for each component, since they might be in different tax regions.

Inflation: Can be real, nominal or none. If it is real, the cash flow is multiplied by $(1+\text { inflation })^{\wedge}(-y)$. If it is nominal, the cash flow is multiplied by $(1+\text { inflation })^{\wedge} y$. In both cases, inflation is given by <inflation $>$ in the $<$ Global $>$ block. If a cash flow with inflation equal real or nominal is the driver of another cash flow, the cash flow without the inflation is used as driver for the new cash flow.

Multiply: This is an optional attribute. This can be the name of any scalar variable passed in from RAVEN.

Mult_target: Can be true or false. If true, it means that this cash flow multiplies the search variable ' $x$ ' as explained in the NPV_search option above. If the NPV_search option is used, al least one cash flow has to have mult_target $=$ true.

$<$ alpha $>$ : $\quad \alpha_{y}$ multiplier of the cash flow (see Eq. 6). Exactly $<$ Life_time $>+1$ values are expected. One for $\mathrm{y}=0$ to $\mathrm{y}=<$ Life_time $>$.

$<$ reference >: The ref value of the cash flow (see Eq. 6).

$<\mathbf{X}>$ : $\quad$ The $X$ exponent of the cash low (see Eq. 6).

An example of a cash flow is shown in Figure 9. In the example, a cash flow called CAPEX is defined. In the example, the capital expenditure for a reference plant of capacity 1'000'000'000 is $\$ 4$ billion. The driver of this cash flow is the actual plant capacity. Building this plat has some economy of scale, so that a plant double the size does cost less than double the money $(X=0.64)$.

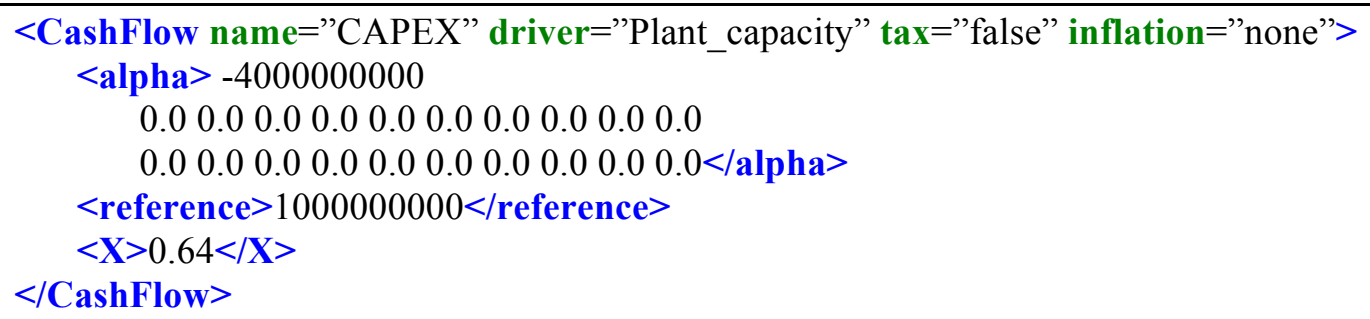

Figure 9. CashFlow input example.

\subsubsection{Future Work on the Cash Flow Model}

The cash flow model so far implemented is fairly flexible, complete both from the aspect of manuals and input error handling and it is therefore approaching being a complete component of the modeling and simulation strategy for hybrid systems. As already mentioned, it could easily be extended to allow some of the parameters to be provided, both, as global and subsystem-based parameters. The code can accept an unbounded number of subsystems and it looks capable to accommodate most of the needed information for the components tested so far. It is not to be excluded that the input structure will need to be expanded especially to accommodate:

- Different region for economy of scale of the different subsystem

- Interest in building time

- Elasticity of the price at which product are sold

- Subsystem component replacement (with down time) 


\subsection{Optimization in RAVEN}

This chapter briefly discusses the optimization capability in RAVEN. Currently, RAVEN has two types of samplers, e.g., statistical sampler and optimizer. The difference between these two is that the latter does not require sampling over a distribution, although certain specific optimizers may utilize stochastic approach to locate the optimality. Figure 10 shows the structure of the optimization workflow. The currently available optimizer is RAVEN is gradient based ${ }^{\mathrm{b}}$ and stochastic, namely, Simultaneous Perturbation Stochastic Approximation (SPSA).

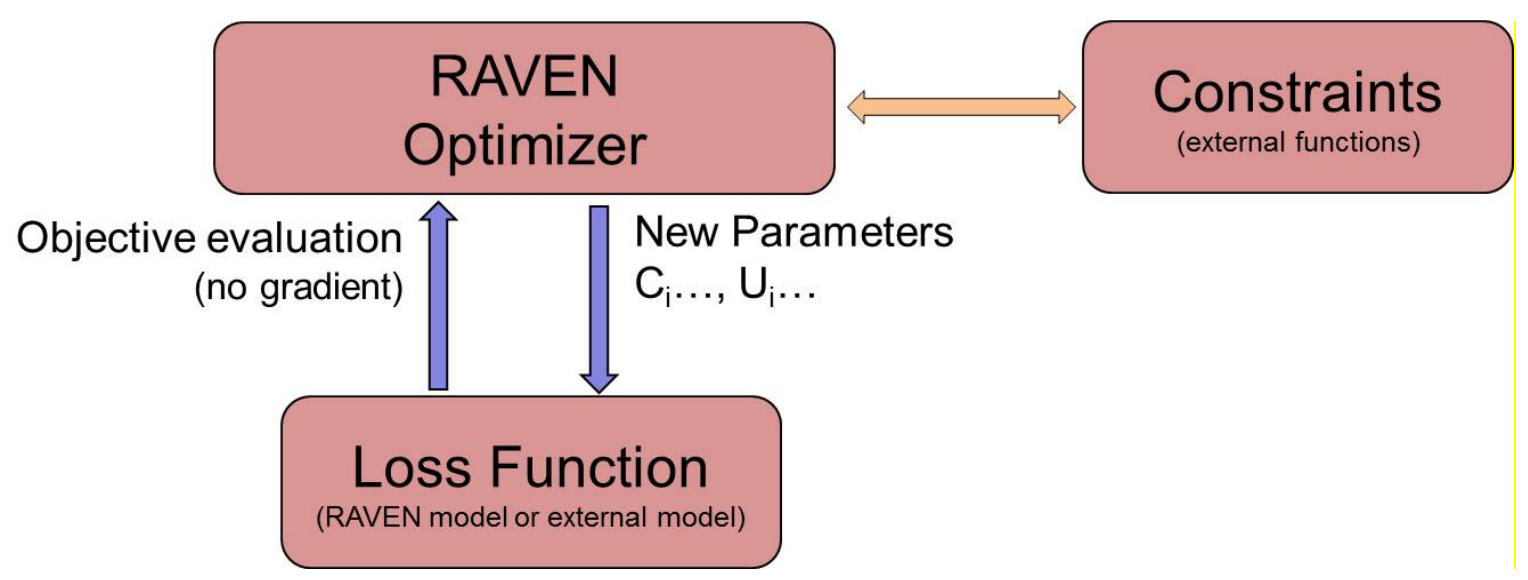

Figure 10. RAVEN optimization workflow.

\subsubsection{Improved Treatment of Boundary Constrain}

In real applications, the optimization search is performed in constrained domains. The objective function (i.e. the figure of merit of interest) cannot freely vary in the optimization domain, since some regions of the space are forbidden, either for physical (e.g. the water level in a tank can not be lower then the bottom of the tank itself) or for engineering/financial reasons. The optimization under constraints represents a formidable challenge, overall in high-dimensional spaces. As already mentioned, the optimization algorithm implemented in RAVEN and used for this activity is based on an approximation (0-order) of the gradient $\left.\bar{\nabla} f_{i}(\bar{x})\right|_{\bar{x}_{k}}$. The gradient is used as driving force to guide the optimization process toward the minimum/maximum of the objective function. In presence of constraints, it is likely that the gradient $\left.\bar{\nabla} f_{i}(\bar{x})\right|_{\bar{x}_{k}}$ points toward a direction that determines the violation of one or more constraints. In these cases, RAVEN needs to find another available direction that moves toward the minimization or maximization (depending of the type of optimization) path. As part of the activities reported in this document, the RAVEN team improved the treatment of boundary constraints (i.e. constraints that can be casted as inequalities of the form $\bar{x} \geq \bar{a} ; \bar{x} \leq \bar{b}$ ). When one or more of these constraints get crossed, RAVEN performs a projection of the gradient toward the direction identified by the inequality of the violated constraints. For all the other types of constraints, RAVEN uses the following strategy:

1. Generate a series of random vectors $\bar{r}$ normal to $\left.\bar{\nabla} f_{i}(\bar{x})\right|_{\bar{x}_{k}}$ until the constraint is satisfied at $\bar{x}_{k+1}=\bar{x}_{k}-\alpha_{k} \bar{r}$ (where $\alpha_{-} \mathrm{k}$ represent the learning rate parameter for iteration $\mathrm{k}$ )

\footnotetext{
${ }^{b}$ The term "gradient based" is used to refer to the fact that the optimizer will utilize gradient information to compute the new inputs. Since the SPSA algorithm will estimate the gradient instead of relying the model to provide such information, it may also be referred to as "gradient free" in literature. The SPSA algorithm is currently implemented as a sub-class of gradient based optimizers in RAVEN.
} 
2. Rotate the vector $\bar{r}$ toward $\left.\bar{\nabla} f_{i}(\bar{x})\right|_{\bar{x}_{k}}$ until finding (after $e$ iterations) an $\bar{r}_{e}$ that does not satisfy the constraints and take the previous vector $\bar{r}_{e-1}$.

3. Pose $\bar{x}_{k+1}=\bar{x}_{k}-\alpha_{k} \bar{r}_{e-1}$.

This approach is far from being optimized but ensures that the constraint is satisfied and preserves some of the information concerning the steepest direction (gradient).

\subsubsection{Future Work on Optimization}

The tested so far performed have confirmed that multiple local evaluations help the convergence of the optimization strongly especially when the gradient and the noise are comparable. Following this indication, an automatic process is being implemented to control some of the parameters, which determines the learning rate of the algorithm, online, based on the decrease of the statistical noise due to multiple evaluation of the gradient.

Another important change in the optimization that will be son implemented is the capability to perform nested level of optimization. This will be used to optimize sub-system capacity and their time dependent dispatching independently. This approach should be more stable, more scalable and capable to effectively tackle optimization problems with several hundreds, and possibly more, optimization variables. 


\section{ECONOMIC DATA FOR NUCLEAR AND HYDROGEN PLANTS}

This section of the report contains information relevant to the economic analysis of a hybrid system consisting of a nuclear plant and of a $\mathrm{H}_{2}$ electrolysis plant. In particular, the specific objective of this work is to provide input parameters for a simulation that will determine the optimal dimensioning of the $\mathrm{H}_{2}$ plant, and its capacity factor, based on the coupling with a nuclear plants in an electricity market where the prices fluctuate frequently. Therefore, when the electricity price is too low, the electricity and steam from the reactor are diverted to the $\mathrm{H}_{2}$ plant and when the price is high, electricity is sold in the market.

Relevant information needed and collected includes:

- Historical electricity prices, at 5 minutes interval (for the current simulation, the data is averaged hourly, but the fine time resolution will be used in later reports), for several years, possibly in a geographic region consistent with the existence of a market for hydrogen.

- As much information as possible on the forming $\mathrm{H}_{2}$ markets in the US, including prices, pipelines and other data.

- Nuclear cost data, including:

- Overnight reactor capital cost

- Total reactor capital cost

- Fuel cost

- O\&M reactor cost

- More discussion on fixed variable O\&M reactor costs

- Scaling factors for nuclear plants

- Cost considerations for a hydrogen facility: this information was collected primarily from [8]. However, some necessary information was missing from this reference, or was otherwise not clear. For these parameters, the uncertainty is clearly indicated in the text, and the provided solution is clearly explained, including its possible limitations.

\subsection{Hydrogen Market}

\subsubsection{Global Hydrogen Market}

The information reported here are found in $[9,10]$. The total (i.e. worldwide) hydrogen market in 2016 was $\$ 118$ billion, expected to grow about 5\% year-over-year over the next few years.

Both a "Captive" and a "Merchant" market exist and various technologies (Steam Methane Reforming, Partial Oxidation, Gasification, and Electrolysis), Applications (Refinery, Ammonia Production, and Methanol Production), and Regions are involved. Refining was the largest customer in 2015, with the primary regional market being the Asia/Pacific region.

Most of the generation is from steam-methane reforming of natural gas: reacting $\mathrm{CH}_{4}$ with $\mathrm{H}_{2} \mathrm{O}$ in the presence of a catalytic converter. Steam methane reforming accounted for more than $1 / 3^{\text {rd }}$ of total generation, while other technologies are partial oxidation, gasification and electrolysis. Leading players in the worldwide hydrogen markets are Linde AG (Germany), Air Liquide SA (France), Air Products \& Chemicals Inc. (U.S.), Praxair Inc. (U.S.), Airgas Inc. (U.S.), and Hydrogenics Corp. (Canada) among others.

North America is the largest market for merchant hydrogen generation, while captive production is expected to dominate the market until 2021. It is noted that hydrogen can be generated and stored using excess electricity generated from intermittent energy sources, or it can be injected into natural gas pipelines. 


\subsubsection{U.S. Hydrogen Market}

The U.S. merchant hydrogen market rose from $\$ 3.36$ billion in 2010 to $\$ 3.44$ billion in 2011 (this corresponds to about $3 \%$ of the total (worldwide) $\mathrm{H}_{2}$ market by comparing the merchant market size with the total size of the market detailed in [9]). By 2016, the merchant market should reach $\$ 3.87$ billion, yielding a compound annual growth rate (CAGR) of $2.4 \%$ for the period.

In terms of volume, the market totaled 1.22 million tons in 2010. In 2011, the U.S. merchant hydrogen market totaled 2.74 billion pounds, and by 2016, the net amount is expected to reach 2.77 billion pounds, yielding a CAGR of $0.2 \%$. By taking a ratio of these two, it is possible to calculate the price of $\mathrm{H}_{2} /$ pound (i.e. for 2010: $\$ 3.36 \mathrm{E} 9 / 2.69 \mathrm{E} 9 \mathrm{lb}=1.25 \$ / \mathrm{lb}$ or $2.75 \$ / \mathrm{kg}$ in 2010 ; for 2016 $\$ 3.87 \mathrm{E} 9 / 2.77 \mathrm{E} 9 \mathrm{lb}=1.40 \$ / \mathrm{lb}$ or $3.1 \$ / \mathrm{kg}$ in 2016$)$.

Other references, such as [11], place the price of hydrogen at $\$ 1.81 / \mathrm{kg}-\mathrm{H}_{2}$ (using $2 \%$ inflation rate to update the costs). In addition, reference [12] prices the hydrogen between $\$ 1.26 / \mathrm{kg}$ and $\$ 2.51 / \mathrm{kg}$.

\subsubsection{Price Uncertainties}

It is not yet clear if the price of hydrogen fluctuates daily, similar to that of electricity in restructured markets, and if so, if the price data are available.

Information is still missing on the conversion from $\mathrm{ft}^{3}$ to $\mathrm{kg}$ : for example, one calculator used by DOE (http://hydrogen.pnl.gov/tools/hydrogen-conversions-calculator) provides several standard conditions to choose from when calculating a conversion from $\mathrm{ft}^{3}$ to $\mathrm{kg}$ :

- Volume of gas at $1 \mathrm{~atm}$ and $68 \mathrm{~F}\left(\right.$ in $\left.\mathrm{ft}^{3}\right)$.

- Volume of gas at $1 \mathrm{~atm}$ and $60 \mathrm{~F}$ (in standard $\mathrm{ft}^{3}$ ).

- Volume of gas at $1 \mathrm{~atm}$ and $0 \mathrm{C}$ (in normal $\mathrm{ft}^{3}$ ).

It is clear that specifying the volume in $\mathrm{ft}^{3}$ without additional data on the standard conditions chosen is not a desirable practice.

\subsubsection{Hydrogen pipelines}

There are 1200 miles of pipelines carrying hydrogen in the U.S. The Air Product's U.S. Gulf Coast hydrogen network map from [13] is shown in Figure 11. Air Products and Chemicals Inc. has a worldwide $40 \%$ market share based on volume. The network includes more than $20 \mathrm{H}_{2}$ plants and over 600 miles of pipelines (i.e. about half of the U.S. pipelines by length based on [14], supplying customers with more than $1 \mathrm{E} 9 \mathrm{ft}^{3}$ of $\mathrm{H}_{2}$ per day.

A new pipeline was constructed between Lake Charles, LA and Plaquemine, LA to unite the east and west interconnect of Air Products and Chemicals Inc. Air Products and Chemicals Inc. also operates pipeline networks that provide $\mathrm{H}_{2}$ to customers in:

- Southern California;

- Sarnia, Ontario, Canada;

- Edmonton, Alberta, Canada;

- Rotterdam, The Netherlands. 


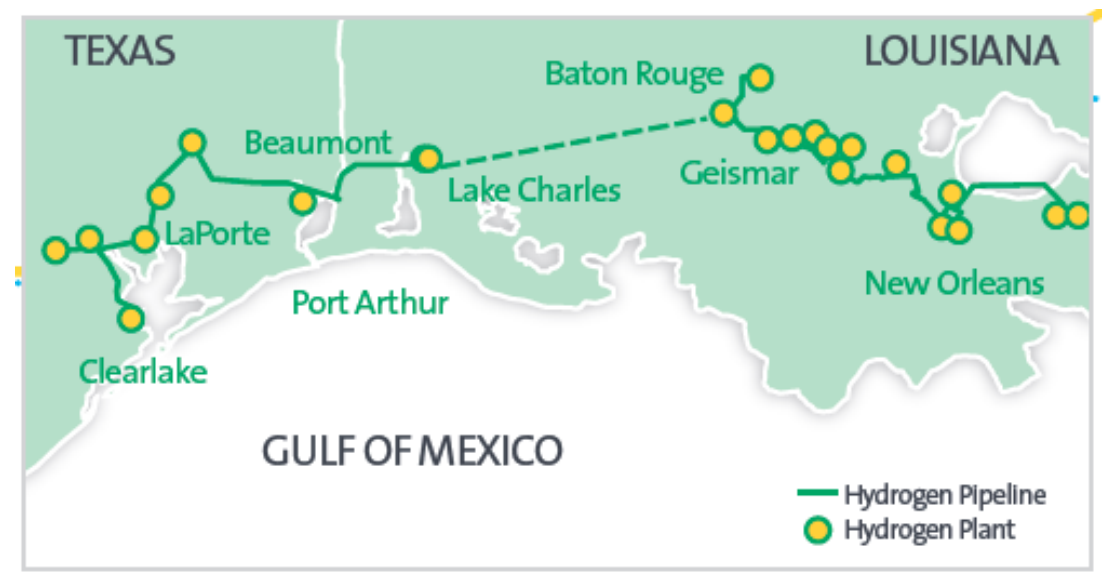

Figure 11. Map of Air Product's hydrogen network, including $\mathrm{H}_{2}$ production plants and major pipelines. Source: [13].

\subsection{Electricity Prices}

The Air Products and Chemicals Inc. pipeline discussed in section 5.1.4 appears to be located in the MISO interconnect, so it should be possible to obtain "Locational Marginal Prices (LMP)" at various nodes of interest while keeping locational consistency. Maps and histories (within the latest 24 hours) of zonal prices can be found in [15].

The primary hub for the region of interest appears to be the "LOUSIANA.HUB", near Baton Rouge, LA, which is both a pricing hub for MISO and a $\mathrm{H}_{2}$ delivery point (see Figure 12). Interestingly, it appears that the interconnection between southern Louisiana east and west may not be well established, at least not at all times. For example, Figure 13 shows that on February 16, 2017 at 7:35 AM central time, Louisiana experienced negative prices in the western part and scarcity prices in the eastern part (where the "LOUISIANA.HUB" is located), all in the same "planning zone 9".

Planning zone 9 includes balancing authorities EES, SME, CLEC, LAGN, LEPA, LAFA; the approximate footprint of each of which is indicated in Figure 14. "A Balancing Authority is the responsible entity that integrates resource plans ahead of time, maintains load-interchange-generationbalance within a Balancing Authority Area and supports Interconnection Frequency in real-time." [16].

The archived annual LMP at 5 minute intervals for the entire MISO for 2012, 2013 and January to May 2014 were found in [17].

It appears that, based on [18], the southern area integration switched from being designated as simply EES to various nodes within the previous EES system, effective $12 / 19 / 2013$. This is why the available 5 minute historical data for 2012 only contain the EES node, while from December 19, 2013 on, 178 different EES nodes became available in 2013 and in 2014. The 5-minute LMP for 2012 and 2013 are plotted in Figure 15 and in Figure 16, respectively. In particular, the 2013 data plotted in Figure 16 are simply the prices at node EES up to December 18, 2013, and from December 19, 2013 onward, the EES.DOWCHEM was chosen as a representative node, since it is close to Air Product US Gulf Coast hydrogen network.

Additionally, this is relevant data for the MISO southern integration (from FAQ of the MISO contour map [19], dated August 7, 2013; this date is consistent with the transition happening in Dec 2013.

“ $Q$ : Why can't I see any South (Entergy) nodes?

A: MISO will expand the footprint to include the South nodes in December when the Entergy expansion is complete. You will be able to view the new South region, the existing Midwest region 
and a combination of the two regions all from our Real Time Market Data menu where the current LMP Contour Map is available."

For the $1^{\text {st }}$ set of runs of this exercise, it is suggested to simply use the EES aggregated data available at 5 minute intervals for the entire years 2012 and 2013. Between December 19, 2013 and December 31, 2013, a representative node such as EES.EXXON or EES.DOWCHEM may be sufficient to obtain representative price points.

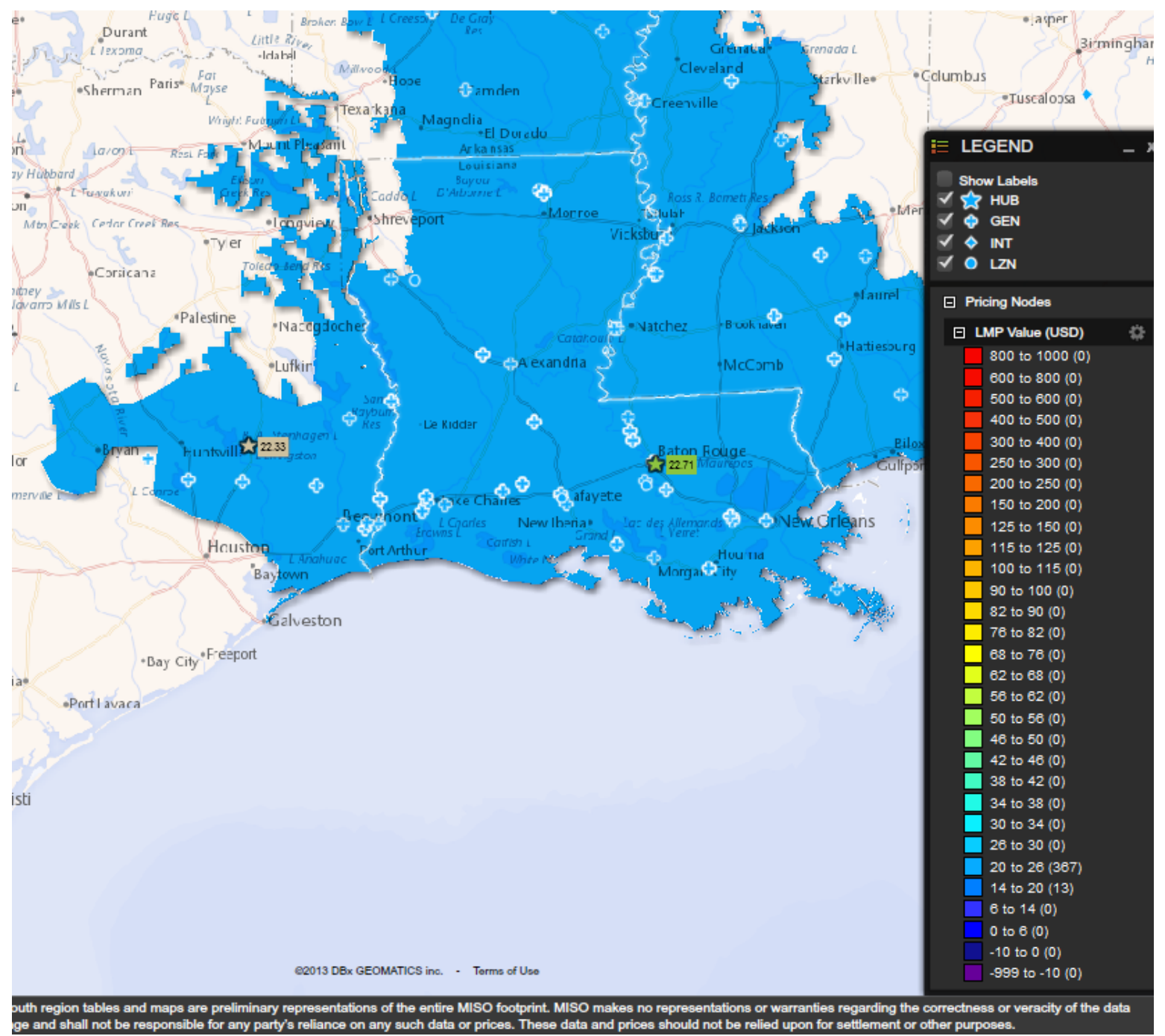

Figure 12. Screen capture of the MISO area that is overlapping with the Air Product $\mathrm{H}_{2}$ network of Figure 11. 


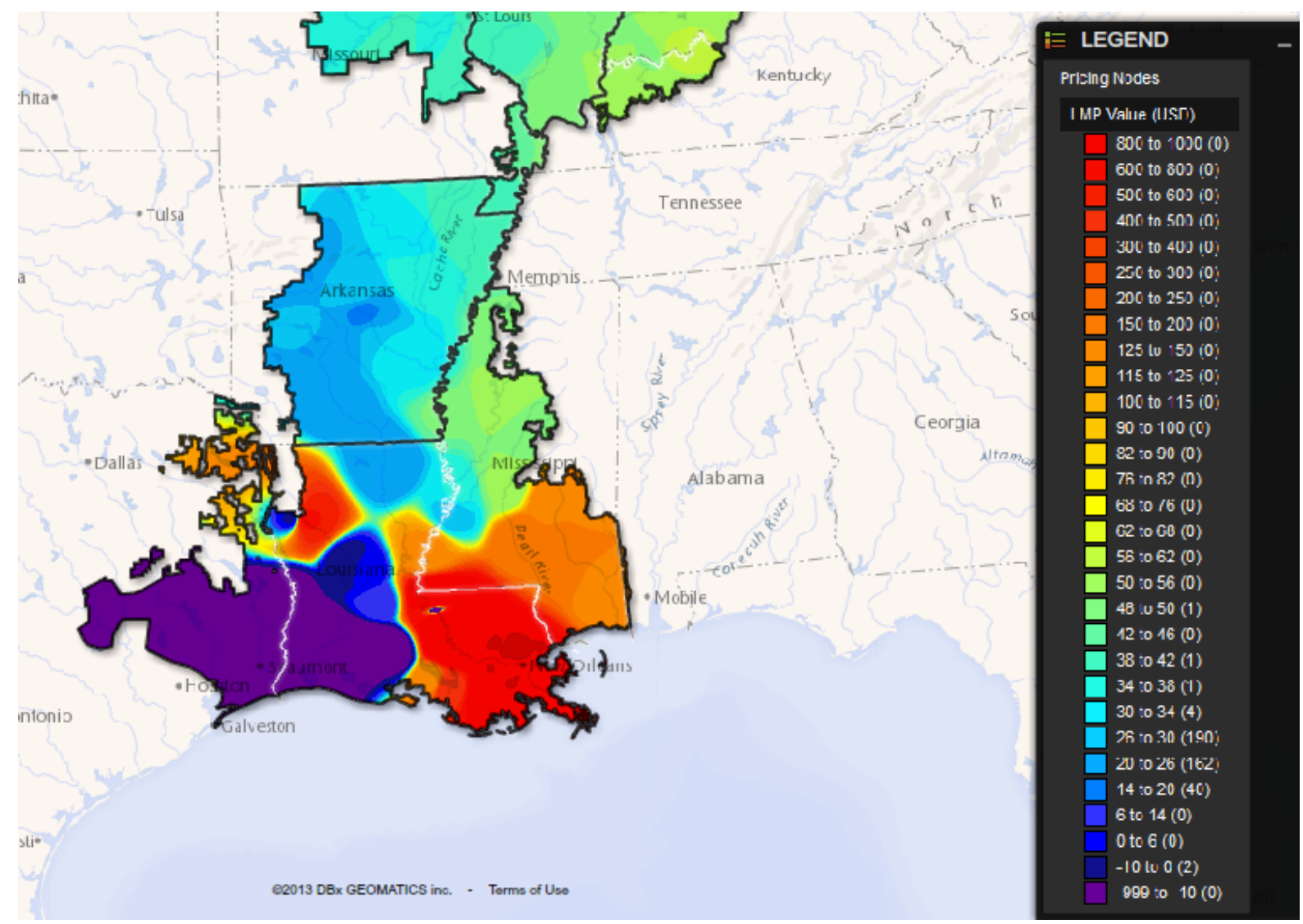

Figure 13. Negative and scarcity prices could co-exist in LA: screenshot from [15], February 16, 2017 at 7:35 AM central. 


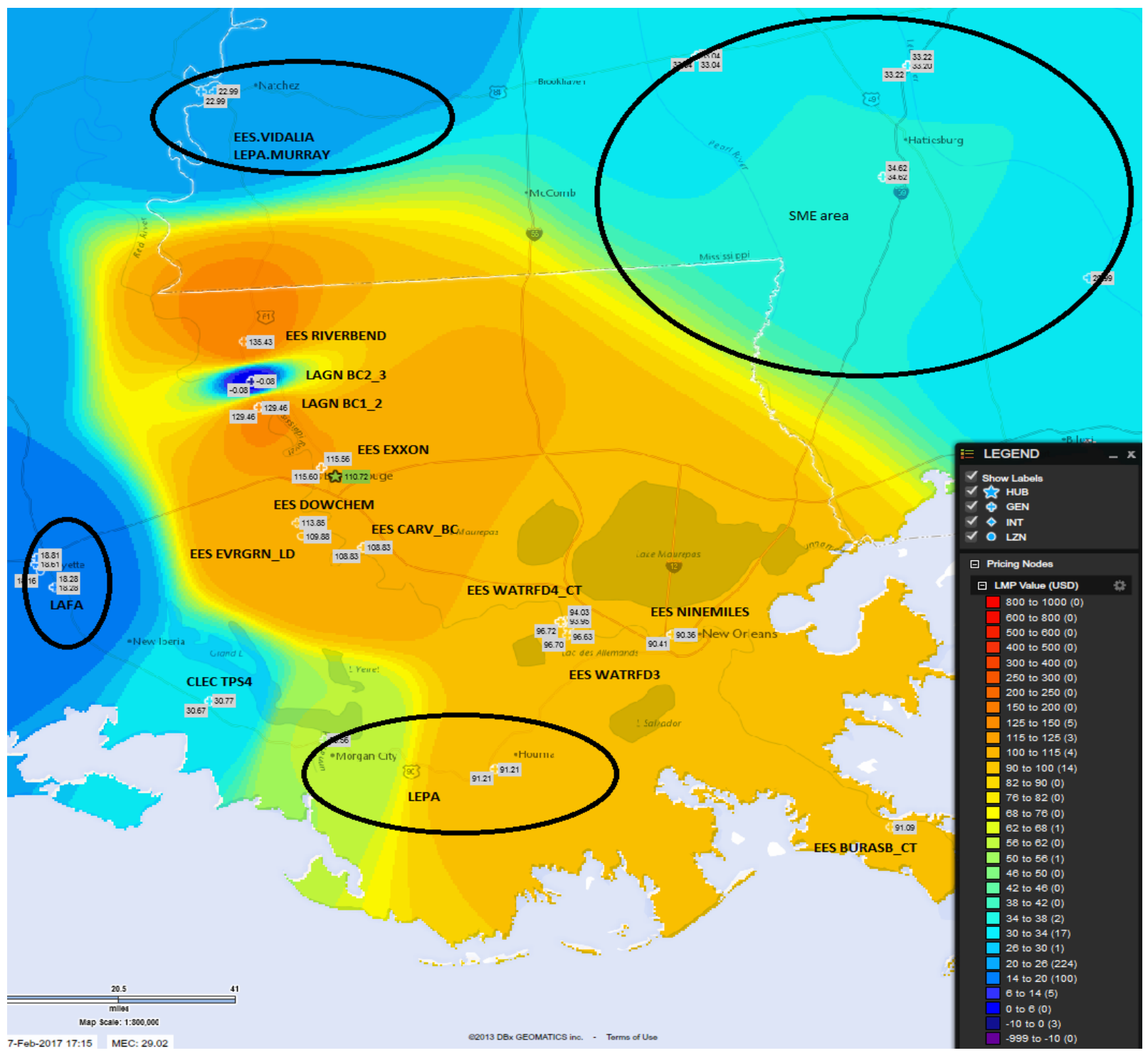

Figure 14. Highlights of some of the node names and name of areas in the region of interest for this study (source MISO web site with superposition of names and circles for areas). 


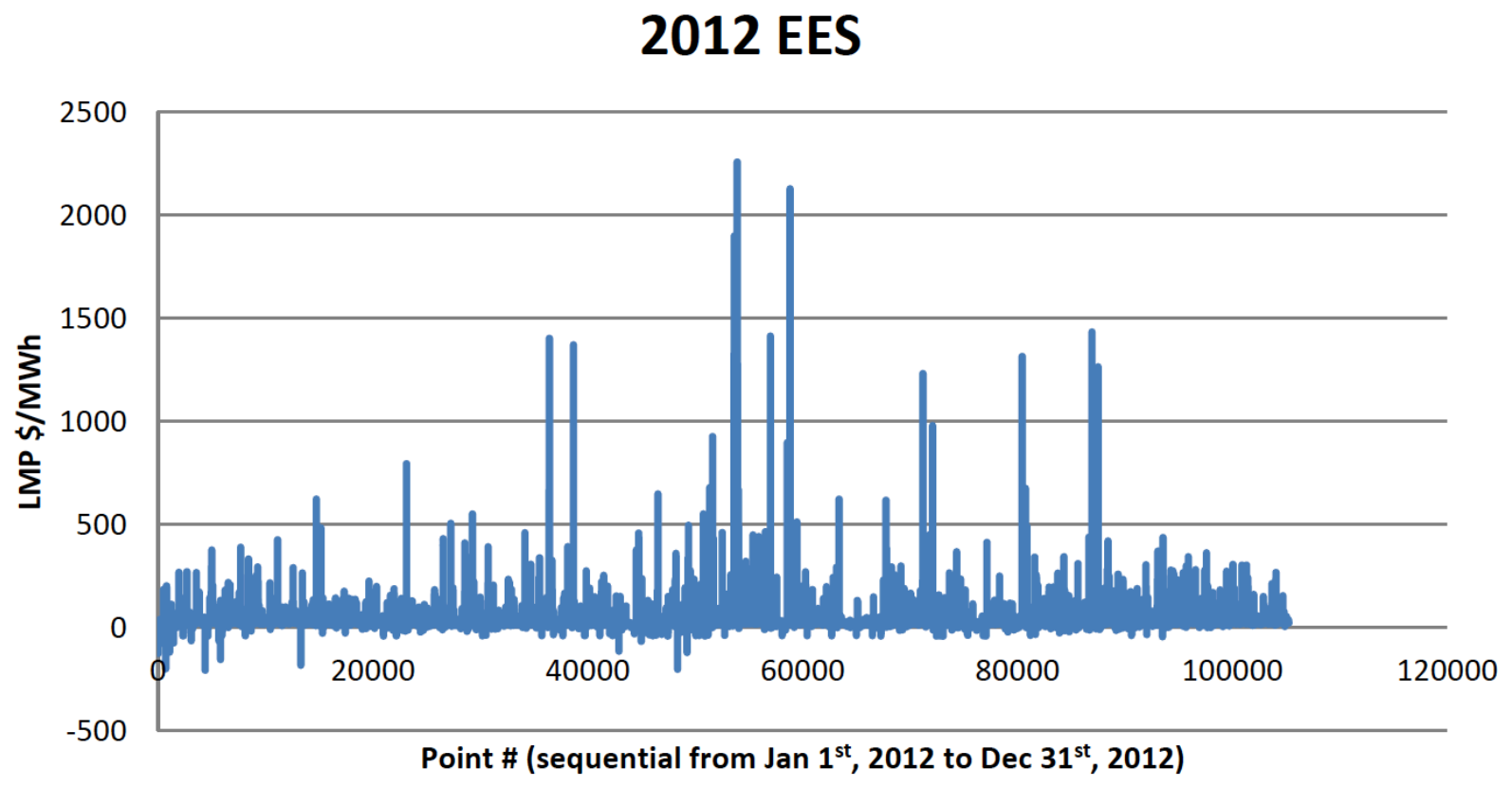

Figure 15. Plot of the 5 minutes interval LMP for the EES node for the entire year 2012.

\section{EES and EES.DOWCHEM}

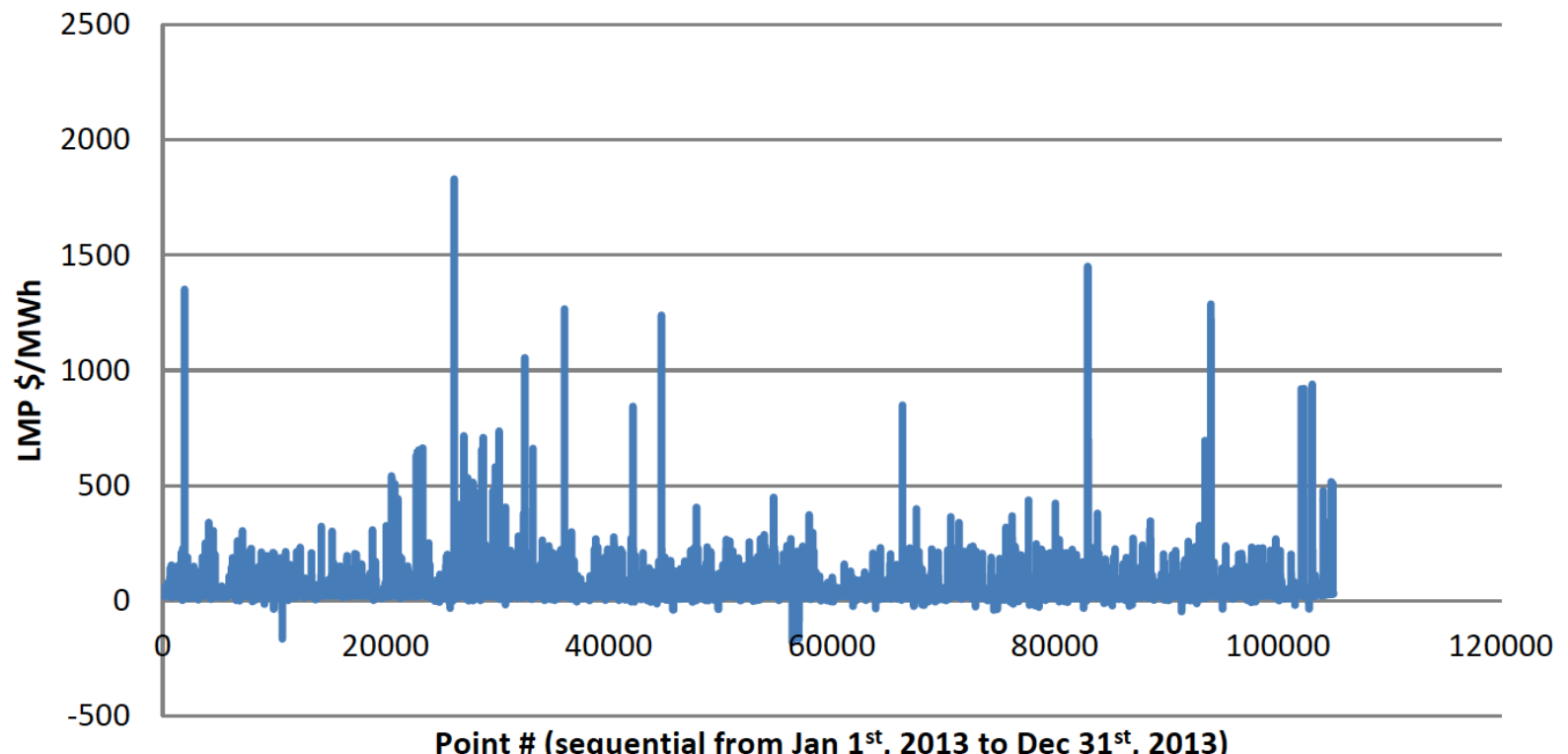

Figure 16. Plot of the 5 minute interval LMP for the EES node for the entire year 2013. Since the EES node was fully integrated into MISO and split into multiple nodes beginning December 19, 2013, the ESS.DOWCHEM was chosen as the representative node after this date. 


\subsection{Additional data found for MISO (useful for future reference)}

Data is also available for the hourly generation mix for hydro, nuclear, gas, wind, and coal, and other generation sources (which likely includes geothermal, solar, oil and possibly others). The data are provided for north, central, south and the entire MISO. While this would be approximate, the 2012 and 2013 load and mix data for "south" may be applicable for this work.

The data can be found at:

- https://www.misoenergy.org/Library/MarketReports/Pages/MarketReports.aspx;

Then select the "Browse all available reports" tab and scroll down to "Summary Generation Fuel Mix". The mix is displayed hourly in a file each day for the period July 2015 until the current date (February 23, 2017 at the time of writing).

There is also an historical generation fuel mix, one file for each year for 2012, 2013, 2014 and 2015 at:

- https://www.misoenergy.org/RTDisplays/MKTRPT/AllReportsList.html?rptName=Historical Generation Fuel Mix (xls))

For example, for 2013 and 2016 the files have been saved. The structure is a long list (on 3 tabs), of the mix (coal, hydro, nuclear, etc....) for each region (north, central for 2013 up to 12/18/2013 and North, Central, South from 12/19/2013 onwards).

Day ahead hourly LMP cost data by node for more recent times (2015 to now) are available at:

- https://www.misoenergy.org/RTDisplays/MKTRPT/AllReportsList.html?rptName=Day-Ahead EPNode LMP (zip)

5 minute historical data are available for more recent times (from January 2015 to present), in weekly files at:

- https://www.misoenergy.org/RTDisplays/MKTRPT/AllReportsList.html?rptName=Weekly RealTime 5-Min LMP (zip).

\section{$5.4 \quad$ Nuclear and other data}

\subsubsection{Overnight reactor capital cost}

Overnight capital cost for a reference $1100 \mathrm{MW}_{\mathrm{e}} \mathrm{PWR}$ is $4100 \$ / \mathrm{kW}_{\mathrm{e}}[20,21,22,23]$. This corresponds to a well-executed construction project without regulatory interventions or design changes after the construction has begun.

\subsubsection{Total reactor capital cost}

The Interest During Construction is calculated based on the methodology implemented in the NECOST code, and described in [24] and reported in Figure 17 for the convenience of the reader. Under the assumption of a cost of capital during construction of $5 \%$, and a 5 year construction duration (in Japan some nuclear plants have been constructed in less than 5 years; therefore, this timing is achievable for a well-managed and well-executed project), the total capital cost including IDC (Interest During Construction) is $4660 \$ / \mathrm{kWe}$, implying an IDC of $13.7 \%$ of the overnight amount. The overnight capital cost so computed might not be coherent with the approach used later on since the cost of capital is a possible optimization parameter (IRR). In the future, this computation will be made part of the financial analysis tool currently developed as an external module for RAVEN. 
The total reactor construction cost is the sum of the overnight cost and of the interest during construction. The timing of the construction costs expenditures can, in practice, often be approximated by the equation below and plotted in the figure below, where the "Normalized time" is the time of construction normalized to $-\pi / 2$ and $\pi / 2$ for the convenience of the calculation.

$$
\text { Cumulative expenditures }=\frac{1}{2}\left(\sin \left(t_{\text {normalized }}+1\right)\right.
$$

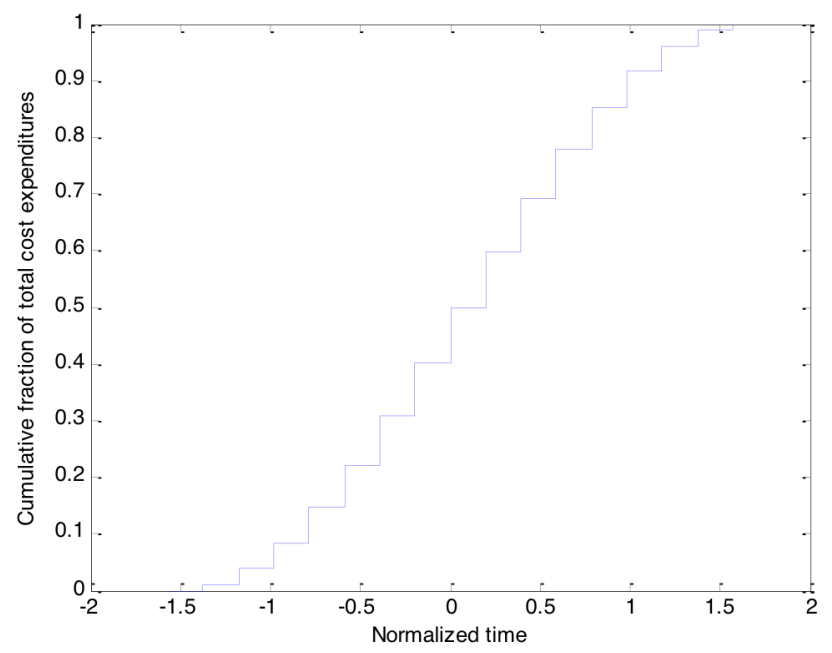

Functional form of the timing of the construction expenditures.

The total capital cost is obtained by including the cost of capital during construction, according to:

$$
\text { Capital Cost }=\sum_{q=1}^{N_{q}} C_{q}\left(1+r_{\text {quarterly }}\right)^{q}
$$

where

$$
\begin{aligned}
& N_{q}=\quad \begin{array}{l}
\text { the number of quarters during construction, Cq are the expenditures in each quarter } \\
\text { as shown in the figure above. } \\
\text { the interest rate during construction converted from annual to quarterly } \\
\text { compounding. }
\end{array}
\end{aligned}
$$

Figure 17. Description of the methodology to compute the Interest During Construction in NE-COST, from [24].

\subsubsection{Fuel cost}

Fuel cost is between 8.0 \$/MWh and 8.8 $\$ / \mathrm{MWh}$. The 8.8 $\$ / \mathrm{MWh}$ value is based on the assumptions of [25] for 2015. Using the average of the front and back end costs for EG01 from [26], the fuel cost was found to be $8.0 \$ / \mathrm{MWh}$. While the electricity produced supposedly drives fuel cost, this could be incorrect depending on plant and fuel vendor agreements. Even if the fuel burn-up is less than that predicted at the point of discharge, the cost is still incurred in total. To assume that this cost is variable, it is necessary to assume that the plant has somehow performed a prediction of the effective load capacity factor, allowing the plant operator to negotiate with the vendor different enrichment levels. Essentially, in a reactor that is not performing load following, the fuel cost driver is the installed capacity times the theoretical load capacity factor (only planned outages are accounted to compute the load capacity factor).

\subsubsection{Reactor operations and maintenance cost}

LWR average variable costs based on the U.S. experience in the late 1980s can be extracted from [27], Appendix D (O\&M Cost Break Down), page 129. Total variable cost is evaluated as a fraction of total fixed cost. 
Reference [27] has cost data for the average plant in 1988 dollars for fixed and variable costs (variable costs include only some maintenance material and supplies and expenses, but in a smaller quantity than the same contributions as fixed costs, i.e. maintenance material is $4.7 \mathrm{M} \$$ fixed and $1.5 \mathrm{M} \$$ variable, and supplies and expenses is $8.1 \mathrm{M} \$$ fixed and $2.2 \mathrm{M}$ \$ variable). In summary, the variable contributions are smaller than the fixed contributions. Total variable costs as a fraction of total fixed costs is between $4.6 \%$ for the LWR/ME to $5.9 \%$ for the large LWR/BE, as shown in Table 5 . If we assume that the Cost Basis Report [26] total fixed cost of 8.7 \$/MWh for EG01 (1100 MW PWR with 90\% capacity factor) is defensible, then $4.6 \%$ to $5.9 \%$ would be between $0.4 \$ / \mathrm{MWh}$ to $0.52 \$ / \mathrm{MWh}$. This can be approximated as $0.5 \$ / \mathrm{MWh}$. Using instead a range of 9.5 to $11.5 \$ / \mathrm{MWh}$ as discussed below for the fixed cost component, then the variable component would be between $0.44 \$ / \mathrm{MWh}$ and $0.68 \$ / \mathrm{MWh}$. Again 0.5 \$/MWh would represent an approximate intermediate value.

Table 5. Reference data for fixed and variable costs from Ref [8] and consequent deduction of variable costs based on current fixed cost data from Cost Basis Report.

\begin{tabular}{|c|c|c|c|}
\hline & $\begin{array}{c}\text { LWR/BE } \\
1100 \mathrm{MWe}\end{array}$ & $\begin{array}{c}\text { LWR/BE } \\
2 \times 550 \mathrm{MWe}\end{array}$ & $\begin{array}{c}\text { LWR/ME } \\
1100 \mathrm{MWe}\end{array}$ \\
\hline $\begin{array}{c}\text { Total fixed }\left(\mathrm{M}_{\text {1987 }} \text { ) from }\right. \\
\text { Ref. [27] }\end{array}$ & 62.5 & 71.2 & 89.9 \\
\hline $\begin{array}{c}\text { Total variable }\left(\mathrm{M}_{1987}\right) \\
\text { from Ref. [27] }\end{array}$ & 3.7 & 3.8 & 4.1 \\
\hline Ratio & $5.9 \%$ & $5.3 \%$ & $4.6 \%$ \\
\hline
\end{tabular}

Regarding the defensibility of the CBR O\&M cost data, the O\&M costs of module R1 are not discussed in CBR 2012 [26], but in CBR 2009 [26], section R1-6 page R1-12. The key statement is: "Historically U.S. reactors have non-fuel O\&M costs in the range of \$70M-\$120M per unit annually.", but without any references.

Moreover: "Over the last 15 years, the average cost has decreased markedly as utilities have learned how to operate their plants more efficiently. Cost escalation has not affected O\&M costs nearly as markedly as capital costs. New simpler reactor designs should also experience further decreases. There is some variation of $O \& M$ costs with reactor size and energy output. According to Roques et al. (2006), the fixed component of the O\&M cost depends on the reactor electrical capacity, which is typically around $\$ 60 / \mathrm{kW} y \mathrm{r}$. The variable component depends on energy production and is typically around 0.5 mills/kWh."

\subsubsection{More discussion on fixed variable O\&M reactor costs}

The recommended fixed O\&M cost is $85 \$ / \mathrm{kWe} /$ year. This is similar to the recent cost average for the Exelon fleet [28]. In [28]: the average production cost (i.e. combined Fuel \& O\&M costs) of the Exelon nuclear fleet for 2011-2013 was reported to be $18.86 \$ / \mathrm{MWh}, 19.5 \$ / \mathrm{MWh}$ and $19.83 \$ / \mathrm{MWh}$, respectively. Assuming a fuel cost of 8.0-8.8 $\$ / \mathrm{MWh}$ as discussed above, the O\&M cost would be approximately between 10 and $12 \$ / \mathrm{MWh}$. Assuming that the variable O\&M costs are $0.5 \$ / \mathrm{MWh}$ as discussed above, the fixed O\&M cost would be approximately between 9.5 and $11.5 \$ / \mathrm{MWh}$. Then, the fixed O\&M from the Exelon experience would be between $76 \$ / \mathrm{kW}_{\mathrm{e}} /$ year and $93 \$ / \mathrm{kW}_{\mathrm{e}} /$ year, with an average of $85 \$ / \mathrm{kW}_{\mathrm{e}} /$ year. 


\subsubsection{Scaling factors for nuclear plants}

Weighted average scaling exponents for nuclear plants is 0.64 from [29]. This section presents a concise summary of the cost effect of size and modularity, derived from cost analysis performed in [30], extracted from a more detailed write-up in [31].

Reference [30] contains calculations for the overnight construction cost of:

- Modular large PWR as compared to a standard large PWR;

- Modular small PWR as compared to a standard small PWR;

- Standard small PWR as compared to a standard large PWR;

- Modular small PWR as compared to a modular large PWR.

Via a comparative analysis, it was found that both the direct and indirect total costs are expected to increase 27\%-29\% (when normalized per $\mathrm{kW}_{\mathrm{e}}$ ), both for the Best Experience PWRs and for a modular PWR when reducing their sizes from the nominal $1100 \mathrm{MW}$ to $550 \mathrm{MW}$. This leads to an overnight and to total cost including interest during construction also in that range, implying an exponent factor of 0.64. The commonly used formula to scale capital expenditure is:

$$
C A P E X=\text { CAPEX }_{\text {ref }}\left(\frac{\text { Capacit }_{\text {new }}}{\text { Capacity }_{\text {ref }}}\right)^{\text {exp }=0.64}
$$

Within the total direct cost, however, it was found that the cost increases are expected to be uneven between the various cost components. In particular, comparatively larger economies of scale are expected for the "Electrical" part of construction costs (with an exponent factor of 0.47), and to a minor extent for the "Reactor/Boiler" and for the "Structures and Improvement" (with exponent factors in the range 0.53 to 0.58 ), while "cooling and miscellaneous" are not expected to feature large economies of scale (with exponent factors in the range 0.80 to 0.84 ) The individual contributions to the indirect costs tend to show roughly even economies of scale, with exponents all around the cost-weighted average values of 0.64 .

\subsection{Hydrogen facility (cost considerations)}

The design configuration assumed for the hydrogen facility is from reference [8]. The hydrogen production facility is based on high temperature steam electrolysis (HTSE). The cost of $\mathrm{H}_{2}$ production is $2.56 \$ / \mathrm{kg}$ (in 2012 dollars) at a production rate of $1.85 \mathrm{kgH}_{2} / \mathrm{sec}$ in the optimized case [8]. [Note: This would allow a profit in a market in which the sale price of $\mathrm{H}_{2}$ would be $3.1 \$ / \mathrm{kg}$, neglecting the costs of distributions, which are unknown at this point.]

Table 6 and Table 7, both from reference [8], contain important economic parameters for this analysis. The total plant cost is $\$ 97.8$ million according to [8], with all the needed systems to feed $\mathrm{H}_{2}$ into a pipeline, including the cost of the SOEC module that will need relatively frequent replacements. However, the total cost as reported in [8] does not appear to include indirect costs. Indirect costs could be estimated by analogy with Combined Cycles Gas Turbines (CCGT) plants, which also include extensive piping, valves and connection to pipelines and supplies. While not perfect, this can be used here as a first approximation until a better estimate or reference is found. Reference [32] contains defensible cost information for both combustion turbines (CT) and CCGT. The direct costs of CT and CCGT plants are estimated at $62 \%$ and $64 \%$ of total costs, with the rest including indirect costs, owner's costs and contingencies. If the same $64 \%$ assumption is made here, then the total costs including indirect costs, owner's costs and contingencies would be \$153M. 
Table 6. Capital costs summary from [8].

\begin{tabular}{|l|c|rr|rr|rr|}
\hline Parameter Or Variable & Units & \multicolumn{2}{|c|}{ Value } & \multicolumn{2}{|c|}{ Lower Bound } & Upper Bound \\
\hline \hline Energy Cost $(\$ / \mathrm{kWe}-\mathrm{hr})$ & $\$ / \mathrm{kWe}-\mathrm{hr}$ & $\$$ & 0.06 & $\$$ & 0.04 & $\$$ & 0.08 \\
\hline Plant Heat Cost $(\$ / \mathrm{kWe}-\mathrm{hr})$ & $\$ / \mathrm{kWe}-\mathrm{hr}$ & $\$$ & 0.02 & $\$$ & 0.01 & $\$$ & 0.04 \\
\hline SOEC Cell Cost & $\$ / \mathrm{kWe}$ & $\$$ & 30.00 & $\$$ & 20.00 & $\$$ & 70.00 \\
\hline
\end{tabular}

Table 7. Capital costs summary from [8].

\begin{tabular}{|c|c|c|c|}
\hline System & & Iled Costs & $\%$ of total \\
\hline HTSE & $\$$ & $38,314,119$ & $39 \%$ \\
\hline Balancing Gas & $\$$ & $13,764,568$ & $14 \%$ \\
\hline Feed and Utility & $\$$ & $9,289,394$ & $9 \%$ \\
\hline Sweep Gas & $\$$ & $9,013,967$ & $9 \%$ \\
\hline Hydrogen / Steam & $\$$ & $22,983,675$ & $24 \%$ \\
\hline Hydrogen / Oxygen Purification & $\$$ & $4,430,023$ & $5 \%$ \\
\hline Total battery Cost & $\$$ & $97,795,744$ & - \\
\hline Construction Cost $\$ / k W e$ & $\$$ & 423 & - \\
\hline Electricity Costs $(\$ / k g)$ & $\$$ & 2.12 & - \\
\hline Plant Heat Costs $(\$ / \mathrm{kg})$ & $\$$ & 0.19 & - \\
\hline SOEC Replacement Costs3 (\$/kg) & $\$$ & 0.08 & - \\
\hline Construction Cost $\$ / k g$ (10 yr depreciation) & $\$$ & 0.17 & - \\
\hline Total Hydrogen Production Cost (\$/kg) & $\$$ & 2.56 & - \\
\hline
\end{tabular}

Total power required [per HTGR, assuming it is total], from Table 2-12 of [8] is $231 \mathrm{MW}_{\mathrm{e}}$. Total construction cost: $\$ 97.8 \mathrm{M}: 97795 / 231=423 \$ / \mathrm{kW}_{\mathrm{e}}$. The construction cost per $\mathrm{kW}_{\mathrm{e}}$, while reported in [8], does not appear to be a useful metric for this economic investigation, but it is recalculated here to verify that the understanding of the data is correct.

In Table 2-6 of [8], it is mentioned that 289209 cells are needed of $1 \mathrm{~kW}_{\mathrm{e}}$ each, for a total cost of $\$ 8.7 \mathrm{M}$, which means that $30 \$ / \mathrm{kW}_{\mathrm{e}}$ is the purchase price of the cells. Moreover, the cost of the SOEC modules is mentioned at $\$ 8.7 \mathrm{M}$ in Table 2-6 of [8]. [It is not clear if only the cells will need to be replaced due to degradation, or also other components, such as the module assembly].

The degradation rate of the SOEC cells is $0.5 \% / 1000$ hours of operation, and the SOEC cells will be replaced after $20 \%$ degradation. This would be achieved after approximately 40,000 hours of operations if $0.5 \%$ is intended to be the degradation rate of the original level of functionality, or after approximately 45,000 hours if $0.5 \%$ is of the present level of functionality after some degradation has already occurred. [It is not clear at this point which is intended in the article].

If operated at $80 \%$ capacity factor, the plant operates for $7000 \mathrm{~h} / \mathrm{y}$, so it will reach EOL at 5.7 years using 40k hours and 6.4 years using 45k hours replacement rate. In any case, the SOEC cells will likely have to be replaced several times during the life of the plant.

The cost of the degradation can therefore be calculated as follows: using the production rate of 1.85 $\mathrm{kg} / \mathrm{s}$ of $\mathrm{H}_{2}$, and 40000 or 45000 hours of operations before replacement, the total $\mathrm{H}_{2}$ production before replacement would be $266 \mathrm{E} 6 \mathrm{kgH}_{2}$ to $300 \mathrm{E} 6 \mathrm{kgH}_{2}$. A simple division of the $\$ 8.6 \mathrm{M}$ cost to replace the SOEC cells by the amount of $\mathrm{H}_{2}$ produced with those cells would lead a cost of replacement of 2.9 cents to 3.3 cents per $\mathrm{kg} \mathrm{H}_{2}$. This is substantially below the cost of 8 cents $/ \mathrm{kgH}_{2}$ reported in [8]. An explanation for the inconsistency could be that not only the SOEC cells need to be replaced, but also the module 
assembly or other parts. Alternatively, it is possible that the 8 cents $/ \mathrm{kgH}_{2}$ includes discounting. However, in our case, discounting presents some difficulties, since it is not clear what level of utilization of the cells will be possible before having to replace them. For example, if the utilization rate of the plant was $80 \%$ as envisioned in [8], then the SOEC cells would need to be replaced every $\sim 6$ years. If instead the utilization rate was only $40 \%$ for example, then the SOEC cells would need to be replaced every 12 years. Discounting could be applied in this uncertain environment by using a higher discount rate to account for the "utilization risk". For example, if we use 10\% instead of 5\% discount rate because of this, and apply it over a 5.7 year period consistent with 40000 hours of operation at $80 \%$ capacity factor, the annual cost of SOEC cell replacement would be $\$ 2 \mathrm{M}$. This amount, divided by the annual production at $1.85 \mathrm{~kg} / \mathrm{sec}$ would lead to an annual cost of 4.3 cents $/ \mathrm{kg}$.

Figure 18 shows the calculated cost of SOEC replacement at $5 \%$ and at $10 \%$ discount rates for different capacity factors. A unit cost of SOEC cell replacement of 8 cents $/ \mathrm{H}_{2}$ would be consistent with a $10 \%$ capacity factor and a discount rate of $5 \%$ or with a $20 \%$ capacity factor and a discount rate of $10 \%$. It is also observed that for a discount rate of about $5 \%$ and a capacity factor of $\sim 40 \%$ or higher, the cost of SOEC cell replacement is about 4 cents/ $\mathrm{kgH}_{2}$ or lower. For higher capacity factors (above $60 \%-70 \%$ ) the replacement times become short enough that the difference between discount rates becomes small. At $80 \%$ capacity factor, for example, the $\mathrm{H}_{2}$ SOEC replacement cost would be about 3.7 cents $/ \mathrm{kgH}_{2}$ with a $5 \%$ discount rate and 4.3 cents $/ \mathrm{kgH}_{2}$ at $10 \%$ discount rate.

It is not clear at this point what will be the expected lifetime of the rest of the hydrogen plant. Since no information was found in [8], 40 years is assumed by analogy with the historical operational license of nuclear plants. Also, it is not clear if a longer or shorter lifetime could be expected by operating the plant for smaller or larger capacity factors, respectively. While a lower capacity factor may increase the life of the plant due to the lower usage of the components, it is also possible that the higher cycling of the systems, with higher thermo-mechanical stresses, may actually decrease the expected plant life with lower capacity factors.

\section{SOEC replacement cost}

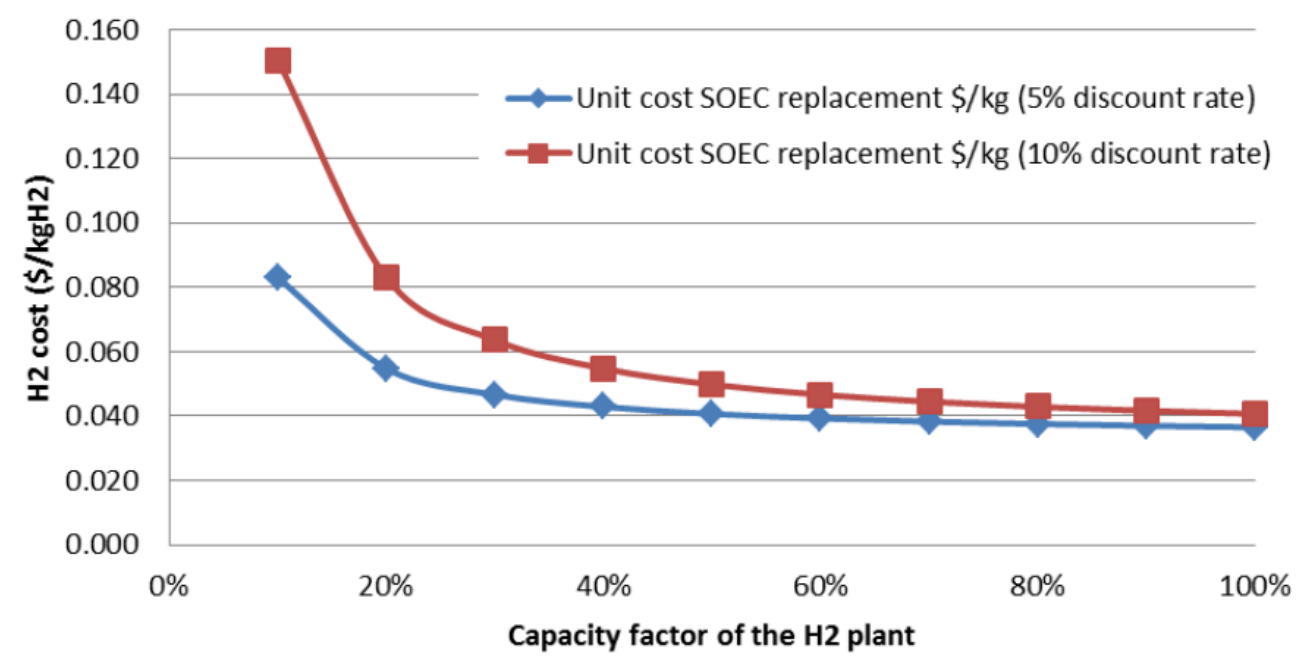

Figure 18. Calculated cost of SOEC replacement at 5\% and at 10\% discount rates for different capacity factors. A unit cost for SOEC cell replacement of 8 cents $/ \mathrm{kgH}_{2}$ would be consistent with a $10 \%$ capacity factor and a discount rate of $5 \%$ or with a $20 \%$ capacity factor and a discount rate of $10 \%$. 


\section{Plant capital cost}

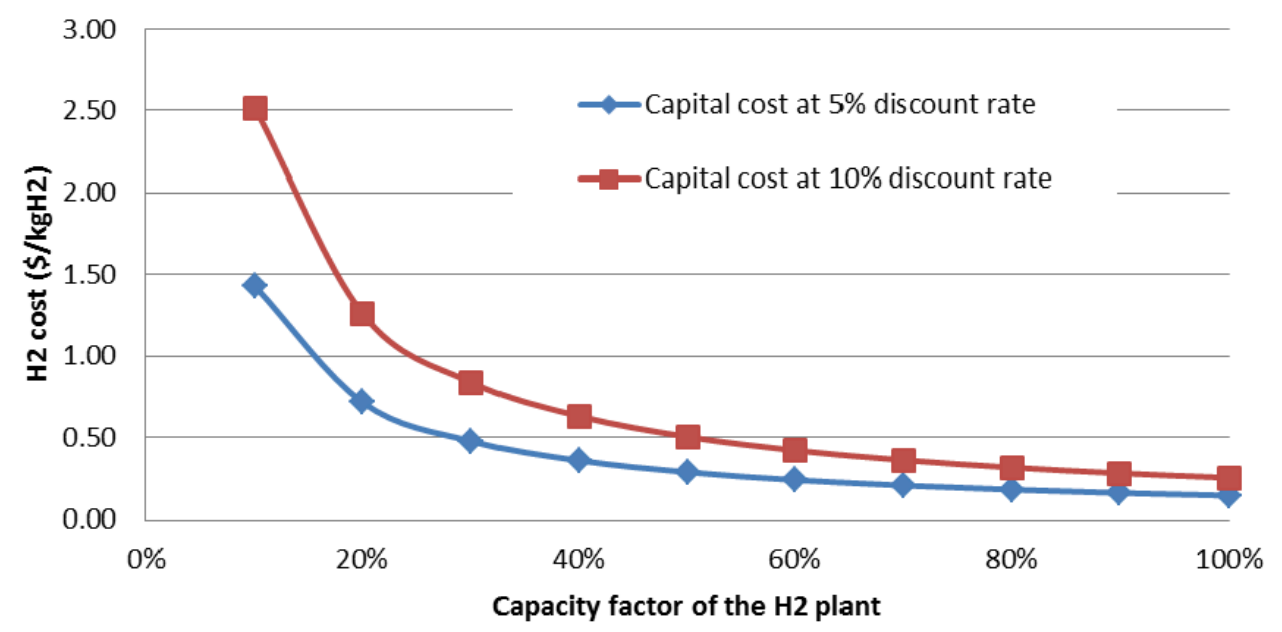

Figure 19. Calculated capital cost for the plant (minus the SOEC) at $5 \%$ and at $10 \%$ discount rates for different capacity factors.

If the total plant cost is $\$ 153 \mathrm{M}$ including indirect, owner and contingency costs, and the SOEC module treated previously is $\$ 8.7 \mathrm{M}$, the rest of the plant is $\$ 144.3 \mathrm{M}$. With a 40 year lifetime that does not change with the capacity factor, the capital cost is plotted in Figure 19 for different capacity factors. It is observed that at 5\% discount rates and capacity factors higher than $50 \%$, the capital cost is small and generally between $0.1 \$ / \mathrm{kgH}_{2}$ and $0.3 \$ / \mathrm{kgH}_{2}$. Additionally, the difference between $5 \%$ and $10 \%$ discount rates tends to become less relevant at higher capacity factors. The numerical values of the capital cost components of the $\mathrm{H}_{2}$ cost is also displayed in Table 8, both for the SOEC replacement costs and for the total capital costs as a function of capacity factors and for 5\% and 10\% discount rates. No information on discount rate was found in [8].

It is observed that the capital cost of $0.16 \$ / \mathrm{kgH}_{2}$ reported in [8] for $80 \%$ capacity factor is below the values of 5\% and $10 \%$ discount rates, indicating that in [8] the total capital costs may not have included the indirect, owner's and contingencies costs.

From Table 2-13 of [8], the total electricity cost and the total heat costs are $2.12 \$ / \mathrm{kgH}_{2}$ and 0.19 $\$ / \mathrm{kgH}_{2}$, respectively. Therefore, assuming an electricity cost of $0.06 \$ / \mathrm{kWh}$ and a heat cost of $0.02 \$ / \mathrm{kWh}$ (the latter is assumed to be just $\$ / \mathrm{kWh}$, not $\$ / \mathrm{kW}_{\mathrm{e}}$-hr as stated in [8]), respectively, from Table 2-14 of [8], the total electricity and heat needed for each $\mathrm{kgH}_{2}$ is $35.3 \mathrm{kWh}_{\text {electricity }} / \mathrm{kgH}_{2}$ and $9.5 \mathrm{kWh}_{\text {steam }} / \mathrm{kgH}_{2}$.

The O\&M costs do not appear to have been reported in [8]; therefore, similarly to the indirect costs, CCGT are taken as reference. Reference [32] provides defensible information on the O\&M costs of CT and CCGT, both for the fixed and variable components.

Typically the fixed part is expressed as a fraction of the initial capital investment: for CT is $2.4 \%$ and for CCGT is $2.3 \%$. Therefore, using the CCGT value as reference, the annual fixed O\&M costs would be $\$ 3.5 \mathrm{M}$. Variable costs can be expressed as a function of fixed costs. For CCGT the reported values range from $20 \%$ variable/fixed ratio at $30 \%$ capacity factor to $72 \%$ at $90 \%$ capacity factor. At $80 \%$ capacity factor, the ratio is $64 \%$. The variable O\&M costs should not change with the capacity factor; based on analogy with CCTG, it was estimated at $0.048 \$ / \mathrm{KgH}_{2}$. Table 9 summarizes the fixed and variable O\&M as a function of capacity factor. 
Table 8. Numerical values of Figure 18 and Figure 19.

\begin{tabular}{|c|c|c|c|c|c|c|}
\hline Capacity factor & $\begin{array}{l}\text { Full time } \\
\text { production } \\
\text { hours/year }\end{array}$ & $\begin{array}{c}\mathrm{kgH} 2 \\
\text { produced/y }\end{array}$ & $\begin{array}{l}\text { Capital cost at } \\
5 \% \text { discount } \\
\text { rate }(\$ / \mathrm{kgH} 2)\end{array}$ & $\begin{array}{l}\text { Capital cost at } \\
10 \% \text { discount } \\
\text { rate }(\$ / \mathrm{kgH} 2)\end{array}$ & $\begin{array}{l}\text { Unit cost of } \\
\text { SOEC } \\
\text { replacement at } \\
5 \% \text { discount } \\
\text { rate }(\$ / \mathrm{kgH} 2)\end{array}$ & $\begin{array}{l}\text { Unit cost of } \\
\text { SOEC } \\
\text { replacement at } \\
10 \% \text { discount } \\
\text { rate }(\$ / \mathrm{kgH} 2)\end{array}$ \\
\hline $10 \%$ & 876.6 & 5838156 & 1.43 & 2.52 & 0.083 & 0.151 \\
\hline $20 \%$ & 1753.2 & 11676312 & 0.71 & 1.26 & 0.055 & 0.083 \\
\hline $30 \%$ & 2629.8 & 17514468 & 0.48 & 0.84 & 0.047 & 0.064 \\
\hline $40 \%$ & 3506.4 & 23352624 & 0.36 & 0.63 & 0.043 & 0.055 \\
\hline $50 \%$ & 4383 & 29190780 & 0.29 & 0.50 & 0.041 & 0.050 \\
\hline $60 \%$ & 5259.6 & 35028936 & 0.24 & 0.42 & 0.039 & 0.047 \\
\hline $70 \%$ & 6136.2 & 40867092 & 0.20 & 0.36 & 0.038 & 0.044 \\
\hline $80 \%$ & 7012.8 & 46705248 & 0.18 & 0.31 & 0.038 & 0.043 \\
\hline $90 \%$ & 7889.4 & 52543404 & 0.16 & 0.28 & 0.037 & 0.042 \\
\hline $100 \%$ & 8766 & 58381560 & 0.14 & 0.25 & 0.037 & 0.041 \\
\hline
\end{tabular}

Table 9. Summary of the Fixed and Variable O\&M costs as a function of the unit capacity factor.

\begin{tabular}{|c|c|c|c|c|}
\hline Capacity factor & $\begin{array}{c}\text { Full time } \\
\text { production } \\
\text { hours/year }\end{array}$ & kgH2 produced/y & Fixed O\&M (\$/kgH2) & $\begin{array}{c}\text { Variable O\&M } \\
(\$ / \mathrm{kgH} 2)\end{array}$ \\
\hline $10 \%$ & 876.6 & 5838156 & 0.61 & 0.048 \\
\hline $20 \%$ & 1753.2 & 11676312 & 0.30 & 0.048 \\
\hline $30 \%$ & 2629.8 & 17514468 & 0.20 & 0.048 \\
\hline $40 \%$ & 3506.4 & 23352624 & 0.15 & 0.048 \\
\hline $50 \%$ & 4383 & 29190780 & 0.12 & 0.048 \\
\hline $60 \%$ & 5259.6 & 35028936 & 0.10 & 0.048 \\
\hline $70 \%$ & 6136.2 & 40867092 & 0.09 & 0.048 \\
\hline $80 \%$ & 7012.8 & 46705248 & 0.08 & 0.048 \\
\hline $90 \%$ & 7889.4 & 52543404 & 0.07 & 0.048 \\
\hline $100 \%$ & 8766 & 58381560 & 0.06 & \\
\hline
\end{tabular}


Table 10 provides a summary of the $\mathrm{H}_{2}$ production cost as a function of the capacity factor. Electricity and steam costs are provided as required amounts, in $\mathrm{kWh}$, per $\mathrm{kgH}_{2}$.

Table 10. Summary table of the $\mathrm{H}_{2}$ production cost as a function of the plant capacity factor. Electricity and steam costs are provided as the amount needed per $\mathrm{kgH}_{2}$.

\begin{tabular}{|c|c|c|c|c|c|c|c|}
\hline $\begin{array}{c}\text { Capacity } \\
\text { factor }\end{array}$ & $\begin{array}{c}\text { Capital } \\
\text { cost at } \\
5 \% \\
\text { discount } \\
\text { rate } \\
(\$ / \mathrm{kgH} 2)\end{array}$ & $\begin{array}{c}\text { Unit cost of } \\
\text { SOEC } \\
\text { replacement } \\
\text { at 5\% } \\
\text { discount rate } \\
(\$ / \mathrm{kgH} 2)\end{array}$ & $\begin{array}{c}\text { Fixed } \\
\text { O\&M } \\
(\$ / \mathrm{kgH} 2)\end{array}$ & $\begin{array}{c}\text { Variable } \\
\text { O\&M } \\
(\$ / \mathrm{kgH} 2)\end{array}$ & $\begin{array}{c}\text { TOTAL } \mathrm{kgH2} \text { non- } \\
\text { utilities production } \\
\text { cost at 5\% real } \\
\text { discount rate } \\
(\$ / \mathrm{kgH} 2)\end{array}$ & $\begin{array}{c}\text { Electricity needs } \\
\mathrm{kWh}_{\text {electricity } / \mathrm{kgH}_{2}}\end{array}$ & $\begin{array}{c}\text { Steam needs } \\
\mathrm{kWh}_{\text {steam } / / \mathrm{kg}_{2}}\end{array}$ \\
\hline $10 \%$ & 1.43 & 0.083 & 0.61 & 0.048 & 2.171 & 35.3 & 9.5 \\
\hline $20 \%$ & 0.71 & 0.055 & 0.3 & 0.048 & 1.113 & 35.3 & 9.5 \\
\hline $30 \%$ & 0.48 & 0.047 & 0.2 & 0.048 & 0.775 & 35.3 & 9.5 \\
\hline $40 \%$ & 0.36 & 0.043 & 0.15 & 0.048 & 0.601 & 35.3 & 9.5 \\
\hline $50 \%$ & 0.29 & 0.041 & 0.12 & 0.048 & 0.499 & 35.3 & 9.5 \\
\hline $60 \%$ & 0.24 & 0.039 & 0.1 & 0.048 & 0.427 & 35.3 & 9.5 \\
\hline $70 \%$ & 0.2 & 0.038 & 0.09 & 0.048 & 0.376 & 35.3 & 9.5 \\
\hline $80 \%$ & 0.18 & 0.038 & 0.08 & 0.048 & 0.346 & 35.3 & 9.5 \\
\hline $90 \%$ & 0.16 & 0.037 & 0.07 & 0.048 & 0.315 & 35.3 & 9.5 \\
\hline $100 \%$ & 0.14 & 0.037 & 0.06 & 0.048 & 0.285 & 35.3 & 9.5 \\
\hline
\end{tabular}

\subsection{Addressing Uncertainties}

- The cost of $\mathrm{H}_{2}$ distribution was neglected in the $\mathrm{H}_{2}$ production cost. In a private conversation, Thanh Hua (ANL) made the following comment: "It's possible to estimate the distribution cost using HDSAM (). The cost depends on the mode of distribution, packaging condition and market penetration, among other factors".

- The total cost for $\mathrm{H}_{2}$ production plants as reported in [8] does not appear to include indirect costs, owner costs and contingencies. It is true that they reported only what appear to be direct costs, but sometimes people partition the other costs to direct costs. However, it appears that Thanh Hua (ANL), based on his experience with $\mathrm{H}_{2}$ plant costs, thought that they had not included these additional costs. Indirect costs can be estimated by analogy with Combined Cycles Gas Turbines (CCGT) plants, which also include extensive piping, valves and connection to pipelines and supplies. Nuclear plants have a higher non-direct cost fraction, but those costs are not likely comparable for the present $\mathrm{H}_{2}$ plant case because of substantially greater complexity in the nuclear plant, and especially because of the extra regulatory requirements. The CCGT analogy was therefore used in this work. It is not clear if only the cells of the $\mathrm{H}_{2}$ plant will need to be replaced due to degradation, or also other components, such as the module assembly and possibly other components. In this work it is assumed that only the cells will need to be replaced. However, the cost of cell replacement is relatively small as compared to the total $\mathrm{H}_{2}$ production cost. 
- The degradation rate of the SOEC cells is $0.5 \% / 1000$ hours of operation, and the SOEC cells will be replaced after $20 \%$ degradation. Rick Vilim (ANL) had doubts about this rate of degradation, which appears low as compared to the values that appeared more realistic based on past discussions he had with Steve Herring (INL). Reference [8] states that this degradation rate is based on other technical reports in references 1-4 of [8]. However, it appears outside the scope of the present work to judge the merit of this technical assumption. Also, the time of replacement would be achieved after approximately 40,000 hours of operations if $0.5 \%$ is intended to be the degradation rate of the original level of functionality, or after approximately 45,000 hours if $0.5 \%$ is of the present level of functionality after some degradation has already occurred. [It is not clear which one is intended.]

- It is not clear at this point what the expected lifetime of the rest of the hydrogen plant will be. Since no information was found in [8], 40 years is assumed by analogy with the historical operational license of nuclear plants. Also, it is not clear if a longer or shorter lifetime could be expected by operating the plant for smaller or larger capacity factors, respectively. While a lower capacity factor may increase the life of the plant due to the lower usage of the component, it is also possible that the higher cycling of the systems, with higher thermo-mechanical stresses, may actually decrease the expected plant's life with lower capacity factors.

- The O\&M costs do not appear to have been reported in [8]; therefore, similarly to the indirect costs, CCGT are taken as reference. Reference [32] provides defensible information on the O\&M costs of CT and CCGT, both for the fixed and variable components. 


\section{SIMULATION}

As mentioned in Section 3.1, the goal of the simulation is to optimize two cases for a Hybrid Energy System. The system is comprised of a nuclear reactor and an IP. The industrial process selected is High Temperature Steam Electrolysis for hydrogen production. For both cases that were evaluated, a profitability optimization to enter an existing market was performed, i.e. the assumption was made that the hybrid system is to be considered a price taker without the capability to influence the market. A summary of the two cases, while already reported in section 3.1 is reported here for convenience.

Case 1:

- Simulation: hourly for one year

- Copper plate model (no inertia)

- Dispatching (reactor produces electricity or provides process heat) based on marginal cost

- Size of nuclear plant fixed

- Goal function is the IRR

- Target variable size of hydrogen plant

Case 2:

- Simulation: hourly for one year

- Copper plate model (no inertia)

- Dispatching (reactor produces electricity or provides process heat) based on marginal cost

- Total capital investment for NPP and IP capped

- Goal function is the NPV

- Target variable size of hydrogen plant and nuclear power plant

The simulation flow in RAVEN for these two examples is shown in Figure 20. As one can see, four "external models" are involved that are coordinated by RAVEN. The combination of the four models and the passing of information between them are done using the RAVEN capability "EnsembleModel". The cash flow analysis model requires some additional inputs that are not provided directly by RAVEN. These inputs are stored in an external XML input file.

- The ARMA model produces the synthetic time history for the electricity price. The output of the ARMA is an hourly electricity price for one year. This price is the price the nuclear plant can sell electricity to the grid and also the price the industrial process can buy electricity from the grid if needed. For more details on how the ARMA model has been trained and what data has been used, see Section 6.1.

- The dispatch model decides for every hour what the nuclear plant and the industrial process are going to do, i.e. first, is steam used to produce electricity or diverted to the hydrogen plant as process heat and second, is the industrial plant buying more electricity from the grid or not. For more information on how the dispatch model works, see Section 3.2.

- The CashFlow preprocessor receives the hourly dispatch data from the dispatch model and computes the cash flow drivers needed by the CashFlow module, i.e. total electricity $\mathrm{c}=$ generated in a year, total hydrogen produced, etc.

- Finally, the CashFlow module computes the economic indicators, such as IRR or NPV, and passes it back to the Optimizer in RAVEN. For more information on the economics values and cash flows considered in the calculation, see Section 6.2.

In addition to the optimization, parametric studies have been performed for the price of hydrogen, an assumed $\mathrm{CO}_{2}$ tax on electricity bought from the grid as well as the economy of scale factor $\mathrm{X}$ (see economy inputs later). 


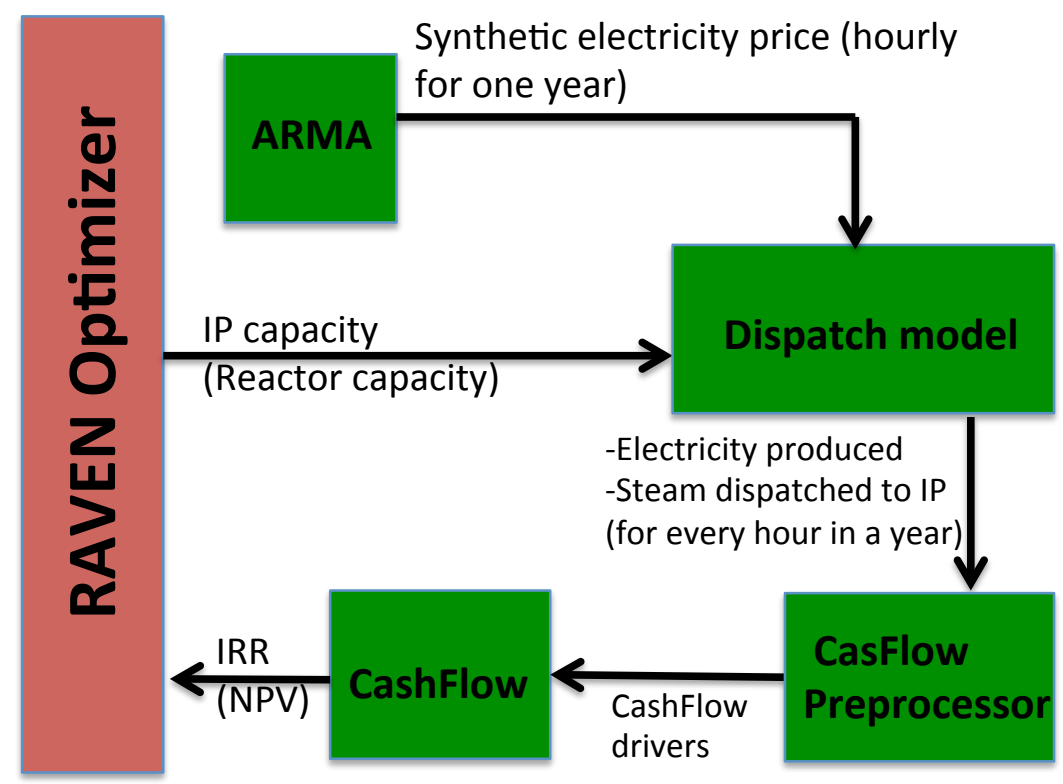

Figure 20. Data flow for optimization calculation.

\subsection{ARMA price generation}

This chapter briefly discusses the procedure to generate synthetic scenarios for the electricity price data. The generated price time series are statistically conformed to the actual measurement but possess different temporal profiles. In particular, a combined model with Fourier series and ARMA is utilized to de-trend the yearly measurement (condensed to hourly resolution) and to characterize the autocorrelation of the residues. The trained model is then able to generate synthetic time series. The synthetic data generation consists of generating independent white noise for each time step, utilizing the ARMA model to compute residues for each time step, and finally adding the Fourier series representing seasonal trends. The model is implemented as part of RAVEN [33].

As explained above, the electricity price data corresponds to a region where a hydrogen market exists as well. Therefore, as suggested, the data used in the evaluation is from the MISO [34] database using the EES aggregated data available at 5 minute intervals for the entire years 2012 and 2013; and between December 19, 2013 and December 31, 2013, data from the representative node EES.DOWCHEM (see Table 11). The 5-minute data is then collapsed into hourly data and used to train the ARMA model with the following ARMA and Fourier settings:

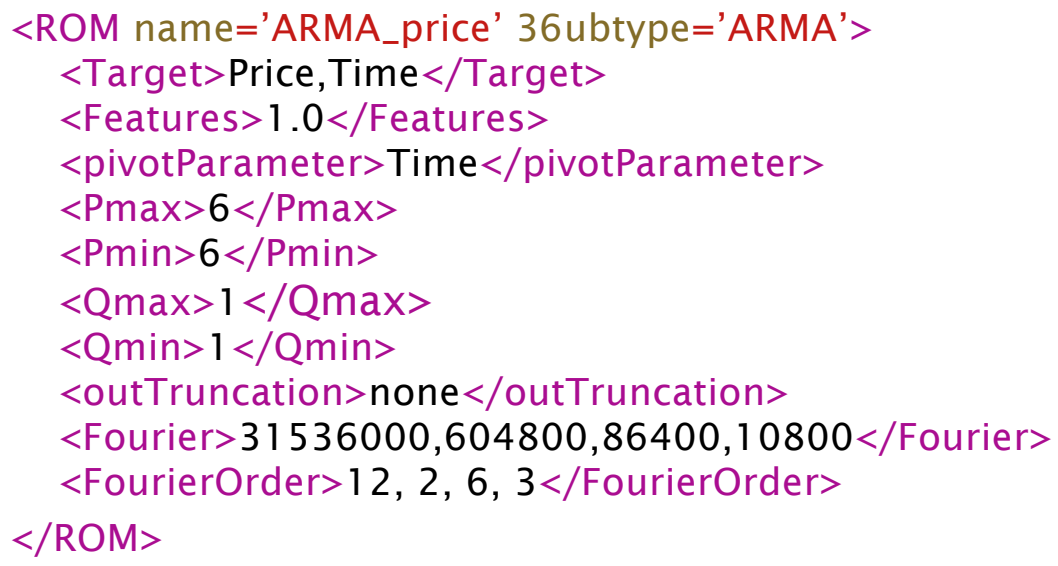


Table 11. Database for electricity prices.

\begin{tabular}{|c|c|c|c|c|}
\hline Data Type & Time Span & Resolution & Region & Source \\
\hline Electricity prices & $2012-2013$ & $\begin{array}{c}5 \text { min (collapsed } \\
\text { to hour) }\end{array}$ & $\begin{array}{c}\text { EES (EES. } \\
\text { DOWCHEM ) }\end{array}$ & MISO \\
\hline
\end{tabular}

\subsection{Economics inputs}

For the problem with the nuclear reactor and the hydrogen plant as the coupled industrial process considered in this report, the goal is to maximize the profit (IRR) for each of the two cases. As mentioned, the first case considers a fixed nuclear reactor capacity of $300 \mathrm{MWe}$ (corresponding to 968MWth assuming an thermal efficiency of $31 \%$ ) and the capacity of the hydrogen plant is to be optimized. The second case considers a fixed combined capital expenditure and the goal is to find the capacity of the reactor and the hydrogen plant that maximizes the IRR. In both cases, for the computation of the IRR, the following cash flow has been considered.

\subsection{1 $\mathrm{FCFF}_{\mathrm{R}, \mathrm{y}}$ (Free Cash Flow to Firm, Real discounting, year $\mathrm{y}$ )}

The Free Cash Flow to Firm (FCFF) for year y is given by

$$
F C F F_{y}=\left(R_{y}-O M-D A_{y}\right)(1-\operatorname{tax})+D A_{y}-\Delta W C_{y}-C A P E X_{y}
$$

Assuming that all the quantities scale with the inflation, except the depreciation, as:

$$
X_{y}=X_{0}(1+i)^{y}
$$

where $\quad X \quad$ Any quantity to be discounted by inflation

i Inflation rate

one finds the following $\mathrm{FCFF}_{\mathrm{R}, \mathrm{y}}$ for different years in the lifetime of a component.

Year

0

1

A

$\mathrm{A}+1$

$\mathrm{N}$
FCFF $_{\text {R,y }}$

$$
\begin{gathered}
-C \\
\left(R_{0}-O M_{0}\right)(1-\operatorname{tax})+D A_{1}(1+i)^{-1} \operatorname{tax} \\
\left(R_{0}-O M_{0}\right)(1-\operatorname{tax})+D A_{A}(1+i)^{-A} \operatorname{tax} \\
\left(R_{0}-O M_{0}\right)(1-\operatorname{tax}) \\
\left(R_{0}-O M_{0}\right)(1-\operatorname{tax})+S V(1+i)^{-N}
\end{gathered}
$$

$\begin{array}{lll}\text { where } & \text { A } & \text { Years of amortization of the component. } \\ \mathrm{C} & \text { Capital } \\ \mathrm{R} & \text { Revenue } \\ \mathrm{OM} & \text { Operation \& maintenance } \\ \mathrm{DA}_{\mathrm{y}} & \text { Depreciation/amortization } \\ \mathrm{SV} & \text { Salvage value }\end{array}$

The different components of the cash flow have been defined in the CashFlow software as follows. The nominal CashFlow input deck can be found in Appendix A. The deck provided contains reference values for variables that have been perturbed for the parametric studies presented later. 


\subsubsection{Nuclear reactor}

The nuclear reactor has an assumed lifetime of 60 years. The tax and inflation rates are assumed to be $39.2 \%$ and $4 \%$, respectively. For the computation of the NPV, a WACC of $5 \%$ (real) has been assumed. The whole cash flow is computed in real terms (compared to nominal).

\section{Capital expenditure (CAPEX)}

The capital expenditure (CAPEX) cash flow for the nuclear reactor is called BOP_CA (for balance of plant). An overnight capital cost is considered. The driver for this cash flow is the nuclear reactor capacity (electric). The reference for this cash flow is a $1100 \mathrm{MWe}$ plant that has an overnight construction cost of $\$ 4.51$ billion. The weighted average scaling exponent (X), i.e. the economy of scale factor for nuclear plants, is 0.64 .

\section{Revenue}

The cash flow is called BOP_RE in the CashFlow module. The electric revenue of the reactor for one year is calculated in the CashFlow preprocessor as shown in Eq 11. The simulation time is one year. All subsequent years in the lifetime of the nuclear plant are assumed to have the same electric revenue.

$$
B O P_{-} R E=\sum_{t=1}^{8760} D_{e l}(t) \cdot P_{e l}(t)
$$

where $\quad 8760 \quad$ hours in one year.

$\mathrm{D}_{\mathrm{el}}(\mathrm{t}) \quad$ Dispatch of hour $\mathrm{t}$, i.e. amount of electricity produced during hour $\mathrm{t}$. The dispatch model decides how much electricity is produced during hour $t$ (see dispatch model above) and passes it into the CashFlow preprocessor.

$\mathrm{P}_{\mathrm{el}}(\mathrm{t}) \quad$ Electricity price for hour $\mathrm{t}$. The ARMA model generates this (see above).

Since this cash flow is generated in the preprocessor for the one year of simulation time and assumed to be the same for every year of the lifetime of the nuclear plant, the $<$ alpha $>$ vector for this cash flow is 1.0 for all years except the year zero. $<$ reference $>$ and $<\mathbf{X}>$ are 1.0. Taxes are applied to this cash flow, but no inflation is considered, since it is in real terms.

\section{O\&M}

$\mathrm{O} \& \mathrm{M}$ for the nuclear reactor is split into fixed $\mathrm{O} \& \mathrm{M}$, variable $\mathrm{O} \& \mathrm{M}$ and fuel cost:

- Fixed O\&M: The fixed O\&M cash flow for the nuclear reactor is called BOP_OmperCap. The driver for this cash flow is the nuclear reactor capacity (electric). The reference for this cash flow is a $1100 \mathrm{MWe}$ plant that has yearly fixed O\&M cost of $\$ 93.5$ million. The weighted average scaling exponent (X), i.e. the economy of scale factor for nuclear plants is 0.64 . Taxes are applied to this cash flow.

- Variable O\&M: The variable O\&M cash flow for the nuclear reactor is called BOP_OmperProduction. Since the reactor is supposed to work at full capacity all the time (just the split of selling thermal vs. electric energy changes), the driver for this cash flow is the nuclear reactor capacity (electric). The variable O\&M for the reactor is $0.5 \$ / \mathrm{MWh}$. The <alpha> given in the CashFlow input are therefore 0.5E-6 [\$/Wh] $* 8760[\mathrm{~h} /$ year] $=0.00438 \$ / \mathrm{W}$ capacity. $<$ reference $>$ and $<\mathbf{X}>$ are 1.0. Taxes are applied to this cash flow. 
- Fuel cost: The fuel cost cash flow for the nuclear reactor is called BOP_OmperFuel. Since the reactor is supposed to work at full capacity all the time (just the split of selling thermal vs. electric energy changes), the driver for this cash flow is the nuclear reactor capacity (electric). The fuel cost for the reactor is $8.4 \$ / \mathrm{MWh}$. The $<$ alpha $>$ given in the CashFlow input are therefore $8.4 \mathrm{E}-6$ $[\$ / \mathrm{Wh}] * 8760[\mathrm{~h} /$ year $]=0.073584 \$ / \mathrm{W}$ capacity. $<$ reference $>$ and $<\mathbf{X}>$ are 1.0 . Taxes are applied to this cash flow.

\section{Depreciation}

A 15 year Modified Accelerated Cost Recovery System (MACRS) is applied to the nuclear reactor. The MACRS applicable percentages for the 15-year property class are given in Table 12.

Table 12. MACRS applicable percentage for 15 year property class.

\begin{tabular}{|c|c|c|c|}
\hline Recovery Year & Percentage & Recovery Year & Percentage \\
\hline 1 & 5.00 & 9 & 5.91 \\
\hline 2 & 9.50 & 10 & 5.90 \\
\hline 3 & 8.55 & 11 & 5.91 \\
\hline 4 & 7.70 & 12 & 5.90 \\
\hline 5 & 6.93 & 13 & 5.91 \\
\hline 6 & 6.23 & 14 & 5.90 \\
\hline 7 & 5.90 & 15 & 5.91 \\
\hline 8 & 5.90 & 16 & 2.95 \\
\hline
\end{tabular}

As one can see in Eq. 10, the depreciation for year y is $D A_{y}(1+i)^{-y} \operatorname{tax}$. This is constructed inside the CashFlow module as $D A_{y}(1+i)^{-y}-D A_{y}(1+i)^{-y}(1-\operatorname{tax})$. For this reason, two cash flows have been defined. The first (BOP_DA1) computes the depreciation for year y. The second cash flow (BOP_DA2) uses the first one as a driver, has all $<$ alpha $>$ equal $-1.0(<$ reference $>$ and $<\mathbf{X}>$ are 1.0$)$ and includes the tax. In this case, BOP_DA1 + BOP_DA2 leads to the desired depreciation equation as shown above.

\section{Salvage value}

A cash flow for a salvage value has been defined. This is for possible parametric analysis to study the influence of the salvage value on the profit. For the reference case, the salvage value has been set to zero.

\subsubsection{Industrial process (hydrogen production plant)}

The nuclear reactor has a lifetime of 40 years. The tax and inflation rates are assumed to be $39.2 \%$ and $4 \%$ respectively. For the computation of the NPV, a WACC of $5 \%$ (real) has been assumed.

\section{Capital expenditure (CAPEX)}

The capital expenditure (CAPEX) cash flow for the industrial process is called IP_CA. An overnight capital cost is considered. The driver for this cash flow is the hydrogen plant capacity (in energy input, i.e. electric and thermal). The reference for this cash flow is a $231 \mathrm{MW}$ hydrogen plant that has an overnight construction cost of $\$ 153$ million. The weighted average scaling exponent (X), i.e. the economy of scale 
factor for hydrogen plants is assumed to be the same as for the reactor (0.64). Since there is no reference for the economy of scale for the reactor, a parametric study is performed for this value (see later).

\section{Revenue}

The cash flow is called IP_RE in the CashFlow module. The revenue from hydrogen sales from the industrial plant for one year is calculated in the CashFlow preprocessor as shown in Eq. 12. The simulation time is one year. All subsequent years in the lifetime of the industrial plant are assumed to have the same revenue.

$$
I P_{-} R E=\sum_{t=1}^{8760} D_{H_{2}}(t) \cdot P_{H_{2}}
$$

where $\quad 8760$ hours in one year.

$\mathrm{D}_{\mathrm{H} 2}(\mathrm{t}) \quad$ Dispatch of hour $\mathrm{t}$, i.e. amount of hydrogen produced during hour $\mathrm{t}$. The dispatch model decides how much $\mathrm{H}_{2}$ is produced during hour $\mathrm{t}$ (see dispatch model above) and passes it into the CashFlow preprocessor.

$\mathrm{P}_{\mathrm{H} 2} \quad$ Constant hydrogen price.

Since this cash flow is generated in the preprocessor for the one year of simulation time and assumed to be the same for every year of the lifetime of the nuclear plant, the $<$ alpha $>$ vector for this cash flow is 1.0 for all years except the year zero. $<$ reference $>$ and $<\mathbf{X}>$ are also zero. Taxes are applied to this cash flow.

\section{O\&M}

O\&M for the industrial $\mathrm{H}_{2}$ plant is split into fixed O\&M, variable O\&M, cost of electricity from the grid and $\mathrm{CO}_{2}$ tax for electricity bought from the grid:

- Fixed O\&M: The fixed O\&M cash flow for the $\mathrm{H}_{2}$ plant is called IP_OmperCap. The driver for this cash flow is the $\mathrm{H}_{2}$ plant capacity. The reference for this cash flow is a $231 \mathrm{MW}$ plant that has yearly fixed O\&M cost of $\$ 3.5$ million. The weighted average scaling exponent (X), i.e. the economy of scale factor for nuclear plants is 0.64 . Taxes are applied to this cash flow.

- Variable O\&M: The variable O\&M cash flow for the $\mathrm{H}_{2}$ plant is called IP_OmperProduction. The driver for this cash flow is the amount of $\mathrm{H}_{2}$ produced in a year. This value is calculated in the CashFlow preprocessor as shown in Eq. 13.

$$
I P_{-} \text {TOT_production } B Y=\sum_{t=1}^{8760} D_{H_{2}}(t)
$$

where 8760 hours in one year.

$\mathrm{D}_{\mathrm{H} 2}(\mathrm{t}) \quad$ Dispatch of hour $\mathrm{t}$, i.e. amount of hydrogen produced during hour $\mathrm{t}$. The dispatch model decides how much $\mathrm{H}_{2}$ is produced during hour $\mathrm{t}$ (see dispatch model above) and passes it into the CashFlow preprocessor.

The variable $\mathrm{O} \& \mathrm{M}$ for the $\mathrm{H}_{2}$ plant is $0.048 \$ / \mathrm{kg}$ of $\mathrm{H}_{2}$ (the value of the $<$ alpha $>$ ). $<$ reference $>$ and $<\mathbf{X}>$ are 1.0. Taxes are applied to this cash flow.

- Cost of electricity bought from grid: The industrial plant has the possibility to receive electricity not only from the coupled nuclear reactor but also to buy additional electricity from the grid. This might be needed if the capacity of the $\mathrm{H}_{2}$ plant is too large for the reactor to provide all thermal and electrical power needed. The cash flow expressing the cost of the electricity bought from the grid is called IP_Omelec. The cost of the electricity bought from the grid of the industrial plant for 
one year is calculated in the CashFlow preprocessor as shown in Eq. 14. The simulation time is one year. All subsequent years in the lifetime of the industrial plant are assumed to have the same cost of electricity bought from the grid.

$$
I P_{-} T O T_{-} \cos t E L=\sum_{t=1}^{8760} D_{e l, H_{2}}(t) \cdot P_{e l}(t)
$$

where 8760 hours in one year.

$\mathrm{D}_{\mathrm{el}, \mathrm{H} 2}(\mathrm{t})$ Dispatch of hour t, i.e. amount of electricity bought from the grid during hour t. The dispatch model decides how much electricity is bought from the grid (see dispatch model above) and passes it into the CashFlow preprocessor.

$\mathrm{P}_{\mathrm{el}}(\mathrm{t}) \quad$ Electricity price for hour $\mathrm{t}$. It is assumed that the selling price to the grid and the buying price from the grid for electricity are the same. The ARMA model generates this (see above).

Since this cash flow is generated in the preprocessor for the one year of simulation time and assumed to be the same for every year of the lifetime of the industrial plant, the $<$ alpha $>$ vector for this cash flow is -1.0 for all years except the year zero. $<$ reference $>$ and $<\mathbf{X}>$ are 1.0. Taxes are applied to this cash flow.

- $\mathrm{CO}_{2}$ tax for electricity bought from grid: It is assumed that the industrial plant has to pay a $\mathrm{CO}_{2}$ tax for electricity bought from the grid that is not included in the electricity price. This cash flow is used to study the influence of hypothetical $\mathrm{CO}_{2}$ taxes. The $\mathrm{CO}_{2}$ tax is zero in the reference case. The cash flow expressing this $\mathrm{CO}_{2}$ tax is called IP_CO2. The driver for this cash flow is the total amount of electricity bought from the grid during a year. The CashFlow preprocessor computes this quantity as shown in Eq. 15. The simulation time is one year. All subsequent years in the lifetime of the industrial plant are assumed to have the same amount of electricity bought from the grid.

$$
I P \_T O T \_\cos t E L=\sum_{t=1}^{8760} D_{e l, H_{2}}(t)
$$

where 8760 hours in one year.

$\mathrm{D}_{\mathrm{el}, \mathrm{H} 2}(\mathrm{t})$ Dispatch of hour t, i.e. amount of electricity bought from the grid during hour t. The dispatch model decides how much electricity is bought from the grid (see dispatch model above) and passes it into the CashFlow preprocessor.

The U.S. average $\mathrm{CO}_{2}$ emission for electricity production is $500 \mathrm{~kg} / \mathrm{MWh}$ [35]. The <alpha $>$ vector is therefore $500 \mathrm{E}-6[\mathrm{~kg} / \mathrm{Wh}] *$ tax $[\$ / \mathrm{kg}]$ for all years except the year zero (the assumed tax varies between $\$ 0$ and $\$ 100$ per ton of $\mathrm{CO}_{2}$ ). $<$ reference $>$ and $<\mathbf{X}>$ are 1.0. Taxes are applied to this cash flow.

\section{Depreciation}

A 15 year MACRS is applied to the industrial plant. The MACRS applicable percentages for the 15year property class is the same as for the nuclear reactor and are given in Table 12 .

As one can see in Eq. 10, the depreciation for year y is $D A_{y}(1+i)^{-y} \operatorname{tax}$. This is constructed inside the CashFlow module as $D A_{y}(1+i)^{-y}-D A_{y}(1+i)^{-y}(1-t a x)$. For this reason, two cash flows have been defined. The first (IP_DA1) computes the depreciation for year y. The second cash flow (IP_DA2) uses the first one as a driver, has all $<$ alpha $>$ equal $-1.0(<$ reference $>$ and $<\mathbf{X}>$ are 1.0$)$ and includes the tax. In this case, BOP_DA1 + BOP_DA2 leads to the desired depreciation equation as shown above. 


\section{Salvage value}

A cash flow for a salvage value has been defined. This is for possible parametric analysis to study the influence of the salvage value on the profit. For the reference case, the salvage value has been set to zero.

\subsection{Results Problem 1: Find the Optimum IP Capacity for a Fixed Reactor Capacity}

As mentioned above, the first problem tries to optimize the capacity of the industrial process (hydrogen plant) for a fixed nuclear reactor size. The size of the nuclear reactor is chosen to be a midsize reactor capable of generating $300 \mathrm{MW}$ electric. The goal function for the optimization is the IRR. The optimization of the IP capacity has been carried out for the following set of parameters:

- $\quad \mathbf{H}_{2}$ price: The literature study (see Section 5.1.2) indicates the price of hydrogen between $\sim \$ 1 / \mathrm{kg}$ and $\sim \$ 3 / \mathrm{kg}$. A parametric study has been performed for the price of hydrogen in this range. In addition, the optimization of the IP capacity has been run for different hydrogen prices.

- Economy of scale $(\mathbf{X})$ : The literature study indicates the economy of scale factor " $X$ " (see Eq. 7) to be 0.64 for nuclear plants (see Section 5.4.6), but no such factor could be determined for the hydrogen plant. A parametric study with $X=1$ (no economy of scale, i.e. a plant double the size costs double the investment) and $\mathrm{X}=0.64$ (same economy of scale than for the nuclear reactor) for the IP was performed.

- $\mathbf{C O}_{2}$ tax: To pronounce the beneficial effect of the steam coupling of the hydrogen plant and nuclear reactor, a hypothetical $\mathrm{CO}_{2}$ tax was introduced to electricity bought from the grid, i.e. as long as the IP uses steam and electricity from the nuclear reactor, there is no $\mathrm{CO}_{2}$ tax to be paid, but if the IP decides to buy additional electricity from the grid (see Section 3.2), the $\mathrm{CO}_{2}$ tax has to be paid for the amount bought from the grid. A parametric study for the $\mathrm{CO}_{2}$ tax has been performed considering the following values in $\left[\$ /\right.$ ton $\left.\mathrm{CO}_{2}\right]: 0,15,20,50$, and 75 .

Figure 21 shows the base case for Problem 1. The 3D plot shows the IRR as a function of IP capacity and hydrogen price for $\mathrm{X}(\mathrm{IP})=0.64, \mathrm{CO}_{2}$ tax $=0 \$ /$ tonCO $\mathrm{O}_{2}$. The points are colored according to the hydrogen price to make the plot easier to read. One can see for this base case:

- For the IP capacity equal zero, i.e. if the hydrogen plant is not built and the reactor just sells all of its electricity to the grid, the IRR does not depend on the hydrogen price (as it should not if the IP is not built) and is negative. This means the $300 \mathrm{MWe}$ reactor on its own is not profitable assuming the economic numbers from Section 5.

- The IRR is monotonically growing with the IP capacity due to the economy of scale coefficient $0.64<1$ (the bigger is the plant the cheaper is the hydrogen production). The slope increases as the hydrogen price increases.

- As mentioned, the optimization was run for a hydrogen price of $\left[\$ / \mathrm{kgH}_{2}\right]: 1.25,1.5,1.75,2.0$ and 3.0. The optimum points are shown as bigger points in the figure. The optimizer correctly finds the optimum hydrogen plant capacities to be at the upper bound set. 


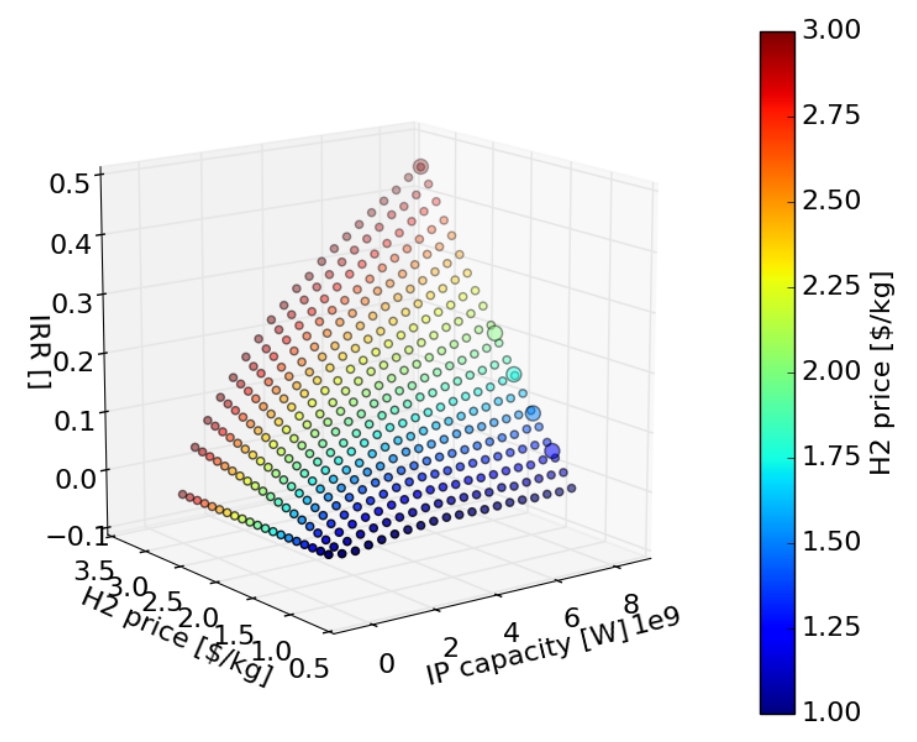

Figure 21. Problem $1, \mathrm{X}(\mathrm{IP})=0.64, \mathrm{CO}_{2}$ tax $=0 \$ /$ tonCO $\mathrm{CO}_{2}$, IRR as a function of IP capacity and hydrogen price, $3 \mathrm{D}$ plot.

From the dispatch rules and the heat utilization schema by the hydrogen production plant, the IRR as a function of IP capacity is expected to have three regions with a different slope (i.e. two points were the slope changes):

- The first change point should occur for an IP capacity such as the reactor can supply all the steam and all the electricity needed for the IP to run at nominal capacity and no electricity has to be bought from the grid. Due to the penalty from the $\mathrm{CO}_{2}$ tax, as soon as the IP capacity exceeds the reactor capacity, the slope in IRR is expected to decrease given the $\mathrm{CO}_{2}$ tax penalty. This inclination point should happen for an IP size similar to the reactor. This point is where a realistic optimum of IP capacity could be found (see Figure 24).

- The second slope changing point should occur when the IP capacity exceeds the capacity where it can absorb all power generated by the reactor in the form of steam. The ratio of maximum steam to electricity ratio for the hydrogen plant is $\sim 1: 3$. This means that for a $300 \mathrm{MWe}$ nuclear reactor this point is at an IP capacity of $\sim 4 \mathrm{GW}$ (300 MWe corresponds to $\sim 1 \mathrm{GW}$ thermal; to absorb 1 GW thermal, the IP capacity has to be $4 \mathrm{GW}$ to satisfy the 1:3 ratio). If the IP capacity is still larger, the benefit of using steam from the reactor does not exist anymore and all heating has to be done with (more expensive) electricity. The slope of the IRR should decrease at an IP capacity of $4 \mathrm{GW}$. Obviously, this possible optimum point is not realistic, since typical hydrogen plants are in the range of several $100 \mathrm{MW}$, not GW. Nevertheless, to show the correct operation of the economical framework, this point is included in the study and the IP capacity in the parametric studies as well as for the optimization has been set to $8 \mathrm{GW}$.

To make the information more readable, the same information shown in Figure 21 is projected onto a $2 \mathrm{~d}$ plot, where the two axes are the IP capacity and IRR. The hydrogen price is still represented with the color bar (see Figure 22). Figure 23 and Figure 24 show the same information, but for a $\mathrm{CO}_{2}$ tax of 15 and $75 \$ /$ tonCO 2 . One can se that: 
- For low hydrogen prices around $\$ 1.25 / \mathrm{kgH}_{2}$ :

- The $15 \$ /$ tonCO $\mathrm{CO}_{2}$ shows the maximum occurring at the first inclination point. The hydrogen price is too low to overcome the $\mathrm{CO}_{2}$ tax for bigger IP capacities and the IRR is decreasing or flat after the first inclination point. The optima found for $\$ 1.75 / \mathrm{kgH}_{2}$ and $2 \$ / \mathrm{kgH}_{2}$ are in the flat part of the IRR. The end point for these depends on the applied convergence criteria in the optimizer.

- The high $\mathrm{CO}_{2}$ tax case $\left(75 \$ /\right.$ tonCO $\left.\mathrm{O}_{2}\right)$ shifts this to higher hydrogen prices, i.e. the hybrid system is unprofitable up to a hydrogen price of about $\$ 2 / \mathrm{kgH}_{2}$. Above that, for prices around $\$ 2.5 / \mathrm{kgH}_{2}$, the maximum is at the first inclination point.

- For high hydrogen prices around $\$ 3 / \mathrm{kgH}_{2}$ :

- If the $\mathrm{CO}_{2}$ tax is low, the IRR slope after the second inclination point is still positive and the optimum IP capacity is at the maximum boundary for the optimization.

- If the $\mathrm{CO}_{2}$ is high, the IRR slope after the second inclination point is negative. This leads to the optimum IP capacity at that point, which we know from the theoretical examination above, is around 4GW. This is confirmed in Figure 24.

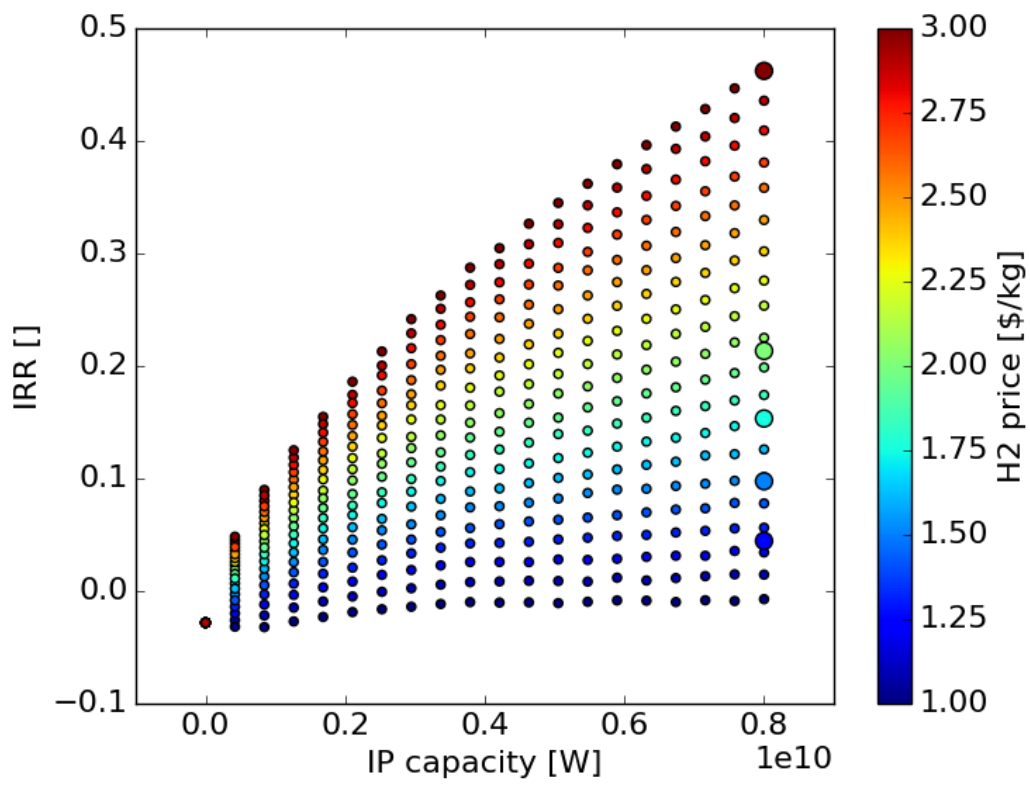

Figure 22. Problem 1, X(IP) $=0.64, \mathrm{CO}_{2}$ tax $=0 \$ /$ tonCO $\mathrm{C}_{2}, \mathrm{IRR}$ as a function of IP capacity and hydrogen price, $2 \mathrm{D}$ projection. 


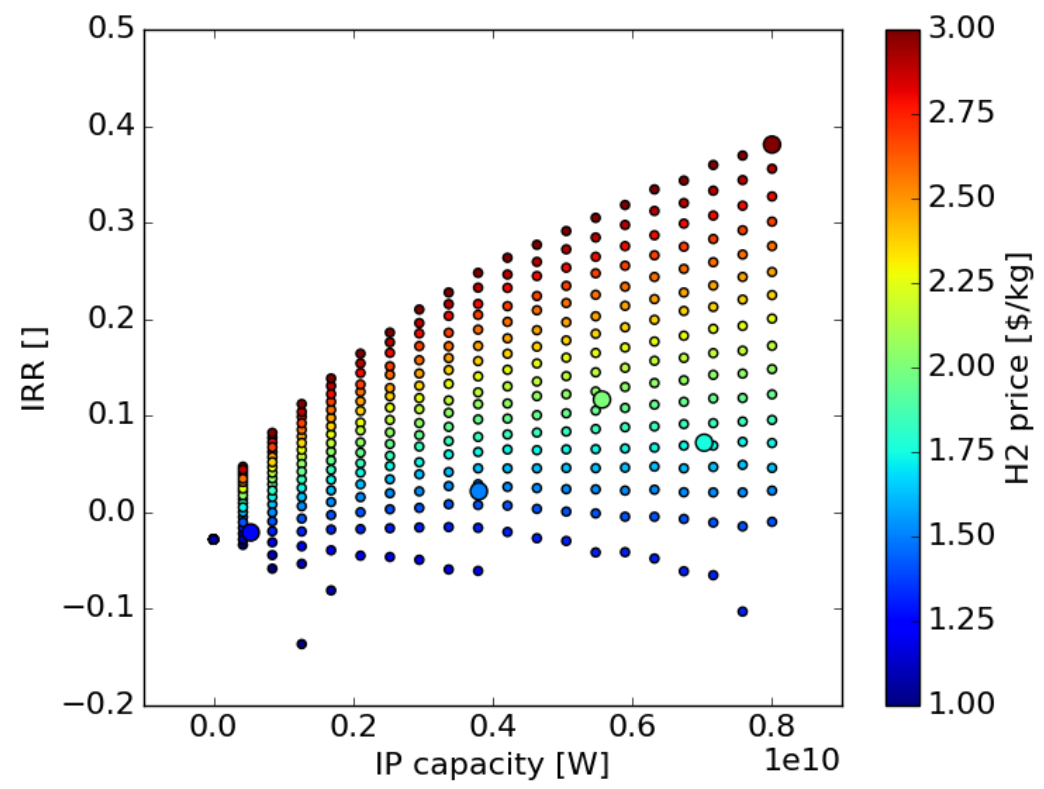

Figure 23. Problem $1, \mathrm{X}(\mathrm{IP})=0.64, \mathrm{CO}_{2}$ tax $=15 \$ /$ tonCO $\mathrm{CO}_{2}$, IRR as a function of IP capacity and hydrogen price, $2 \mathrm{D}$ projection.

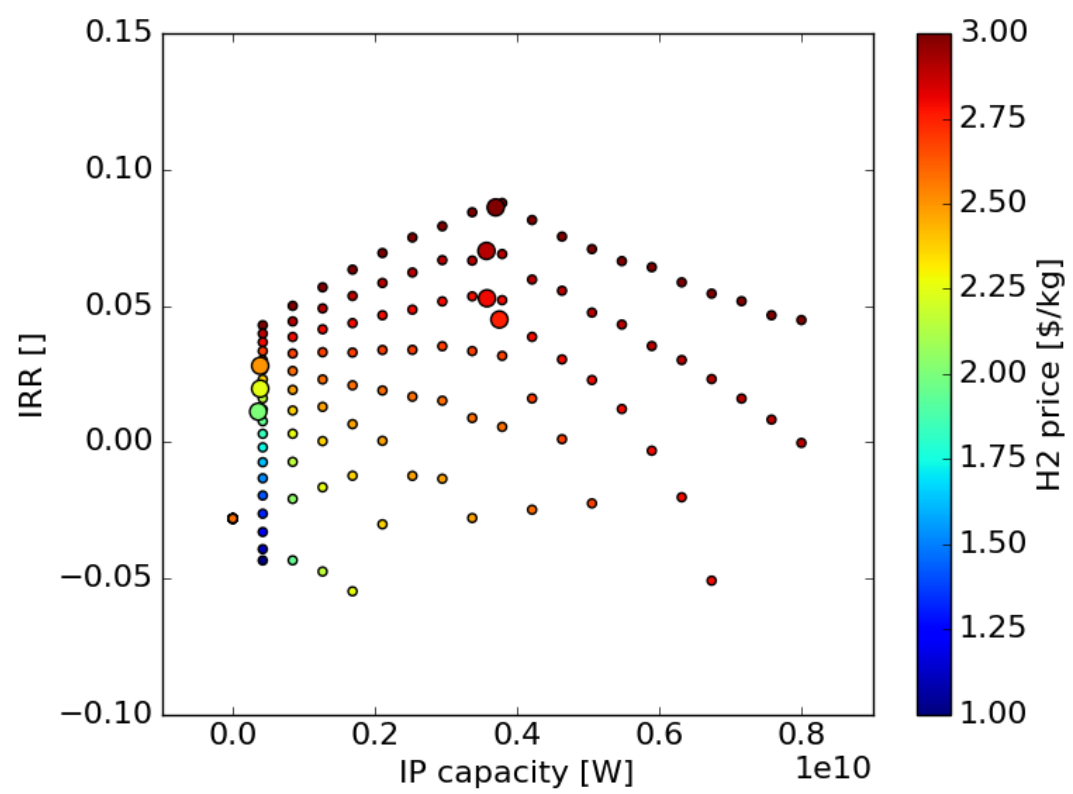

Figure 24. Problem 1, $\mathrm{X}(\mathrm{IP})=0.64, \mathrm{CO}_{2}$ tax $=75 \$ /$ tonCO $\mathrm{CO}_{2}$, IRR as a function of IP capacity and hydrogen price, $2 \mathrm{D}$ projection. 
Moving from the economy of scale $(X=0.64)$ for the industrial plant to a linear economy of scale $(\mathrm{X}=1)$ increases the capital cost (proportionally) for larger capacity hydrogen plants, which makes them less profitable. As one can see in Figure 25 and Figure 26 the IRR slope change at the two inclination points is larger than for the case with $\mathrm{X}=0.64$. The result is that the optimizer finds the optimum at the beginning of the flat part of the IRR (still around $4 \mathrm{GW}$ ) for the low $\mathrm{CO}_{2}$ tax case and finds the first inclination point as the maximum for high $\mathrm{CO}_{2}$ tax (except for the high hydrogen price of $\$ 3 / \mathrm{kgH}_{2}$ ).

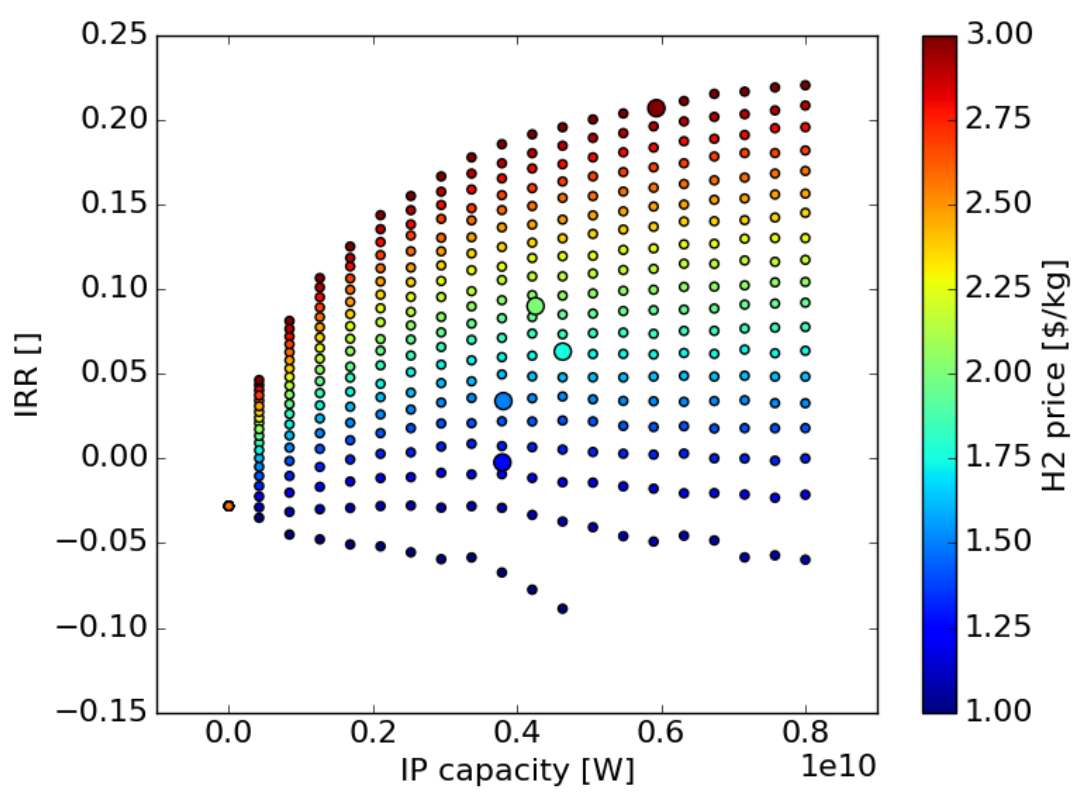

Figure 25. Problem 1, X(IP)=1.0, $\mathrm{CO}_{2}$ tax $=0 \$ /$ tonCO $\mathrm{C}_{2}$, IRR as a function of IP capacity and hydrogen price, $2 \mathrm{D}$ projection.

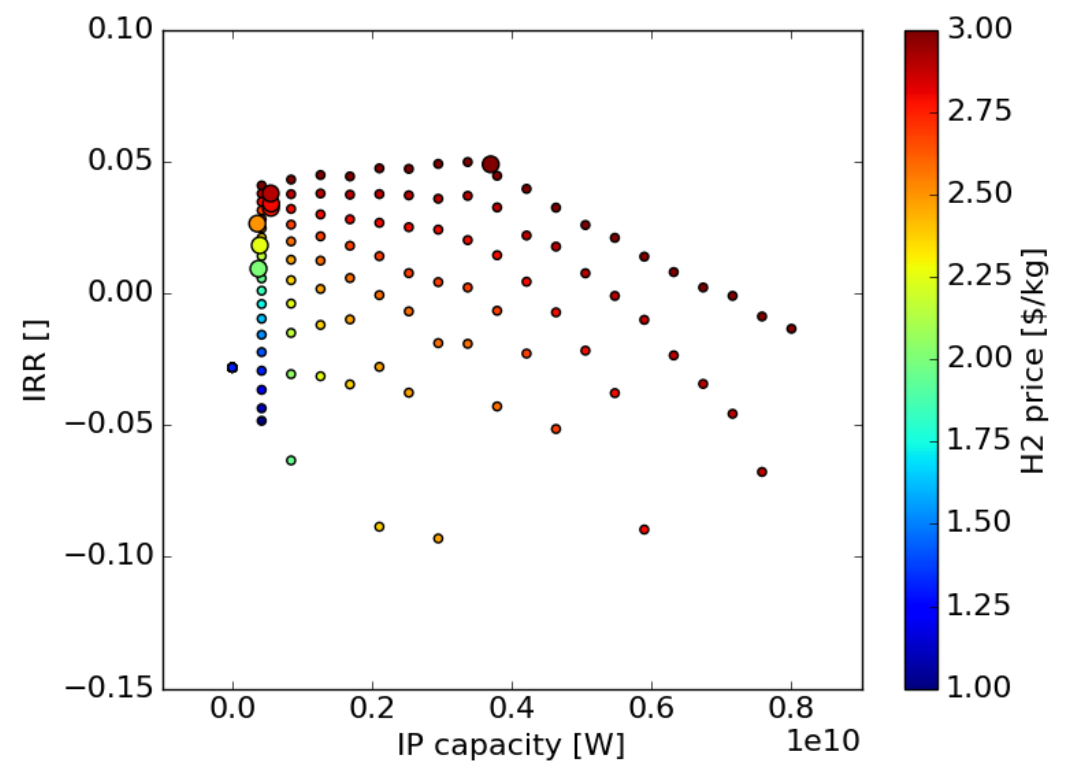

Figure 26. Problem 1, X(IP)=1.0, $\mathrm{CO}_{2}$ tax $=75 \$ /$ tonCO 2 , IRR as a function of IP capacity and hydrogen price, $2 \mathrm{D}$ projection. 
Figure 27 shows the capacity factor for the hydrogen plant for the $\mathrm{X}(\mathrm{IP})=0.64, \mathrm{CO}_{2} \operatorname{tax}=0 \$ /$ tonCO 2 case. The plot shows clearly that, based on marginal cost, the utilization of the hydrogen plant is highly sensible to the price of hydrogen. This explains part of the non-linear behavior seen in the previous plots for IRR.

The optimization search algorithm behavior, for all parametric cases, is very similar. Figure 28 shows a convergence path (bigger points) for $\mathrm{X}(\mathrm{IP})=0.64, \mathrm{CO}_{2} \operatorname{tax}=75 \$ / \mathrm{tonCO}_{2}$ and $\mathrm{H}_{2}$ price $\$ 3 / \mathrm{kgH}_{2}$. One can see that the optimization converges after a few iterations. This is true for all investigated cases.

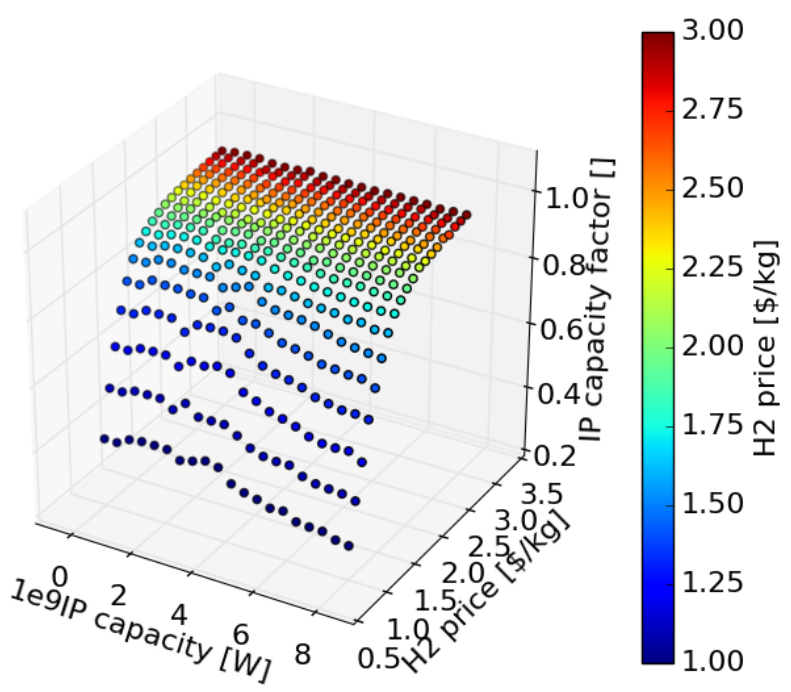

Figure 27. Problem $1, \mathrm{X}(\mathrm{IP})=0.64, \mathrm{CO}_{2}$ tax $=0 \$ /$ tonCO $\mathrm{CO}_{2}$, Industrial process capacity factor as a function of IP capacity and hydrogen price, 3D plot.

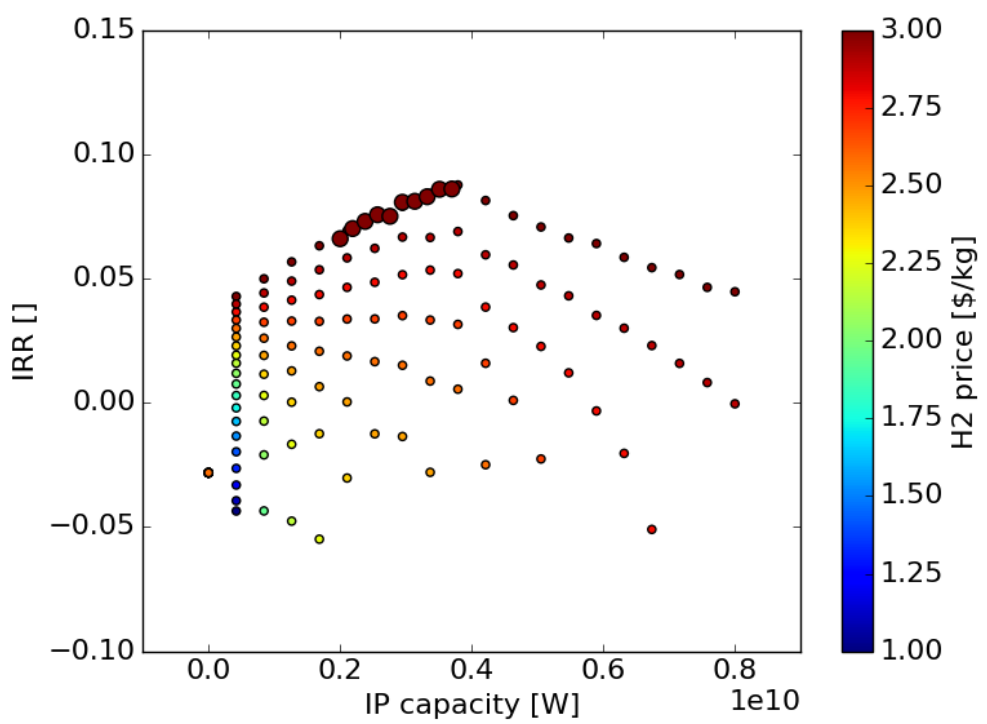

Figure 28. Problem $1, \mathrm{X}(\mathrm{IP})=0.64, \mathrm{CO}_{2}$ tax $=75 \$ /$ tonCO $\mathrm{C}_{2}$, IRR optimizer convergence path. 


\subsection{Results Problem 2: Find the Optimum IP and Nuclear Reactor Capacity for a Capped Total CAPEX}

As mentioned above, the second problem tries to optimize simultaneously the capacity of the industrial process (hydrogen plant) and the nuclear reactor. The constraint is the maximum total capital expenditure. It has been set to $\$ 30$ billion. The goal function for the optimization is the NPV. The same parameters as used in the first problem were considered, i.e. $\mathrm{H}_{2}$ price, economy of scale $\mathrm{X}$ and $\mathrm{CO}_{2}$ tax.

Figure 29 shows the base case for Problem 2. The plot shows the NPV as a function of IP and nuclear capacity for a hydrogen price of $\$ 1.5 \mathrm{~kg} / \mathrm{H}_{2}$ (for $\mathrm{X}(\mathrm{IP})=0.64$ and $\mathrm{CO}_{2} \operatorname{tax}=0 \$ / \mathrm{tonCO} \mathrm{O}_{2}$ ). On the right is a zoomed-in view at the origin. The points are colored according to the NPV. One can see that for this base case:

- The nuclear reactor profits only slightly from its economy of scale compared to the hydrogen plant. It can be seen from the zoom on the right in Figure 29, that on its own, the reactor becomes profitable only above a high capacity of $\sim 7 \mathrm{GW}$ (due to the economy of scale), which is an unrealistic size.

- The optimum is not to build the reactor and invest all money in the IP. Although only the hydrogen price of $\$ 1.5 \mathrm{~kg} / \mathrm{H}_{2}$ is shown here, this behavior is the same for all hydrogen prices.
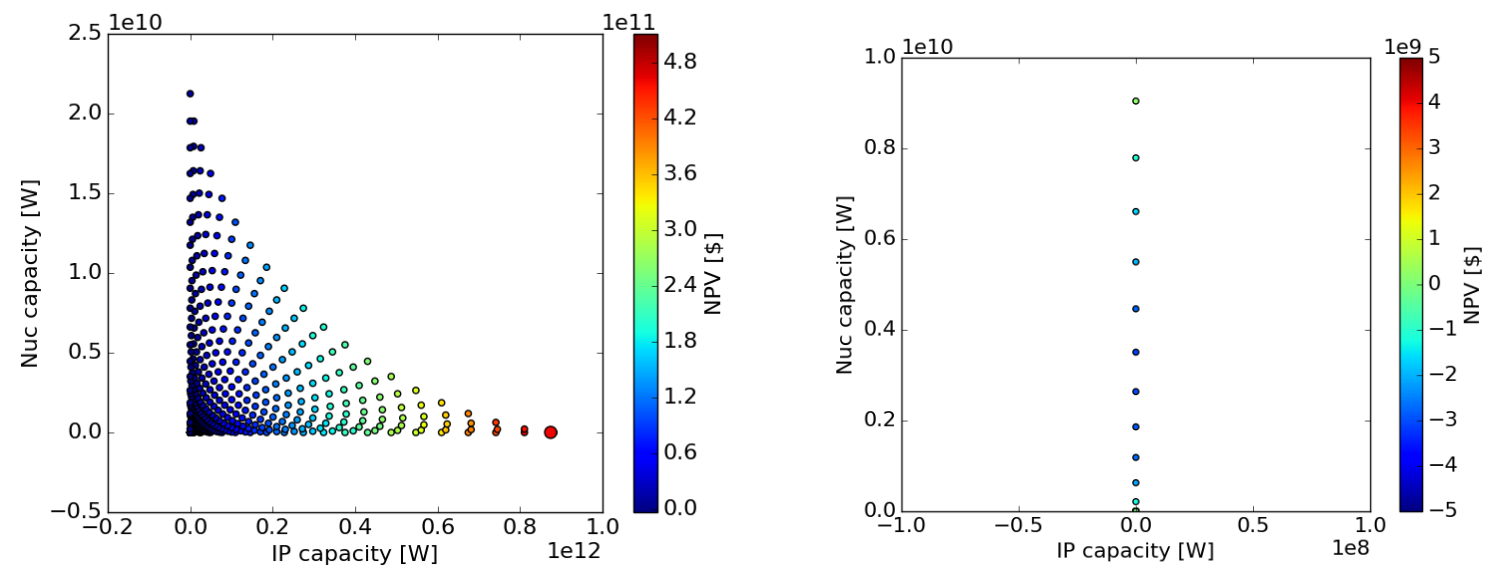

Figure 29. Problem $2, \mathrm{X}(\mathrm{IP})=0.64, \mathrm{CO}_{2}$ tax $=0 \$ /$ tonCO $\mathrm{CO}_{2}, \mathrm{NPV}$ as a function of IP and nuclear capacity for a hydrogen price of $\$ 1.5 \mathrm{~kg} / \mathrm{H}_{2}$; left: full picture, right: zoom on origin.

Including a $\mathrm{CO}_{2}$ tax changes this picture. Figure 30 to Figure 32 show the case for $\mathrm{X}(\mathrm{IP})=0.64$ and $\mathrm{CO}_{2} \operatorname{tax}=20 \$ /$ tonCO $\mathrm{C}_{2}$. Three different $\mathrm{H}_{2}$ prices are shown: $1.25,1.5$ and $2.0 \$ / \mathrm{kgH}_{2}$. One can see that for the low hydrogen price, the hydrogen plant is not profitable and the reactor on its own becomes profitable for (unrealistically) large capacity due to the economy of scale. Hence, the identified optimum is to build only the reactor. For high hydrogen prices above $\$ 2 / \mathrm{kgH}_{2}$, the $\$ 20 / \mathrm{tonCO}_{2}$ tax can be overcome and the optimum is the same as for the no $\mathrm{CO}_{2}$ tax case: invest all money in the hydrogen plant. As one can see from Figure 31, there exists a 'sweet spot' in the hydrogen price for which the industrial process is benefitting from the steam delivered by the nuclear reactor. Within this sweet spot, the optimum moves along the maximum capital boundary and consequently, the optimum is to build a reactor and a hydrogen plant at a certain capacity fraction. Moving to even higher $\mathrm{CO}_{2}$ tax shifts the 'sweet spot' to a higher hydrogen price. 


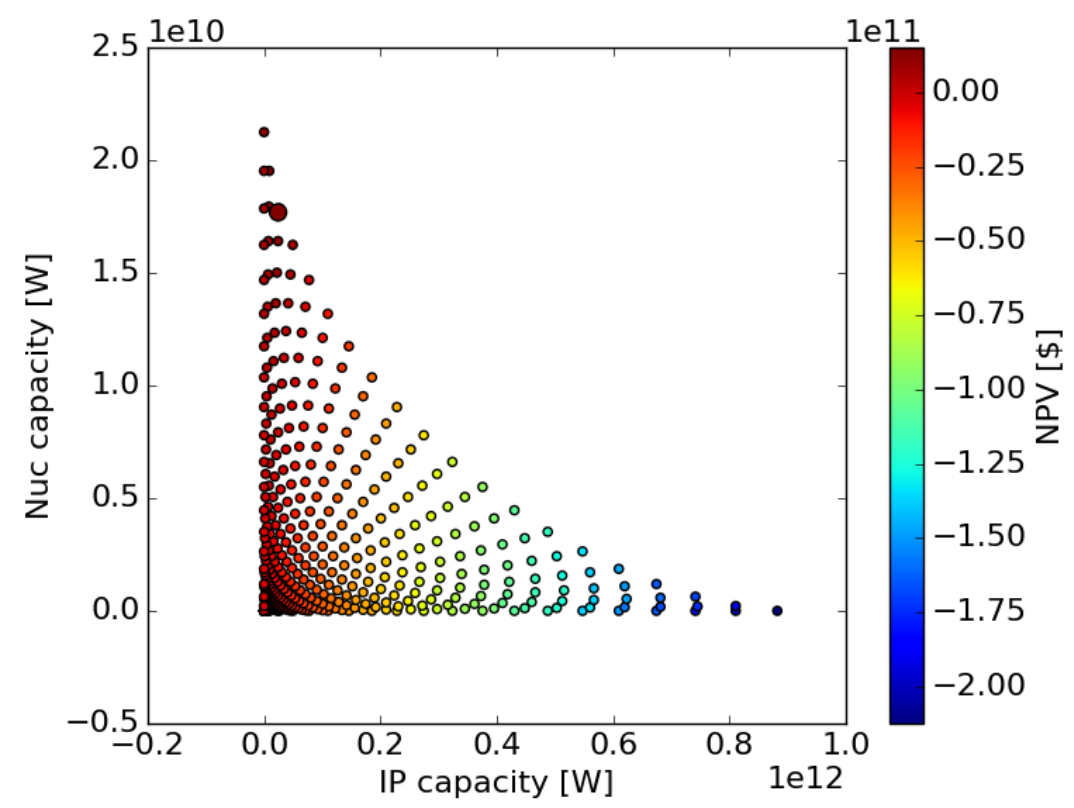

Figure 30. Problem 2, X(IP) $=0.64, \mathrm{CO}_{2}$ tax $=20 \$ /$ tonCO $\mathrm{CO}_{2}, \mathrm{NPV}$ as a function of IP and nuclear capacity for a hydrogen price of $\$ 1.25 \mathrm{~kg} / \mathrm{H}_{2}$.

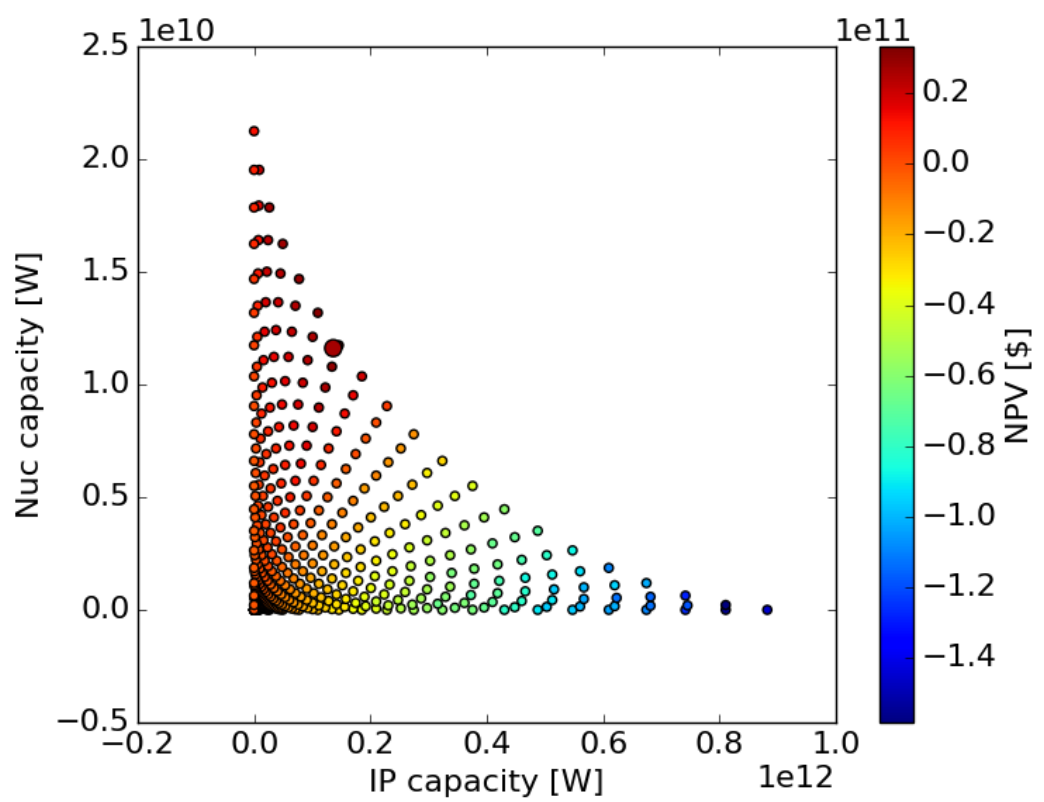

Figure 31. Problem 2, X(IP) $=0.64, \mathrm{CO}_{2}$ tax $=20 \$ /$ tonCO $\mathrm{CO}_{2}, \mathrm{NPV}$ as a function of IP and nuclear capacity for a hydrogen price of $\$ 1.5 \mathrm{~kg} / \mathrm{H}_{2}$. 


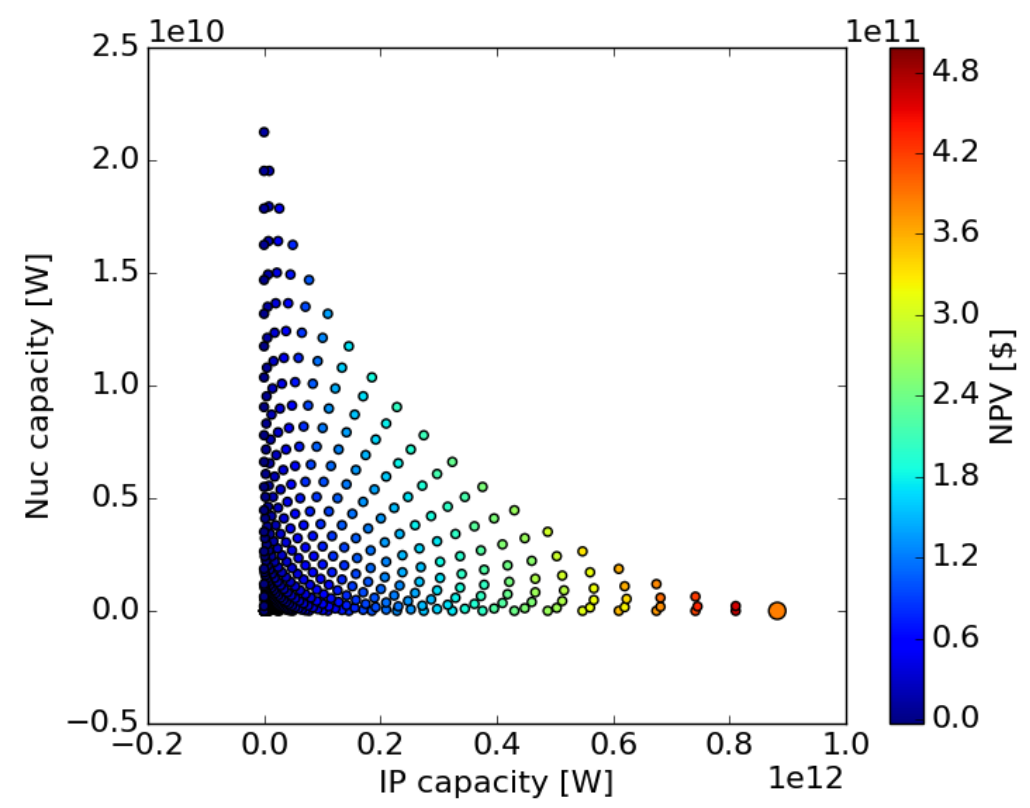

Figure 32. Problem 2, X(IP) $=0.64, \mathrm{CO}_{2}$ tax $=20 \$ /$ tonCO $\mathrm{CO}_{2}, \mathrm{NPV}$ as a function of IP and nuclear capacity for a hydrogen price of $\$ 2 \mathrm{~kg} / \mathrm{H}_{2}$.

Moving from the economy of scale $(X=0.64)$ for the industrial plant to a linear economy of scale $(\mathrm{X}=1)$ decreases the maximum size of hydrogen plant that can be built with the fixed capital. However, the behavior is of the optimum is the same as for the $\mathrm{X}=0.64$ case. As an example, Figure 33 to Figure 35 show the case for $X=1.0, \mathrm{CO}_{2} \operatorname{tax}=15 \$ /$ tonCO $\mathrm{C}_{2}$, a hydrogen price of $\$ 1.5 \mathrm{~kg} / \mathrm{H}_{2}$ and $1.75 \mathrm{~kg} / \mathrm{H}_{2}$.

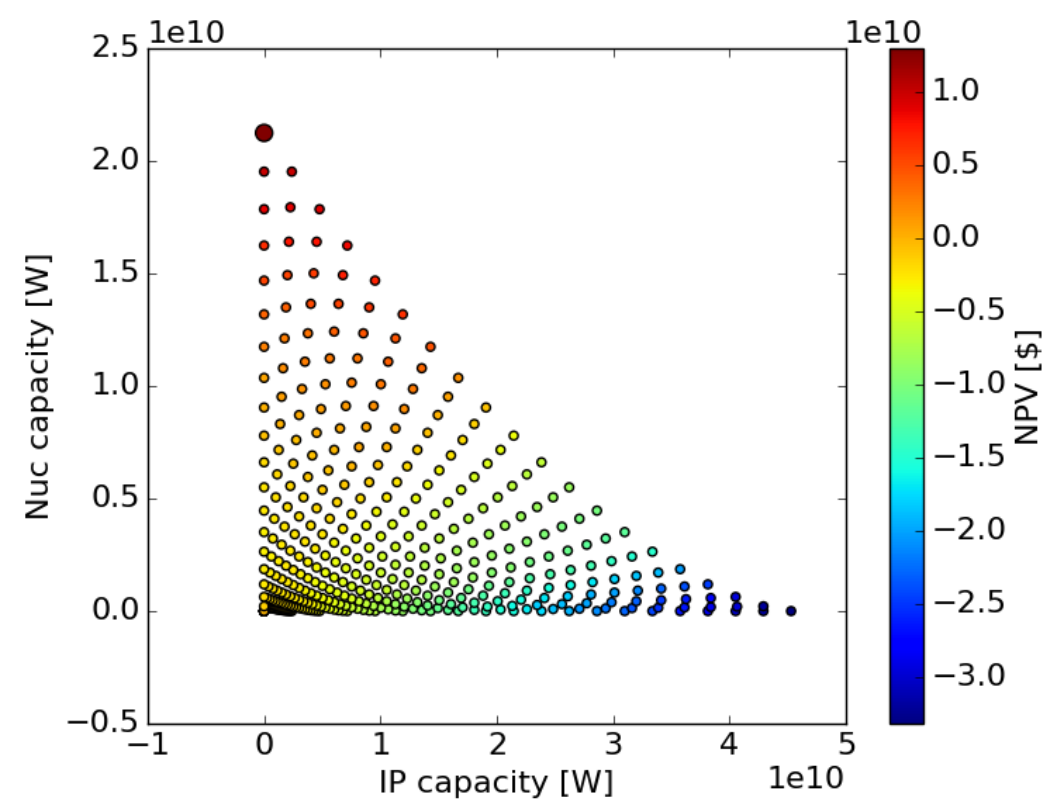

Figure 33. Problem 2, X(IP)=1.0, $\mathrm{CO}_{2}$ tax $=15 \$ /$ tonCO $\mathrm{O}_{2}, \mathrm{NPV}$ as a function of IP and nuclear capacity for a hydrogen price of $\$ 1.5 \mathrm{~kg} / \mathrm{H}_{2}$. 


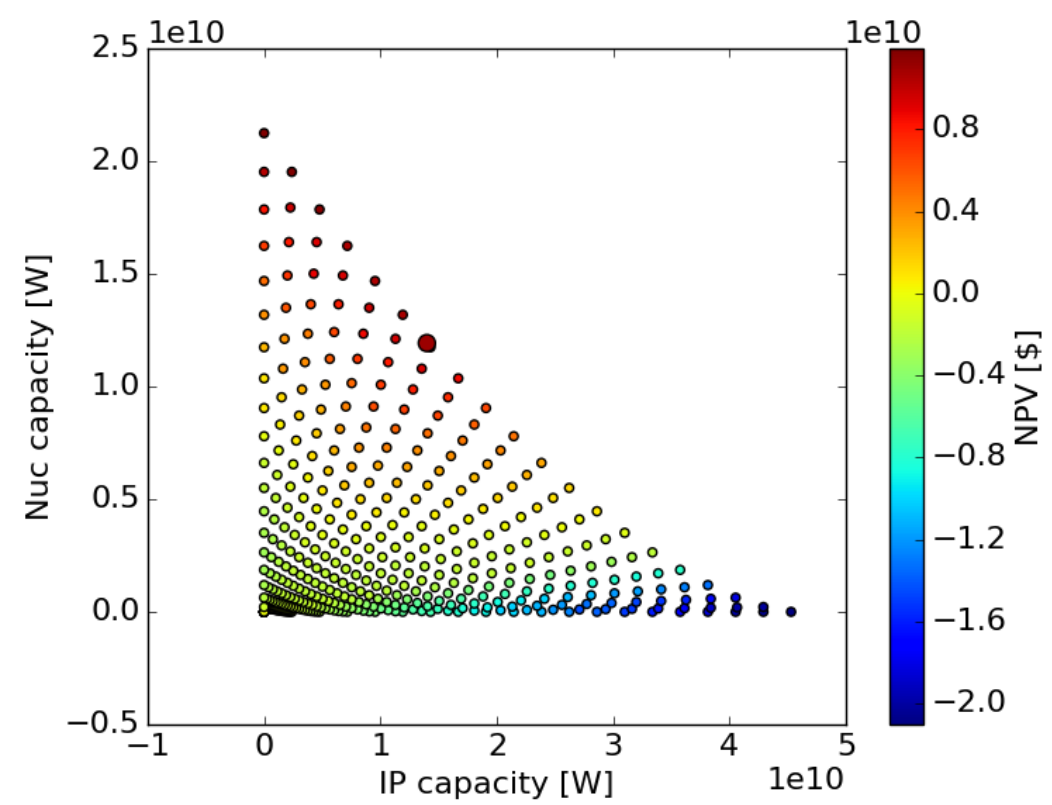

Figure 34. Problem 2, $\mathrm{X}(\mathrm{IP})=1.0, \mathrm{CO}_{2}$ tax $=15 \$ /$ tonCO $\mathrm{CO}_{2}, \mathrm{NPV}$ as a function of IP and nuclear capacity for a hydrogen price of $\$ 1.75 \mathrm{~kg} / \mathrm{H}_{2}$.

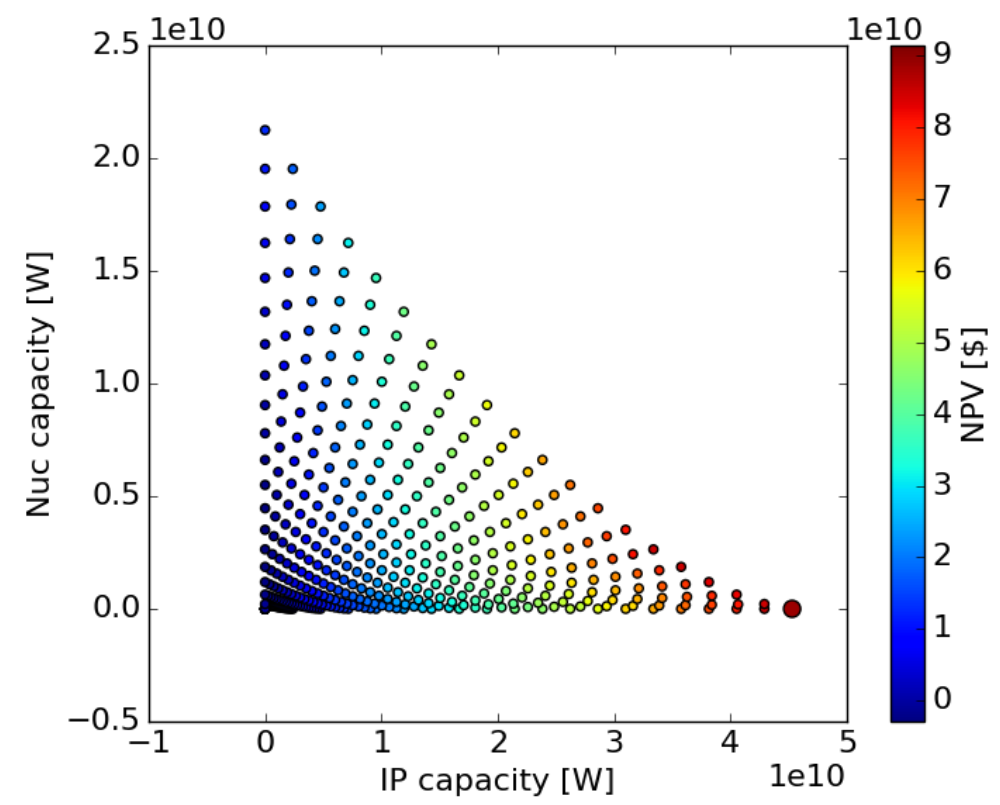

Figure 35. Problem 2, X(IP)=1.0, $\mathrm{CO}_{2}$ tax $=15 \$ /$ tonCO $\mathrm{O}_{2}, \mathrm{NPV}$ as a function of IP and nuclear capacity for a hydrogen price of $\$ 3 \mathrm{~kg} / \mathrm{H}_{2}$. 


\subsection{Surrogate model}

\subsubsection{Introduction}

While the use of the trained ARMA surrogate and collection of python RAVEN modules for the determination of NPV, PI, IRR, and the two plant capacity factors is efficient for individual runs (usually under one minute per evaluation on a modern PC), computation of highly-accurate statistics requires on the order of millions of evaluations. Since a calculation of this magnitude would require two years in processing time, in addition to using high performance computing we seek alternative surrogates to the ARMA-and-scripts model that capture the same response without the computational complexity.

RAVEN provides access to a large number of potential surrogate models, including various orders of regressors, advanced clustering algorithms, and global polynomial interpolation. For comparison, we consider two surrogate models. First, a common first-attempt surrogate model type is the so-called " $\mathrm{K}$ Nearest Neighbors", named this because when evaluated it uses $\mathrm{k}$ nearby points to interpolate the requested response value. For this exercise, we use five neighbors for each evaluation point, penalizing by distance.

Second, because the ARMA is stochastic in nature, we consider the Gaussian Process surrogate model. In Gaussian Process models, the input space is considered to be constructed of a continuum of normally distributed random. The distribution of the Gaussian Process, then, is the joint distribution of the infinitely many random variables.

The process for constructing either surrogate is as follows. The original ARMA-and-scripts model is sampled with twenty thousand Monte Carlo samples. The inputs to the ensemble model are the plant capacities, price of hydrogen, economy of scale parameter, carbon dioxide tax, and market frictional factor, and their range of values are given in Table 13.

Table 13. Range of surrogate input values.

\begin{tabular}{|c|c|c|c|}
\hline Variable & Distribution & Low & High \\
\hline Nuclear capacity & Uniform & 10 & $1.3 \mathrm{E} 9$ \\
\hline IP capacity & Uniform & 10 & $8 \mathrm{E} 9$ \\
\hline Hydrogen Price & Uniform & 1.25 & 3 \\
\hline Carbon Dioxide tax & Uniform & 0 & 75 \\
\hline Economy of Scale & Discrete & 0.64 & 1 \\
\hline Friction Factor & Uniform & 1 & 1.2 \\
\hline
\end{tabular}

Table 14. Surrogate output values.

\begin{tabular}{|c|c|}
\hline Variable & Units \\
\hline NPV & $\$$ \\
\hline PI & \\
\hline IRR & \\
\hline IP Capacity Factor & \\
\hline Nuclear Capacity Factor & \\
\hline
\end{tabular}

Once the Monte Carlo samples are collected, we perform addition screening to remove the samples in which the IRR calculation fails to converge. This happens chiefly in regions with low hydrogen price and high industrial process capacity. The screened samples are then are provided to train the surrogate model in RAVEN, using data normalization to ensure appropriate interpolation between measured data points. The surrogate model is then serialized to file disk, so as to be accessible for calculations in the future. 
To verify the integrity of the surrogate model against the original, we evaluate both surrogates as well as the original AMRA-and-scripts model on an evenly spaced twenty-by-twenty grid spanning the input space. For comprehension, we vary only the IP_capacity and PriceH2 inputs on this grid. We then compare the results of the original model with each surrogate separately, both visually and numerically. To calculate the relative difference between a surrogate and original response point, we take the absolute difference and divide by the scale of the response parameter. Since the surrogate models evaluate approximately seven orders of magnitude faster than the original model, we can perform much more expensive analysis on the surrogates than the original model given limited computational resources.

\subsubsection{K Nearest Neighbors}

Since the K Nearest Neighbors (KNN) surrogate relies on interpolating between neighboring points, we expect it to perform better on the interior of the response domain than the exterior, and to be less extreme on the exterior as it favors values on the interior out of necessity. As can be seen in

Figure 36, in general the error introduced by using the KNN surrogate is on the order of the stochasticity of the ARMA model itself, suggesting it is a suitable surrogate for this model. Table 15 shows a summary of the relative difference between the original model responses and both surrogates, by response.

Table 15. Relative percent difference between the original model responses and KNN surrogate.

\begin{tabular}{|c|c|c|c|}
\hline Response & $\begin{array}{c}\text { Min Error } \\
\mathbf{( \% )}\end{array}$ & $\begin{array}{c}\text { Average Error } \\
\mathbf{( \% )}\end{array}$ & $\begin{array}{c}\text { Max Error } \\
\mathbf{( \% )}\end{array}$ \\
\hline IRR & 0.012 & 4.6 & 34.6 \\
\hline NPV & 0.016 & 2.7 & 16.7 \\
\hline IP capacity fact. & 0.002 & 5.8 & 51.3 \\
\hline Nuc. capacity fact. & 0.002 & 8.8 & 86.2 \\
\hline PI & 0.009 & 4.2 & 26.7 \\
\hline
\end{tabular}

The Nuclear Capacity Factor (see

Figure 36) is represented well by the KNN surrogate, with the exception of the domain with low hydrogen price and higher capacity factor. This region struggles especially because the IRR calculation is difficult in this region. As a result, there are too few samples to accurately resolve this region. However, throughout the remainder of the domain (high hydrogen price as well as low hydrogen price with low industrial process capacity, the error between the two is under 20 percent, which is similar to the stochastic noise of the ARMA model. 


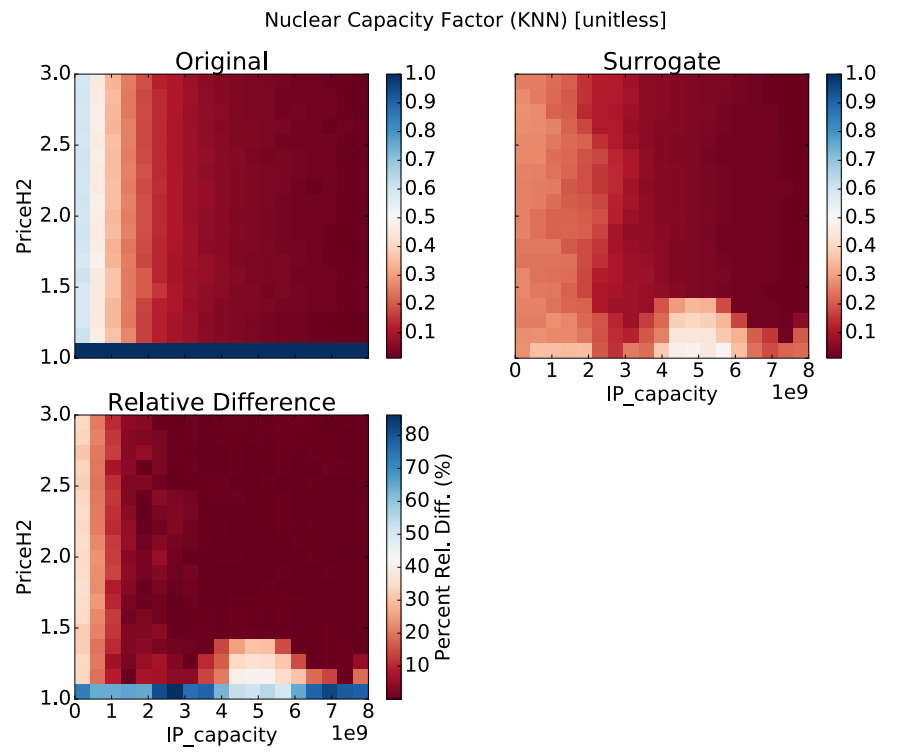

Figure 36. Nuclear capacity factor, KNN.

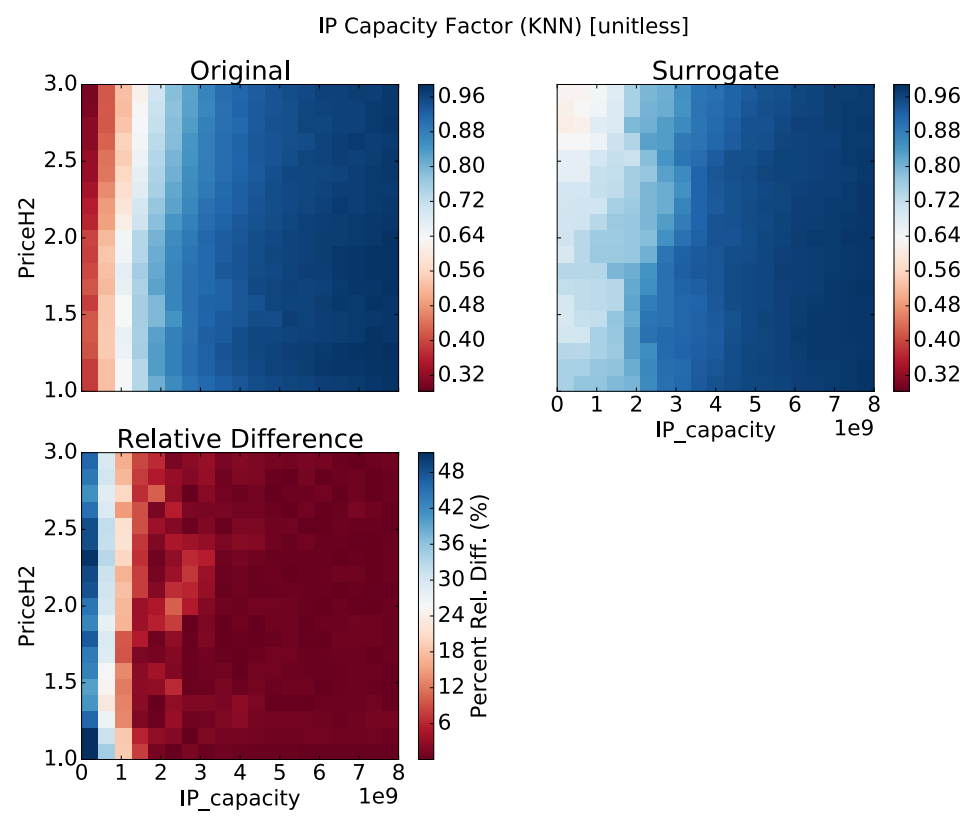

Figure 37. IP capacity factor, KNN.

Similar to the nuclear capacity, the IP capacity (see Figure 37) sees good matching between the surrogate and the original. For this response, the exception is at low IP capacity, due to the lack of good interpolation points outside the sampled domain.

The IRR response shows similar performance (see Figure 38) to the nuclear capacity response, with troublesome differences only occurring at low hydrogen price and high IP capacity, where the original model struggles to resolve IRR. Throughout the rest of the domain, the models are in good agreement with respect to the noise of the ARMA. 


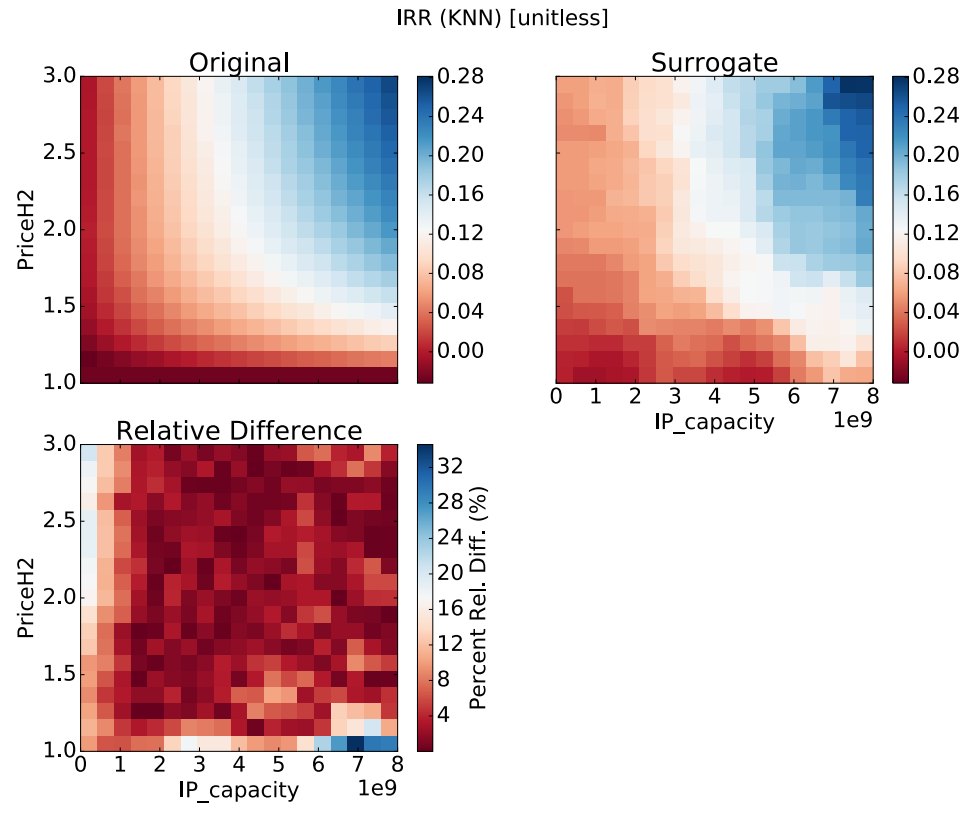

Figure 38. IRR, KNN.

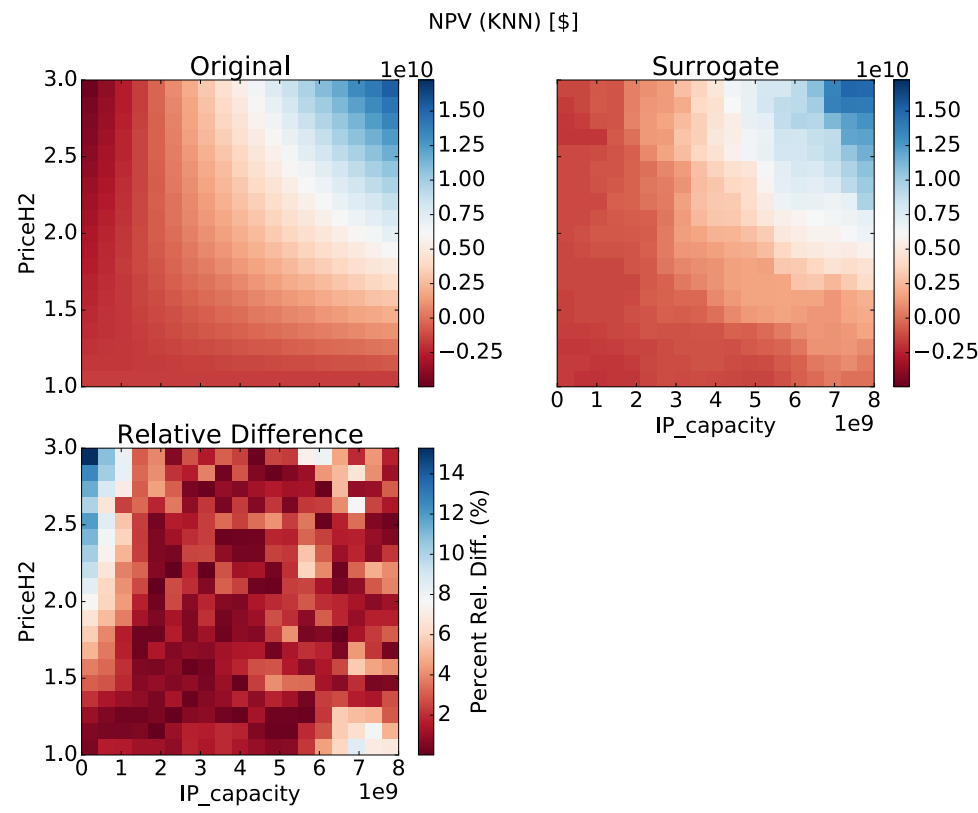

Figure 39. NPV, KNN.

The NPV response (see Figure 39) is similar to the IP capacity factor response, where the most difficult to resolve region is high hydrogen price and low IP capacity. However, the magnitude of the differences is quite small, and is well within the tolerance of the noise of the ARMA model itself.

As with most of the responses, the PI (see Figure 40) sees greatest error between surrogate and original model where the data points are most difficult to resolve; however, the original and surrogate are in good agreement with respect to the noise of the ARMA model. 


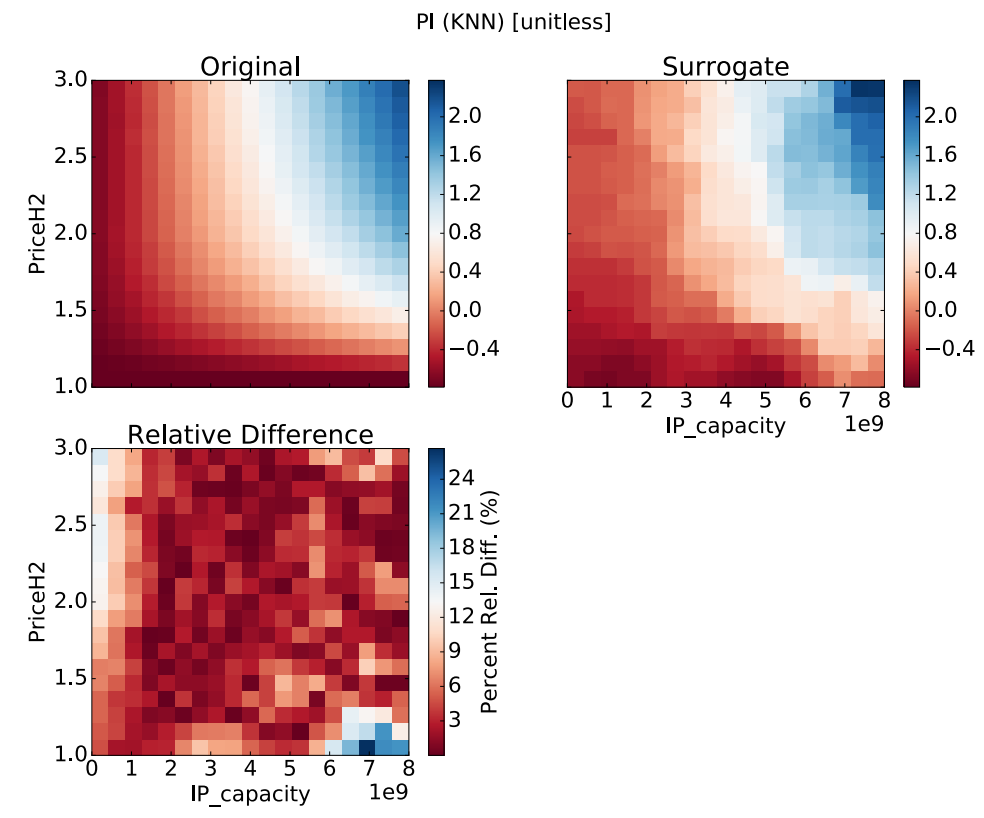

Figure 40. PI, KNN.

\subsubsection{Gaussian Process}

Unlike the KNN, the Gaussian Process (GP) surrogate has a large number of parameters for tuning the model. Here we use all the default parameters in RAVEN, for preliminary comparison. The errors between the surrogate and the original model are good on average, but on the fringes are considerably worse, especially for the capacity factors. Tuning the surrogate training parameters could likely reduce this error. Table 16 shows a summary of the relative errors by response.

Table 16. Relative percent difference between the original model responses and GP surrogate.

\begin{tabular}{|c|c|c|c|}
\hline Response & $\begin{array}{c}\text { Min Error } \\
(\mathbf{\%})\end{array}$ & $\begin{array}{c}\text { Average Error } \\
\mathbf{( \% )}\end{array}$ & $\begin{array}{c}\text { Max Error } \\
(\mathbf{\%})\end{array}$ \\
\hline IRR & 0.009 & 7.0 & 67.7 \\
\hline NPV & 0.014 & 6.5 & 58.2 \\
\hline IP capacity factor & 0.005 & 23.6 & 290.5 \\
\hline Nuclear capacity factor & 0.108 & 18.4 & 307.8 \\
\hline PI & 0.047 & 7.8 & 74.1 \\
\hline
\end{tabular}

The nuclear capacity factor response (see Figure 41) is well-represented by the GP surrogate over most of the domain; however, in the low hydrogen price region where the IRR struggles to converge, there is some discrepancy. In general, however, the error introduced by the surrogate is similar in magnitude to the stochastic noise of the ARMA. 


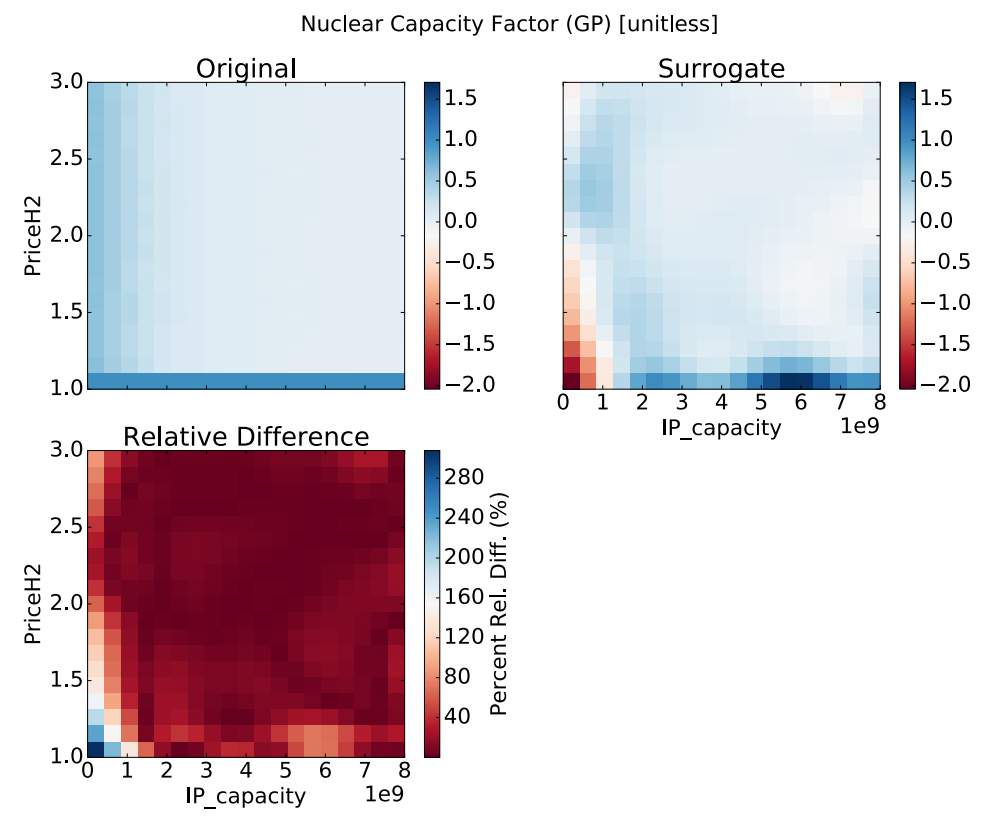

Figure 41. Nuclear capacity factor, GP.

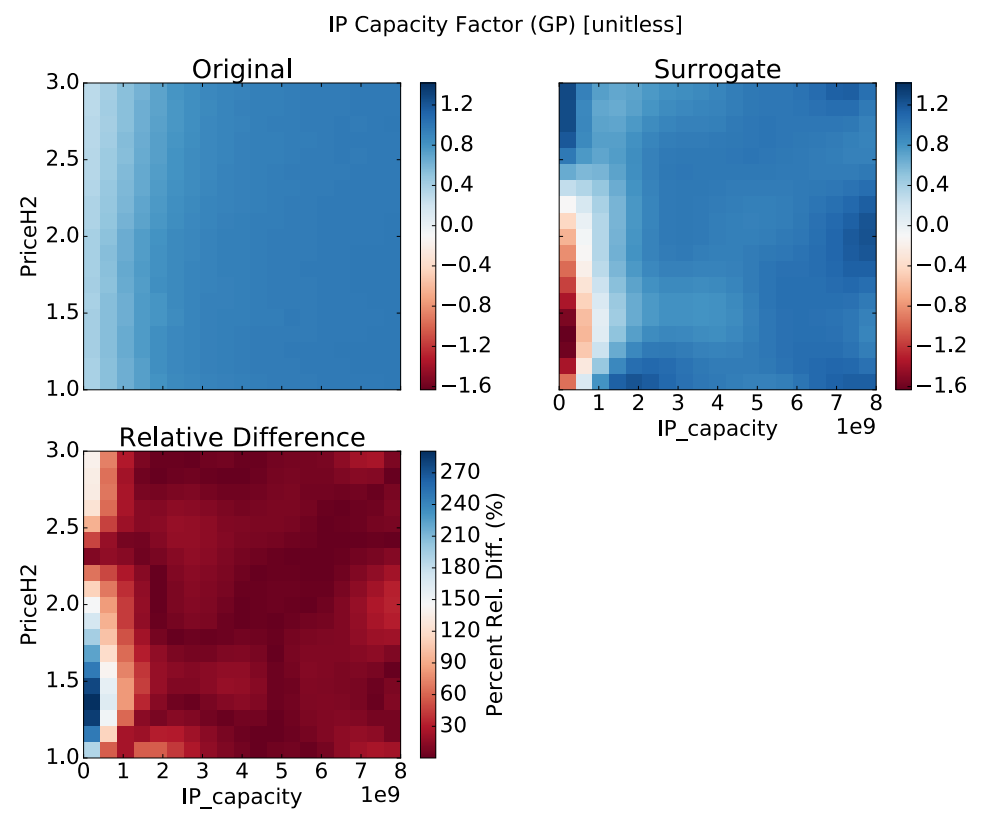

Figure 42. IP capacity factor, GP.

The IP capacity factor (see Figure 42) also demonstrates good agreement between the surrogate and original model, with some large discrepancies in the low hydrogen price and low IP capacity region.

Similar to the previous models, the GP seems to struggle most in low hydrogen price regions for the IRR (see Figure 43), the NPV (see Figure 44) and the PI (see Figure 45), but is in good agreement throughout the rest of the domain, with respect to the noise of the ARMA model. 


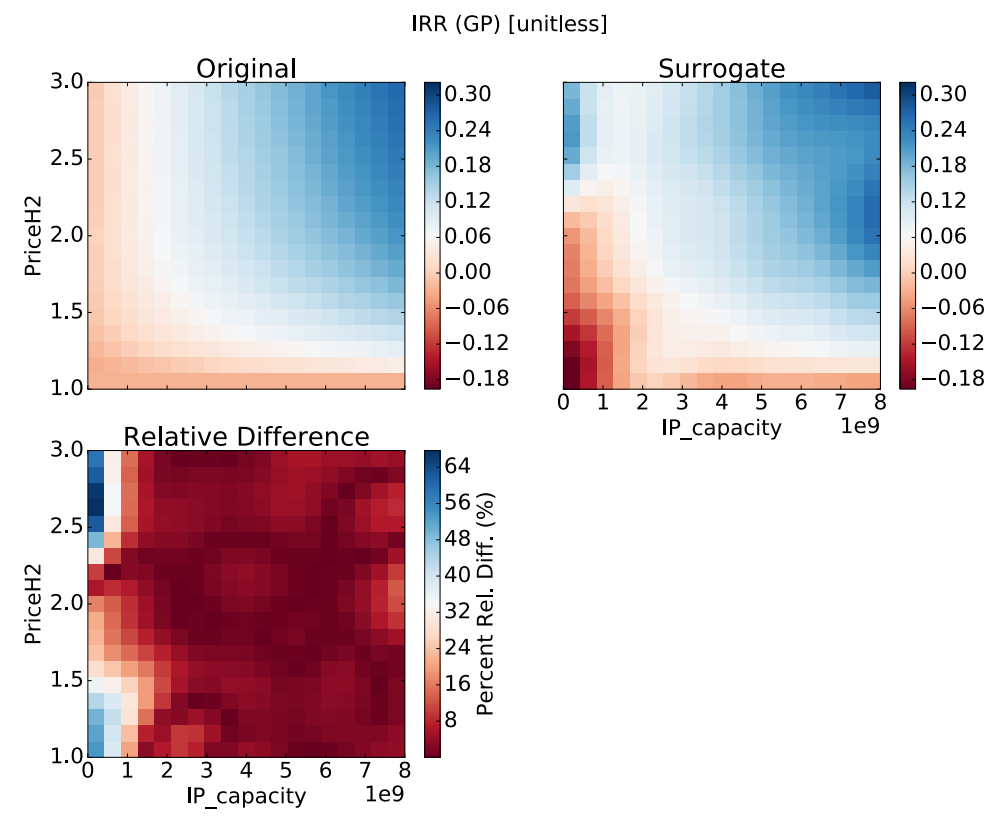

Figure 43. IRR, GP.

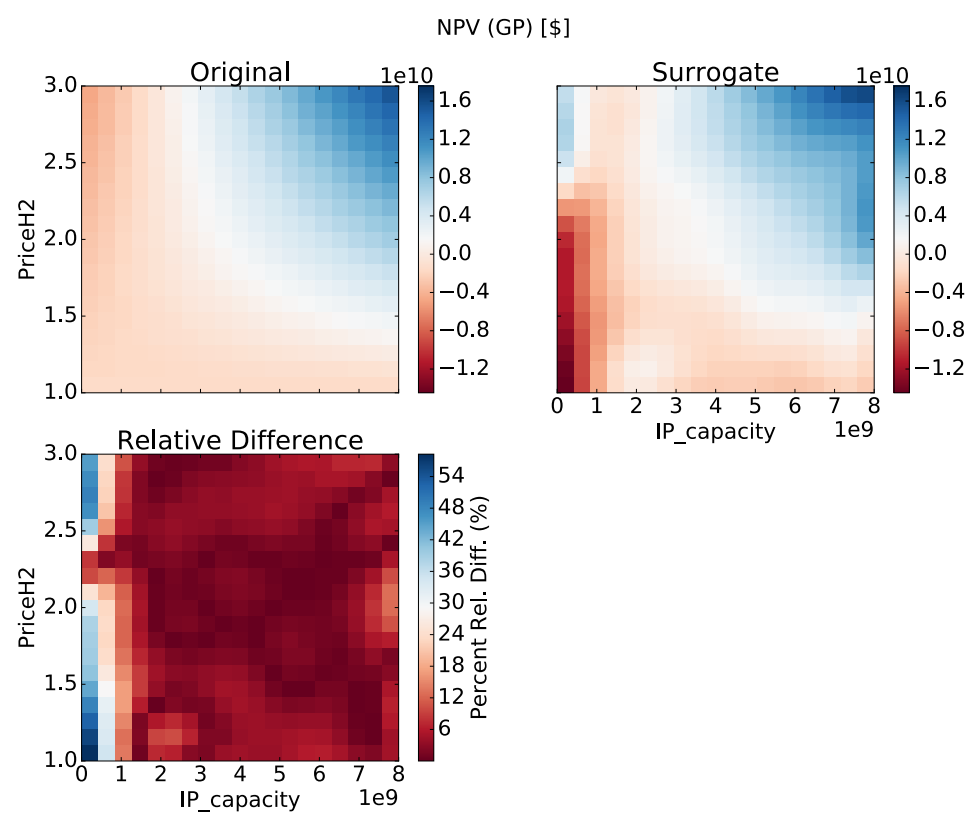

Figure 44. NPV, GP. 


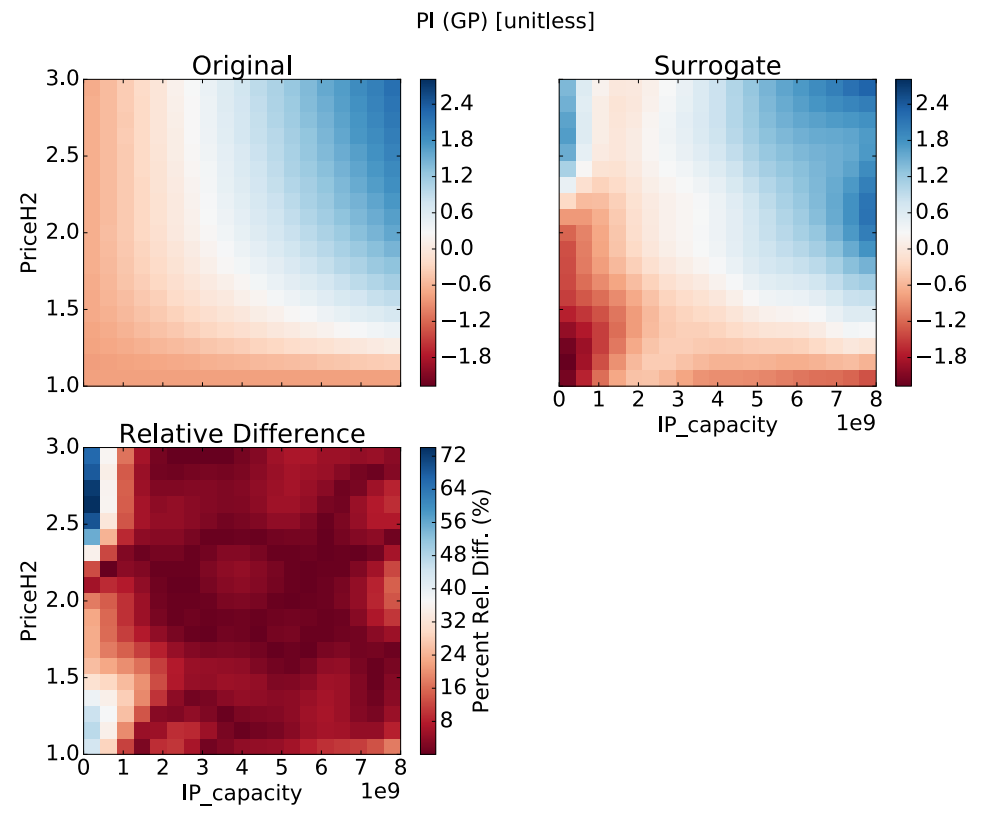

Figure 45. PI, GP.

\subsubsection{Conclusions}

Both the K Nearest Neighbors (KNN) and Gaussian Process (GP) surrogate models show a not completely satisfactory agreement with the original model, two factors make the construction of the surrogate especially challenging. First, the inherent stochastic nature of the response that the surrogate needs to emulate require some de-noising. Second, when the IRR search algorithm struggles in finding the proper IRR, the point is either suppressed or carrying an incorrect value, which either reduces the number of available training points or confuses the training algorithm. More work needs to be done to better understand which surrogate and which training settings should be used. The surrogate approach is useful for quick evaluation of specific scenarios without needing to evaluate the computationally expensive initial model. This refers especially to the future situation in which the physical systems will be represented by Modelica models. 


\section{CONCLUSION}

The framework for the economical analysis of N-R HES is reaching the maturity level necessary to begin analysis of realistic cases.

In this report the time series synthetic emulation for wind and electricity demand were tested on a large scale (several million histories generated) and statistically post processed. This test confirmed the capability to use this approach to produce realistic synthetic data, and built confidence in the use of such methodology in the latter part of this report. In fact, the procedure to generate synthetic data was used to generate electricity price time histories for an optimization demonstration test.

Work was conducted to increase the capabilities of the financial analysis module. This allowed for full utilization of the new data collected, and here reported, on cost of nuclear energy and hydrogen production.

The optimization algorithm was demonstrated to converge quickly for IRR and NPV optimization under stochastic response of the system. The analysis confirmed the qualitative expectations, providing exact numbers that could not be found without the usage of the implemented framework, i.e. the developed model sand software. Overall, the tests performed were successful.

More improvements will be implemented in the near future to account for diseconomy of scale and market elasticity, which have been shown to be two major controlling factors for the optimization of the hybrid system.

The testing of the capability to generate a surrogate model to characterize the financial behavior of the system is still just beginning, and some work will be necessary to tune the training parameters. This is an interesting work that, while not strictly necessary for the overall optimization process, could be a very useful tool for analysts to perform scoping calculations. 


\section{REFERENCES}

1. H. Elmqvist, D. Ab, "Modelica-The Next Generation Modeling Language an International Design Effort", Proceedings of the 1st World Congress on System Simulation (WCSS'97), Singapore, September 1-3, 1997.

2. A. Epiney, J. Chen, C. Rabiti, "Status on the Development of a Modeling and Simulation Framework for the Economic Assessment of Nuclear Hybrid Energy Systems (FY 16)", Idaho National Laboratory, September 2016, INL/EXT-16-39832.

3. J. Chen, C. Rabiti, "Synthetic wind speed scenarios generation for probabilistic analysis of hybrid energy systems", Energy 120, 2017, p507-517.

4. H. E. Garcia, J. Chen, J. S. Kim, M. G. McKellar, W. R. Deason, R. B. Vilim, S. M. BraggSitton, R. D. Boardman, "Nuclear Hybrid Energy Systems - Regional Studies: West Texas \& Northeastern Arizona", Idaho National Laboratory, April 2015, INL/EXT-15-34503.

5. http://www.nrel.gov/electricity/transmission/eastern wind dataset.html

6. http://www.ercot.com/gridinfo/load/load hist/

7. C. Rabiti, H. E. Garcia, R. Hovsapian, R. A. Kinoshita, G. L. Mesina, S. M. Bragg-Sitton, R. D. Boardman, "Strategy and Gaps for Modeling, Simulation, and Control of Hybrid Systems", Idaho National Laboratory, April 2015, INL/EXT-15-34877.

8. P. Krull, J. Roll, R. D. Varrin, Jr., "HTSE Plant Cost Model for the INL HTSE Optimization Study,” R-6828-00-01, Revision 1, March 2013.

9. http://www.marketsandmarkets.com/PressReleases/hydrogen.asp

10. Fuel cell market report, DOE.

11. M. Ruth, D. Cutler, F. Flores-Espino, G. Stark "The Economic Potential of Nuclear-Renewable Hybrid Energy Systems Producing Hydrogen", National Renewable Energy Laboratory, Technical Report NREL/TP-6A50-66764.

12. "Nuclear-Integrated Hydrogen Production Analysis", Technical Evaluation Study Project No. 23843.

13. "Air Products' U.S. Gulf Coast hydrogen network", Data Sheet, accessed on February 2017.

14. http://www.bccresearch.com/pressroom/chm/us-merchant-hydrogen-market-reach-\$3.87-billion2016

15. https://www.misoenergy.org/LMPContourMap/MISO All.html (MISO zonal prices).

16. Level 100 - Introduction to MISO and MISO Markets, April 23, 2014, https://www.misoenergy.org/Library/Repository/Meeting\%20Material/Stakeholder/Training\%20 Materials/100\%20Level\%20Training/Level\%20100\%20-

$\% 20$ Introduction $\% 20$ to $\% 20$ MISO $\% 20$ and $\% 20$ Markets.

17. pdf6a(https://www.misoenergy.org/Library/MarketReports/Pages/ArchivedAnnualRealTimeLMP5-Min.aspx); Under Market information $\rightarrow$ market reports $\rightarrow$ market report archives.

18. Notification Regarding TSR Conversion for MISO South Integrating Companies, MISO website, 2013.

19. LMP Contour Map FAQ

20. F. Ganda, J. Hansen, T. K. Kim, T. A. Taiwo, R. Wigeland, "Reactor Capital Costs Breakdown And Statistical Analysis Of Historical U.S. Construction Costs", Proceedings of ICAPP 2016, April 19th, 2016, San Francisco, CA, Paper 16829.

21. F. Ganda, T. K. Kim, T. A. Taiwo and R. Wigeland, "Analysis of reactor capital costs and correlated sampling of economic input variables", Proceedings of ICAPP 2015, May 03-06, 2015, Nice (France), Paper 15342.

22. F. Ganda, T. K. Kim, T. A. Taiwo, J. Hansen, R. Wigeland, "Economic Evaluation of Promising Options”, FCRD-FCO-2015-000013, September 30th, 2015.

23. F. Ganda, E. Schneider, K. Williams, T. K. Kim, T. A. Taiwo, "Identification and Analyses of Fuel Cycle Economics Issues”, FCRD-FCO-2014-000402, September 30th, 2014.

24. F. Ganda, B. Dixon, K. Williams, "Nuclear Energy System Evaluation and Screening - 
Evaluation Approach and Metric for Financial Risk and Economics", Idaho National Laboratory, August 2012, INL/EXT-12-27055, FCRD-FCO-2012-000270.

25. AEO (2015), “Annual Energy Outlook 2016", U.S. Energy Information Administration, May 17, 2016.

26. CBR (2012), Advanced Fuel Cycle Cost Basis (2012 Addendum), B. Dixon et al., Prepared for U.S. Department of Energy, Fuel Cycle Options Campaign, Feb. 15, 2013, FCRD-FUEL-2012000099. [Addendum to the Advanced Fuel Cycle Cost Basis, D. E. Shropshire et al., Prepared for U.S. Department of Energy, Office of Nuclear Energy, Science, and Technology, December 2009, INL/EXT-07-12107.

27. Nuclear Energy Cost Database (EEDB): DOE/NE-0095.

28. Exelon Co., (2014) "FORM 10K, ANNUAL REPORT PURSUANT TO SECTION 13 OR 15(d) OF THE SECURITIES EXCHANGE ACT OF 1934", Filed February 13, 2014, For the Fiscal Year Ended December 31, 2013.

29. F. Ganda, R. Wigeland, T. K. Kim, T. A. Taiwo, B. Dixon, "Advances in Developing Improved Fuel Cycle Cost Estimates", FCRD-FCO-2016-000498, June 1st, 2016.

30. H. I. Bowers, L C. Fuller, M. L. Myers, "Cost Estimating Relationships for Nuclear Power Plant Operation and Maintenance", ORNL/TM-10563, EEDB (1987), November 1987.

31. B. Dixon, G. Ganda, E. Hoffman, T. Taiwo, M. Todosow, J. Hansen, S. Nair, R. Wigeland, N. Brown, A. Worral, "Impacts of Fuel Cycle Facility Modularization", In preparation, 2016.

32. S. A. Newell, J. M. Hagerty, K. Spees, J. P. Pfeifenberger, Q. Liao, C. D. Ungate, J. Wroble, "Cost of New Entry Estimates for Combustion Turbine and Combined Cycle Plants in PJM With June 1, 2018 Online Date”, Prepared For PJM Interconnection, L.L.C., by The Brattle Group and by Sargent \& Lundy, May 15, 2014.

33. A. Alfonsi, C. Rabiti, D. Mandelli, J. Cogliati, R. Kinoshita, and A. Naviglio,"RAVEN and Dynamic Probabilistic Risk Assessment: Software Overview,"Proceedings of European Safety and Reliability Conference (ESREL), Wroklaw (Poland), 2014.

34. https://www.misoenergy.org/Library/MarketReports/Pages/ArchivedAnnualReal-TimeLMP5Min.aspx

35. https://www.eia.gov/electricity/state/unitedstates/index.cfm 


\section{Appendix A}

\section{CashFlow input deck}

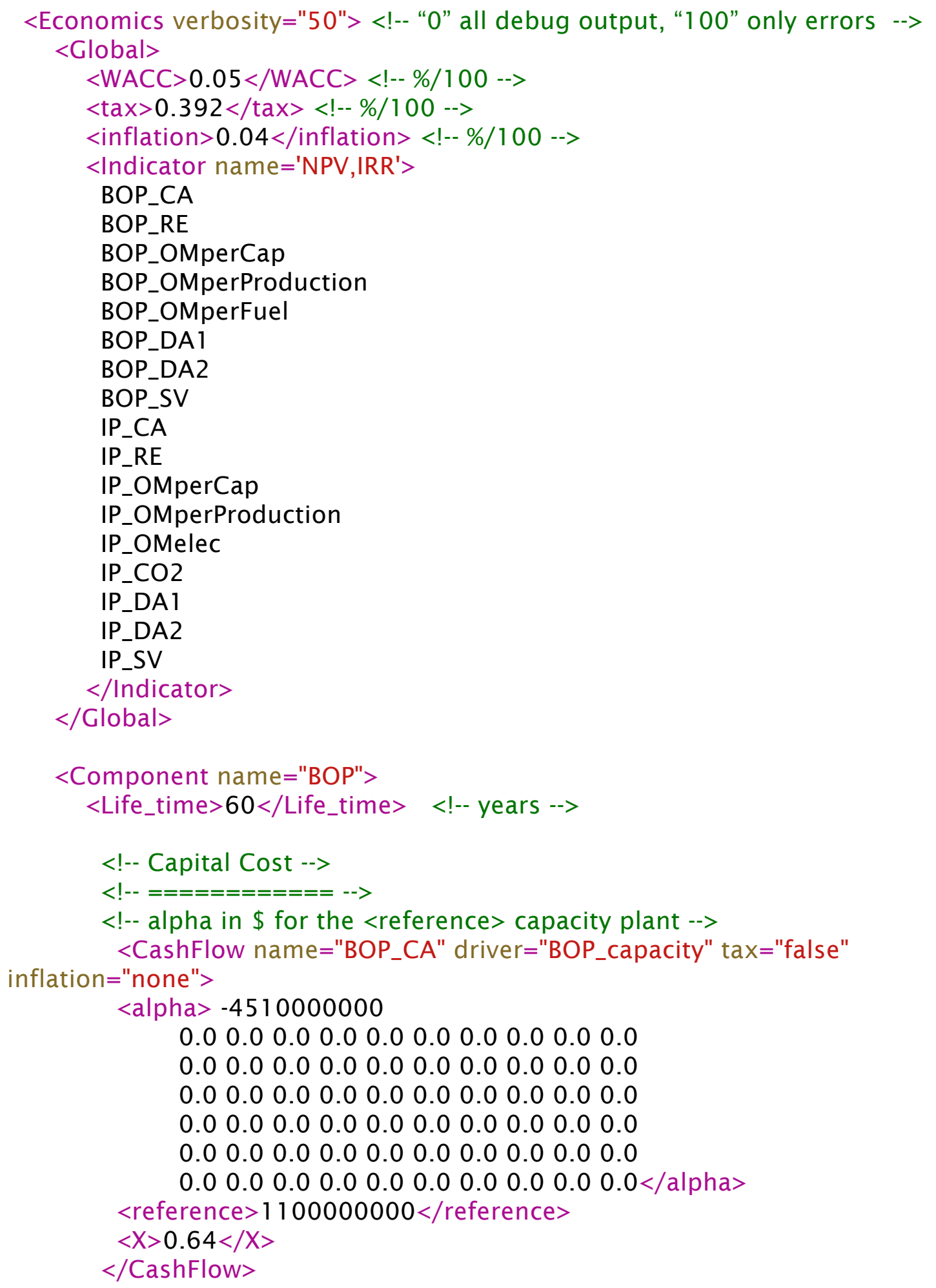




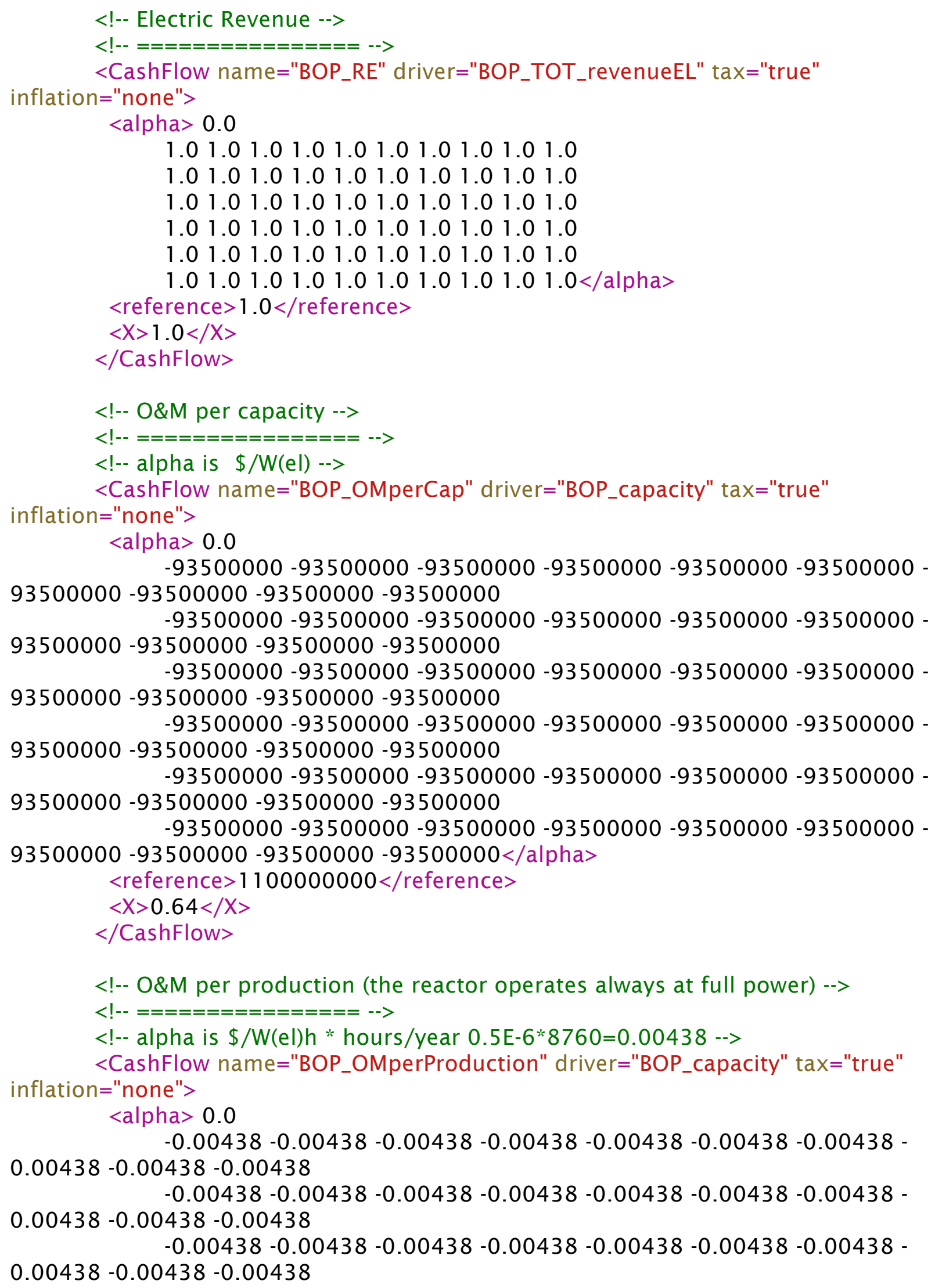


$-0.00438-0.00438-0.00438-0.00438-0.00438-0.00438-0.00438-$

$0.00438-0.00438-0.00438$

$-0.00438-0.00438-0.00438-0.00438-0.00438-0.00438-0.00438-$

$0.00438-0.00438-0.00438$

$-0.00438-0.00438-0.00438-0.00438-0.00438-0.00438-0.00438-$

$0.00438-0.00438-0.00438</$ alpha $>$

$<$ reference $>1.0</$ reference $>$

$<\mathrm{X}>1.0</ \mathrm{X}>$

$</$ CashFlow $>$

$<!--$ O\&M per fuel (the reactor operates always at full power) -->

$<!--================-->$

$<!--$ alpha is $\$ / \mathrm{W}(\mathrm{el}) \mathrm{h} *$ hours/year $8.4 \mathrm{E}-6 * 8760=0.073584$-->

$<$ CashFlow name="BOP_OMperFuel" driver="BOP_capacity" tax="true"

inflation="none">

$<$ alpha $>0.0$

$-0.073584-0.073584-0.073584-0.073584-0.073584-0.073584-$

$0.073584-0.073584-0.073584-0.073584$

$-0.073584-0.073584-0.073584-0.073584-0.073584-0.073584-$

$0.073584-0.073584-0.073584-0.073584$

$-0.073584-0.073584-0.073584-0.073584-0.073584-0.073584-$

$0.073584-0.073584-0.073584-0.073584$

$-0.073584-0.073584-0.073584-0.073584-0.073584-0.073584-$

$0.073584-0.073584-0.073584-0.073584$

$-0.073584-0.073584-0.073584-0.073584-0.073584-0.073584-$

$0.073584-0.073584-0.073584-0.073584$

$-0.073584-0.073584-0.073584-0.073584-0.073584-0.073584-$

$0.073584-0.073584-0.073584-0.073584</$ alpha $>$

$<$ reference $>1.0</$ reference $>$

$<\mathrm{X}>1.0</ \mathrm{X}>$

$</$ CashFlow $>$

$<!--$ Amortisation/Depreciation -->

$<!--===============-->$

$<!--$ alpha is \% * CAPEX [ $\$$ for $1100 \mathrm{MW}$ ref plant ] = MACRS * 4510000000 -->

$<$ CashFlow name="BOP_DA1" driver="BOP_capacity" tax="false" inflation="real"> $<$ alpha $>0.0$

225500000

405900000

385605000

347270000

312543000

280973000

266090000

266090000

266541000

266090000

266541000

266090000

266541000 


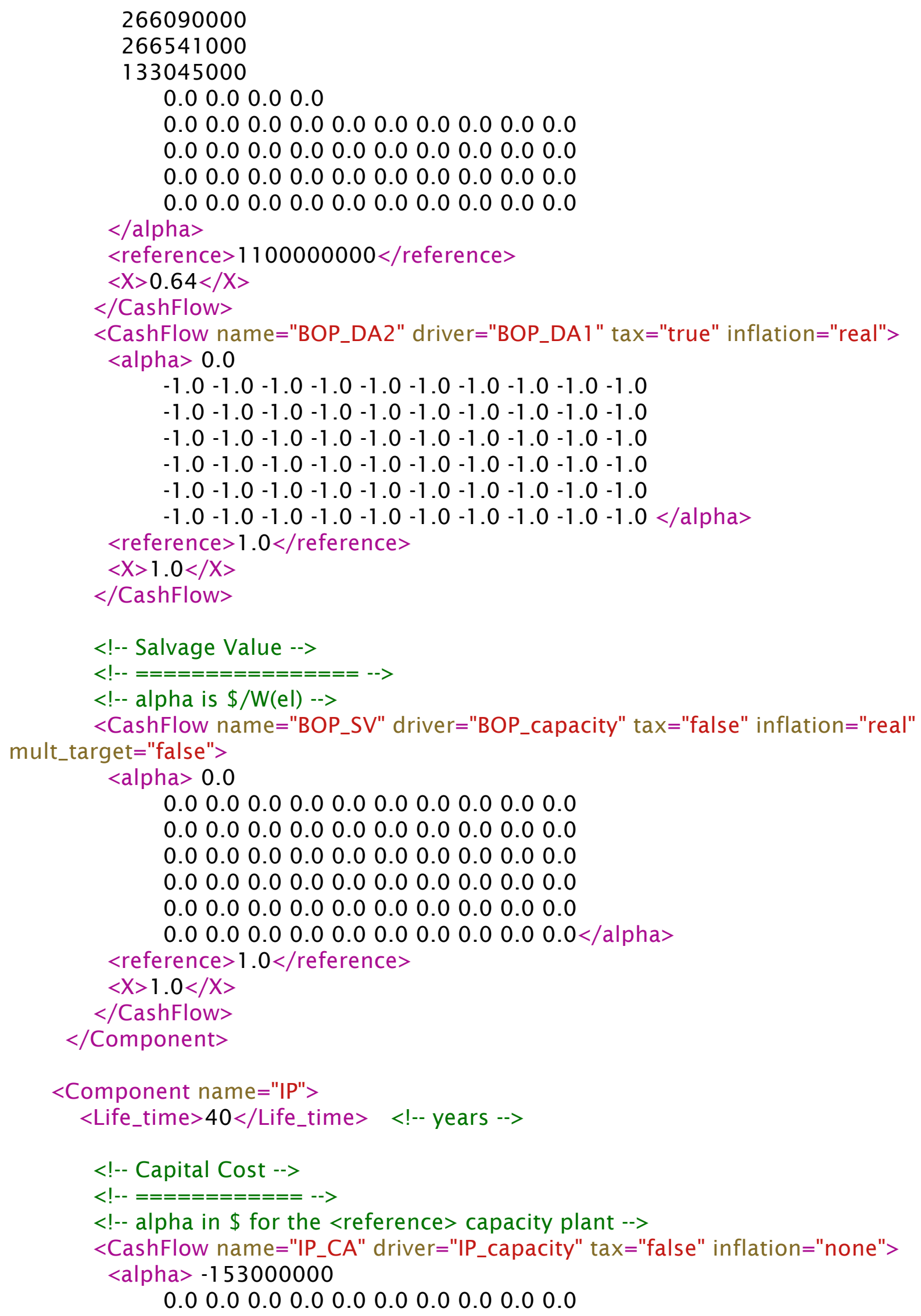




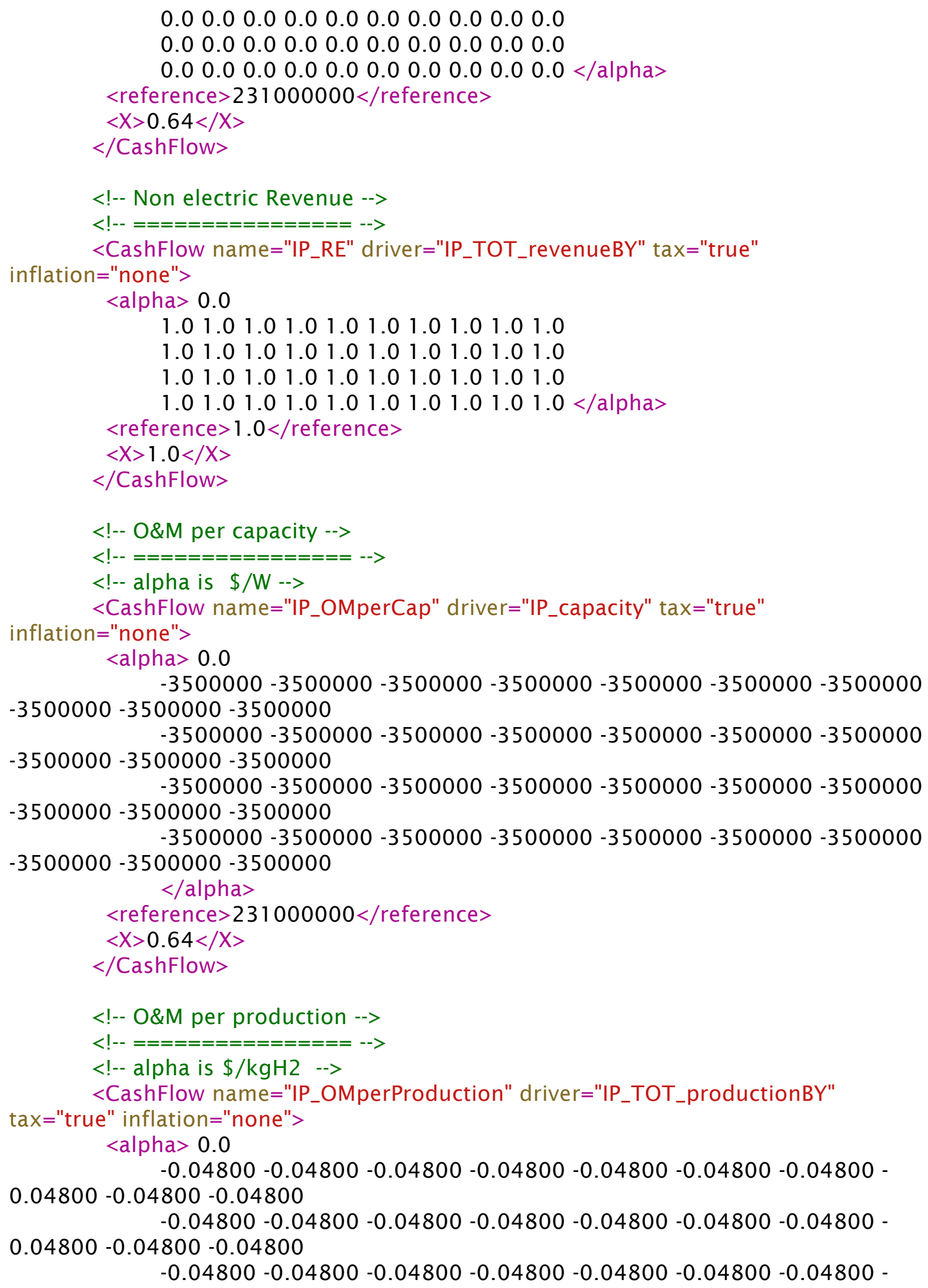




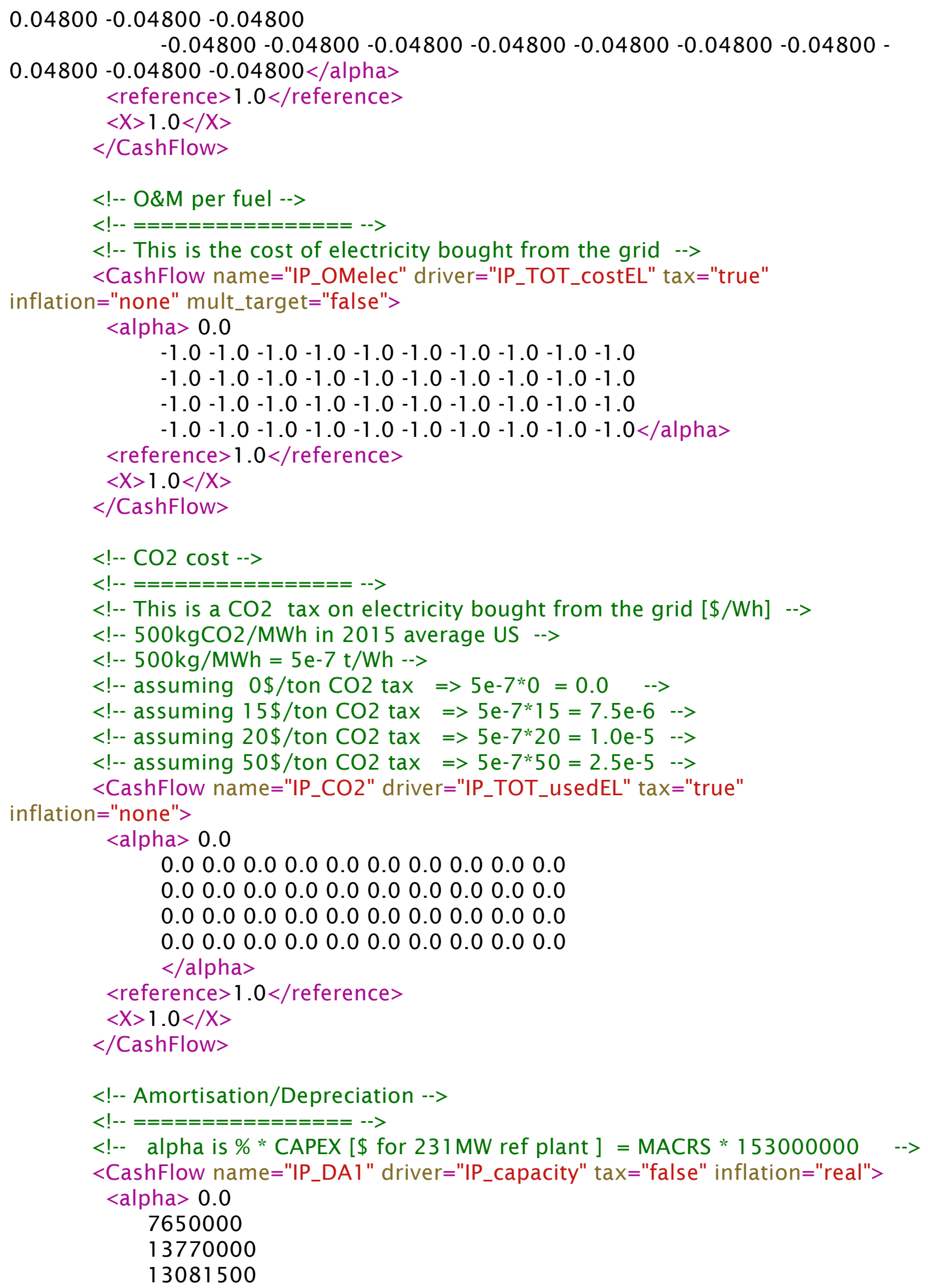




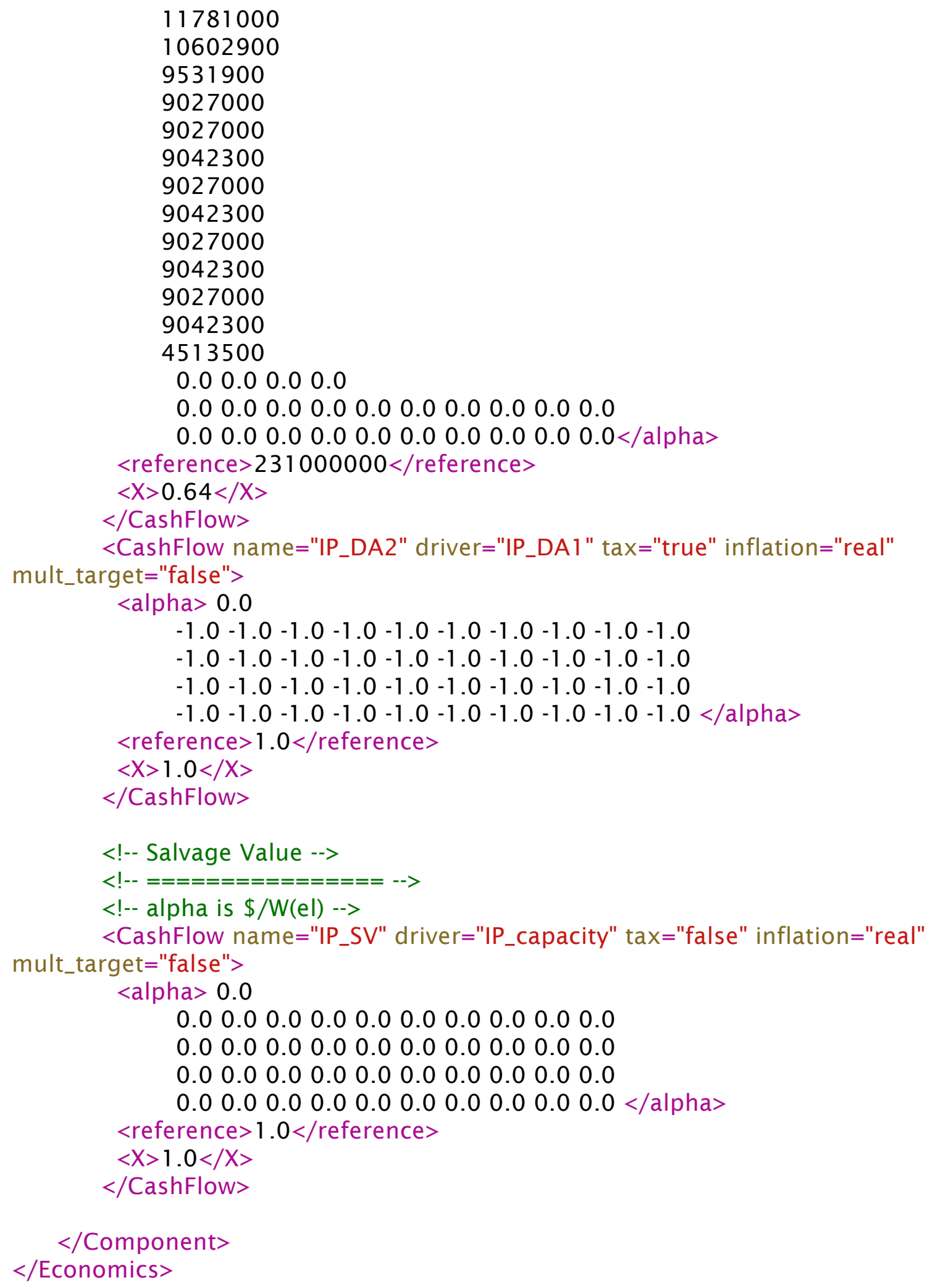

